\title{
Applied Physics and Technologies in Football, The Earth's Gravitational Field and Gravitational Energy Emission, Effects of the velocity, air viscosity (Bernoulli Effect) and turbulence (Magnus Effect) on the Football ball and Effects of the Air Resistance, Atmospheric Pressure and Gravitation in Football and Players: The Variant Pressure and Variant Gravity respect to the altitude of the place above sea level: "The ball doesn't bend"
}

\author{
Giovanni Alcocer (Pipo Zona)
}

Independent Research, Guayaquil, Ecuador. Email: giov_alc_science@hotmail.com

Master in Physics with specialization in Astrophysics and Medical Physics, Professor of Physics, Advanced Mathematics and Science in general, author of the recognized and renowned articles: The Fundaments of the Mass: Gravitation, Electromagnetism and Atom. Pipo Zona: Great sportsman, champion and scorer of many national and international championships, a sportman of the high elite who always competes with love and respect for his teammates and the Football ball without which this beautiful sport could not be practiced thanks to the Supreme Being.

DOI: http://doi.org/10.46382/MJBAS.2021.5109

Copyright: (02021 Giovanni Alcocer. This is an open access article distributed under the terms of the Creative Commons Attribution License, which permits unrestricted use, distribution, and reproduction in any medium, provided the original author and source are credited.

It is possible to play Football on the Earth because of the Gravity and the almost stable and suitable atmospheric conditions ${ }^{6,7,8}$. It is demonstrated at this article the real gravitational interaction between objects with mass with the Cavendish Experiment ${ }^{4}$ which is described by means of the gravitational field $\mathrm{g}$ through a distance action interaction ${ }^{2,3,6}$. The gravitational energy emission and the effect of the gravitation as the gravitational redshift, the deflection of the light passing close to the $\operatorname{Sun}^{4}$ and the Perihelion Precession of Mercury ${ }^{4}$ with the discovered formulas obtained by myself are demonstrated at the article ${ }^{4}$ : "The Fundament of the Mass and Effects of the Gravitation on a Particle and Light"4. They are in agreement with the experiment results and with the Theory of General Relativity with high accuracy ${ }^{4}$. In addition, the electromagnetic energy emission (photons) with the corresponding decrease in mass for the electron (Maxwell's theory) with the discovered formula obtained by myself is demonstrated at the research article of Variant Mass for an accelerated charged particle ${ }^{5}$.

Relating Football, it is investigated the related applied Physics to Football as for example Free fall, Parabolic movement, Newton Laws, Work and Energy, Principle of energy conservation, Impulse and Momentum and Collisions ${ }^{1,2,3}$. Besides, it is researched the effects of the air resistance in the maximum distance and height reached by the ball in the parabolic movement in a Free kick for example.

However, the main objective of this article is to research about the effects of the variable physics as the air resistance, atmospheric pressure and gravity and climatic conditions (heavy rain, wind, snow, hail, high temperature or humidity) that influence in the match and in the Football ball: "the ball does not bend" and in Football players (effects of the altitude in the organism) ${ }^{6}$. It is obtained and demonstrated at this article the formulas of the variation of the atmospheric pressure and the gravity respect to the altitude of the place or city above sea level. For other hand, it is researched the effects of the air viscosity (Bernoulli Effect) and turbulence (Magnus Effect) on the Football ball when the player kicks with high velocity. Besides, it is researched the effects of the variations of the atmospheric pressure and gravity in the Football players and the Physics of the devices to measure the atmospheric pressure and the blood pressure which is important when they plays a Football match in a high altitude city or place ${ }^{6,7,8}$.

It is also researched the effects of the climatic conditions in a Football match. Even the weather conditions (high altitude, warm climates) and location can be used in favor to make the result favorable. For other hand, weather conditions are very important for the development of a good Football game. Many times matches are suspended due the extreme climatic conditions as heavy rain, wind, snow, hail or severe weather conditions as high temperature or humidity. However, it has been possible to apply the technology to build new stadiums that are suitable for these climates and to wear respective clothing that facilitates the practice of Football ${ }^{6,7,8}$.

Therefore, it is also researched at this article the new technology that can be applied for the normal development of a Football game and to get the efficient performance of the Football players and all the best physical conditions on the Football field ${ }^{6}$. Thus, technologies have been incorporated to know characteristics of the players that are very helpful to the coach and physical trainer to obtain efficiency of the player and of the strategies applied in the Football field. It is very important to use all the advantages, characteristics and resources of the team at the appropriate time 6 . In this way, it is maximized the important details that can contribute to win the Football match. It helps a lot the technical body such as the Coach, Technical assistant, Physical trainer, Doctor, Managers, Scientists, who know very well all the best that the team has and the physical conditions, strategies and player skills that can be used in a certain Football game. Thus, Teamwork is the key to this beautiful sport: The Football ${ }^{6,7}$. Moreover, Medical Technologies have been incorporated in Football ${ }^{6,7,8}$ and in future, new technologies can also be incorporated to monitor player performance.

Keywords: Gravity, Atmospheric pressure, Air viscosity, Air resistance, Bernoulli, Turbulence, Magnus, Applied physics, Technology, Medica measurements. 


\section{The Earth's Gravity, the Cavendish Experiment, the Gravitational Field and the Gravitational Energy Emission}

\section{The Earth's Gravity}

The main reason it is possible to play Football is the specific value of the gravity acceleration that we have on our planet $^{6}$. The gravity acceleration is due the gravitational field of the Earth that pulls every object towards the center of the Earth as for example the Football ball and which includes us as well. The gravity acceleration at the surface of the Earth is obtained as follows: $F g=G \frac{M_{e} m}{R_{e}{ }^{2}}$ (Newton Law) $\quad W=m g=G \frac{M_{e} m}{R_{e}{ }^{2}} \quad g=G \frac{M_{e}}{R_{e}{ }^{2}}$

$\mathrm{G}=6.67 * 10^{-11} \mathrm{~N} \mathrm{~m}^{2} / \mathrm{kg}^{2} \quad \mathrm{M}_{\mathrm{e}}=5.98 * 10^{24} \mathrm{~kg} \quad \mathrm{R}_{\mathrm{e}}=6.37 * 10^{6} \mathrm{~m}$

Where, $G$ is the gravitational constant, $M_{e}$ is the Earth mass, $R_{e}$ is the Earth radius and $m$ is the mass of the object or the ball at the surface of the Earth.

By replacing those values, the acceleration of gravity at the Surface of the Earth is $g=9.8 \mathrm{~m} / \mathrm{s}^{2}$ at the MKS or SI (International System) system or $32 \mathrm{ft} / \mathrm{s}^{2}$ at the English or Conventional System ${ }^{1,2,3}$. Besides, it is the value of the constant acceleration for every object that falls freely on the earth regardless of its mass and neglecting the air resistance ${ }^{1,2,3}$. The gravity acceleration $g$ changes depending of the depth or the altitude of the object at the Earth ${ }^{2,3}$. Heavier objects feel a higher gravitational force but at the same time they have higher resistance to being accelerated. Less heavy objects feel a lower gravitational force but at the same time they have less resistance to being accelerated. Then, all objects have the same acceleration and reach the ground at the same time neglecting air resistance, because though the heavier objects have more gravitational force, they present higher resistance to being accelerated and the less heavy objects with less mass have less gravitational force and less resistance to being accelerated. Thus, if two objects with different masses are dropped freely from rest and neglecting the air resistance, both will reach the ground at the same time since they are accelerated with the same constant acceleration $^{1,2,3}$.

For other hand, there is a relation between the gravitational system and the accelerated system. For example, if a rocket rises with constant acceleration $\mathrm{a}=\mathrm{g}$ (system $\mathrm{K}^{\prime}$ in a place where there is no gravitational field), then the objects do not appear to float, but rather rush in the opposite direction to the acceleration as in a planet with gravity [4]. For an observer in a place (system $\mathrm{K}$ ) where there is a gravitational field $\mathrm{g}$ which is the same acceleration of the rocket, the results of the physical experiments carried out will be identical to those of the accelerated rocket. All the phenomena observed by the observer in the accelerated system are identical to those the observer will find in a gravitational field.

In fact, Albert Einstein established the main postulate of Relativity Theory that an accelerated system K with acceleration $\mathrm{a}=\mathrm{g}$ is equivalent to a system $\mathrm{K}^{\prime}$ with a gravitational field with the same acceleration $\mathrm{a}=\mathrm{g}$. Then, the effects of acceleration from an accelerated system cannot be distinguished from those of gravitation ${ }^{4}$ and the same physics results are obtained by using either of the two systems. Due to this equivalence of systems K and $\mathrm{K}^{\prime}$, the 
inertial mass $\mathrm{m}=\mathrm{F} / \mathrm{a}$ is equivalent to the gravitational mass $\mathrm{m}=\mathrm{F}_{\mathrm{g}} / \mathrm{g}$ which is an important result in Relativity Theory ${ }^{4}$.

The value of the gravity in other planets or satellites are differents ${ }^{1,2,3}$. For example, the moon has the value of gravity of $1.62 \mathrm{~m} / \mathrm{s}^{2}$ (1/6 of the gravity of the Earth approximately) and with this value, it is not possible to play Football. The value of the gravity of the Moon is obtained as follows:

$M_{m}=7.36 * 10^{22} \mathrm{~kg} \quad R_{m}=1.74 * 10^{6} \mathrm{~m} \quad g_{m}=G \frac{M_{m}}{R_{m}^{2}} \quad g_{m}=1.62 \mathrm{~m} / \mathrm{s}^{2}$

The value of gravity on Mars is $3.71 \mathrm{~m} / \mathrm{s}^{2}$.

$\mathrm{M}_{\mathrm{ma}}=6.42 * 10^{23} \mathrm{~kg} \quad \mathrm{R}_{\mathrm{ma}}=3.37 * 10^{6} \mathrm{~m} \quad \mathrm{~g}_{\mathrm{ma}}=\mathrm{G} \frac{\mathrm{M}_{\mathrm{ma}}}{\mathrm{R}_{\mathrm{ma}}{ }^{2}} \quad \mathrm{~g}_{\mathrm{ma}}=3.7 \mathrm{~m} / \mathrm{s}^{2}$

The gravity on Venus is $8.87 \mathrm{~m} / \mathrm{s}^{2}$.

$\mathrm{M}_{\mathrm{v}}=4.88 * 10^{24} \mathrm{~kg} \quad \mathrm{R}_{\mathrm{v}}=6.06 * 10^{6} \mathrm{~m} \quad \mathrm{~g}_{\mathrm{v}}=\mathrm{G}^{\mathrm{R}_{\mathrm{v}}{ }^{2}} \quad \mathrm{~g}_{\mathrm{v}}=8.8 \mathrm{~m} / \mathrm{s}^{2}$

This value of gravity of Venus is very similar to that of the Earth. Nevertheless, it is no possible to practice Football in Venus due the atmospheric and climatic conditions of Venus are not suitable for human life which is other important factor to play Football.

\section{Experiment of Cavendish: the Gravitation Interaction}

The objective of the Cavendish Experiment is to demonstrate the real gravitational interaction between objects with mass. As the Newton Theory has established, the gravitational force is proportional to the product of the masses and inversely proportional to the square of the distance between them. During this time, it was unknown the gravitational constant $\mathrm{G}$ and the mass of the Earth. Cavendish used a torsion balance (torsion pendulum) at his famous experiment to obtain the Earth Mass ${ }^{4}$.

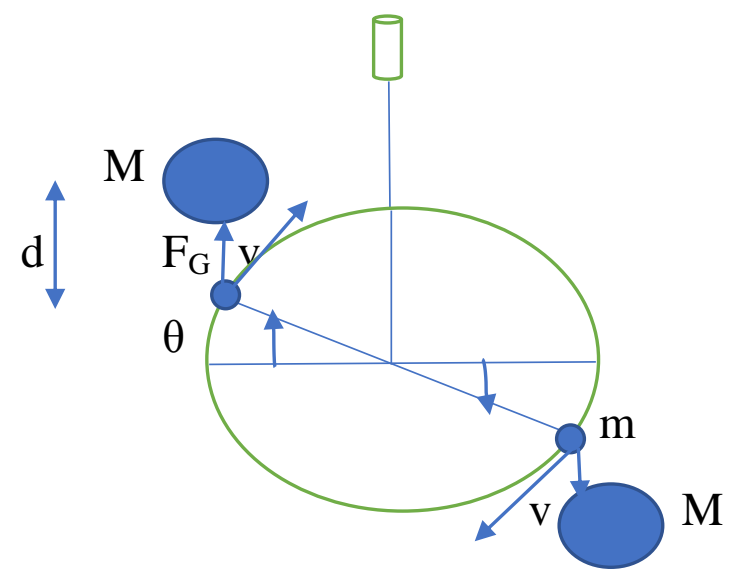

Fig.1. Cavendish Experiment: torsion balance with a light rod with two spheres mass $m$ which are attracted by the two spheres M due the Gravitational Force

The experiment uses a torsion balance which consists of a light rod with two spheres of mass $m$ at its ends which remain horizontal as it is showed at the figure ${ }^{4}$. If the system is moved a small angle $\theta$ from the equilibrium 
position and then left free, it will perform harmonic oscillations. The angular momentum $\mathrm{L}$ of the system is the sum of the angular moments of each ball. Then, the gravitational forces due to the balls of mass $\mathrm{M}$ (located at a distance $\mathrm{d}$ of the balls of mass $\mathrm{m}$ ) are applied to each sphere $\mathrm{m}$. The system will reach a new equilibrium state corresponding to a small angle $\theta_{\mathrm{o}}$. At this angle, the moment of these forces exert is balanced with the torsion or moment of the thrust due the twist. It shows the real gravitational force between the balls ${ }^{4}$.

$\tau=\mathrm{F}_{\mathrm{t}} \mathrm{R} \quad 2 \mathrm{~F}_{\mathrm{t}} \mathrm{R}=\mathrm{k} \theta$ (for the two balls of mass $\mathrm{m}$ )

$F_{t}=\frac{k \theta}{2 R} \quad F_{t}=F_{G}=G \frac{M m}{d^{2}}$

$\mathrm{G} \frac{\mathrm{Mm}}{\mathrm{d}^{2}}=\frac{\mathrm{k} \theta}{2 \mathrm{R}} \quad \mathrm{G}=\frac{\mathrm{k} \theta \mathrm{d}^{2}}{2 \mathrm{RMm}}$

The data of the Cavendish Experiment are:

$M=158 \mathrm{~kg}, \mathrm{~m}=0,73 \mathrm{~kg}, \mathrm{R}=0,90 \mathrm{~m}, \mathrm{~d}=0,23 \mathrm{~m}, \mathrm{~T}=420 \mathrm{~s}, \theta=0,000987 \mathrm{Rad}$

$\mathrm{T}=\sqrt{\frac{8 \pi^{2} \mathrm{~m} R^{2}}{\mathrm{k}}} \quad \mathrm{k}=\frac{8 \pi^{2} \mathrm{mR}^{2}}{\mathrm{~T}^{2}} \quad \mathrm{k}=2,65 \times 10^{-4} \mathrm{~N} \mathrm{~m}$

$\mathrm{G}=6,64 \times 10^{-11} \mathrm{~N} \mathrm{~m}^{2} / \mathrm{kg}^{2}$

Besides, Cavendish obtained the value of the Earth Mass as follows:

$\mathrm{mg}=\mathrm{G} \frac{\mathrm{M}_{\mathrm{em}}}{\mathrm{R}_{\mathrm{e}}{ }^{2}} \quad \mathrm{~g}=\mathrm{G} \frac{\mathrm{M}_{\mathrm{e}}}{\mathrm{R}_{\mathrm{e}}{ }^{2}} \quad \mathrm{M}_{\mathrm{e}}=\frac{\mathrm{gR}_{\mathrm{e}}{ }^{2}}{\mathrm{G}} \quad \mathrm{M}_{\mathrm{e}}=5,98 \times 10^{24} \mathrm{~kg}$

The density of the Earth is calculated as follows:

$\rho_{\mathrm{e}}=\frac{\mathrm{M}_{\mathrm{e}}}{\frac{4}{3} \pi R_{\mathrm{e}}{ }^{3}} \quad \mathrm{M}_{\mathrm{e}}=\frac{\mathrm{gR}_{\mathrm{e}}{ }^{2}}{\mathrm{G}} \quad \rho_{\mathrm{e}}=\frac{3 \mathrm{~g}}{4 \pi \mathrm{GR}_{\mathrm{e}}} \quad \rho_{\mathrm{e}}=5,51 \times 10^{3} \mathrm{~kg} / \mathrm{m}^{3}$

\section{Gravitational Field}

It is possible to consider the gravitational force between two masses as a distance action interaction. Therefore, the two masses interact although they are not in contact. For other hand, the gravitational interaction can be described by the concept of the gravitational field $g$ in the same form as the electric field in Electromagnestim ${ }^{1,2,3}$ proposed by Michael Faraday to describe the electromagnetism interactions ${ }^{1,2,3}$, where it is defined in the next form: $E=\frac{F_{e}}{q_{o}}$ where $\mathrm{E}$ is the electric field, $\mathrm{F}_{\mathrm{e}}$ is the electric force and $\mathrm{q}_{\mathrm{o}}$ is the test charge. Then, the gravitational field is defined as follows: $\mathrm{g}^{\prime}=\frac{\mathrm{Fg}_{\mathrm{g}}}{\mathrm{m}}$ where $\mathrm{F}_{\mathrm{g}}$ is the gravitational force and $\mathrm{m}$ is the test mass. The gravitational field $\mathrm{g}^{\prime}$ exerts a gravitational force $F_{g}=G \frac{M_{e} m}{r^{2}}$ on the particle with mass $m$ which is in the region of the gravitational field $g^{1,2,3}$. The gravitational and electromagnetism fields are vector fields because they are related to a vector for each point of the region of the field. As the test mass $m$ is positive, the direction of the gravitational field is also equal to the direction of the gravitational force which is toward the center of the Earth ${ }^{1,2,3}$. It is different to the scalar field where it is used scalar magnitude to describe the scalar field. For example, the temperature field describes the temperature variation within a temperature region ${ }^{1,2,3}$. 
The gravitational field is obtained as follows:

$g^{\prime}=\frac{F_{g}}{m} \quad F_{g}=G \frac{M_{e} m}{r^{2}} \quad g^{\prime}=-\frac{G M_{e}}{r^{2}} \hat{r}$

where $\hat{r}$ is an unitar vector. The minus sign is because the gravitational field has the direction toward the center of the Earth ${ }^{1,2,3}$. This formula of the gravitational field is valid for all particles located out of the surface of the Earth. If the particle is located very near or just at the Earth surface $r=R_{e}$, and the gravitational field or the gravitational acceleration is: $\quad g^{\prime}=-G \frac{M_{e}}{R_{e}{ }^{2}} \hat{r} \quad g^{\prime}=g=-9.8 \mathrm{~m} / \mathrm{s}^{2}$ and the particle experiments a gravitational force $F_{g}=m g$.

The gravitational field also can be written as follows:

$g^{\prime}=-\frac{G M_{e}}{\left(R_{e}+h\right)^{2}} \hat{r} \quad$ where $r=R_{e}+h$,

Where, $\mathrm{h}$ is the altitude of the respective city or place above sea level ${ }^{1,2,3}$. Thus, when $\mathrm{h}$ increases, the gravity filed $\mathrm{g}^{\prime}$ decreases. Besides, when the gravity field decreases, then the gravitational pull, the gravitational force or weight also decreases because the weight is proportional to the gravity acceleration $\mathrm{F}_{\mathrm{g}}=\mathrm{W}=\mathrm{mg}^{\prime}{ }^{6}$. In addition, the gravity acceleration also decreases because the gravity acceleration is equal to the gravity field. Thus, the gravity acceleration, the gravity field, the gravitational force and the weight decrease when the altitude increases.

For example, when $\mathrm{h}=500 \mathrm{~km}$, the gravity acceleration is: $\mathrm{g}^{\prime}=8.45 \mathrm{~m} / \mathrm{s}^{2}$. Therefore, the weight of the ball, person or object is also decreased because $\mathrm{F}_{\mathrm{g}}{ }^{\prime}=\mathrm{W}^{\prime}=\mathrm{mg}^{\prime}$. It is an important factor to be considered in Football when the match is played in a high altitude city ${ }^{6}$.

\section{Gravitational Energy Emission}

The two masses that are subjected to a gravitational field interact in a distance action interaction although they are not in contact and moreover, it is emitted gravitational energy between them $^{4}$.

The gravitational energy emission and the effects of the gravitation are demonstrated at my article with the discovered formulas: "The Fundament of the Mass and Effects of the Gravitation on a Particle and Light in the Mass, time, distance, velocity, frequency, wavelength: Variant Mass for a Particle which emits Gravitational Energy for a Particle orbiting a large Planet or Sun and for a Binary Star and Variant Frequency for the Light Passing Close a Gravitational Field from a Massive Object (Sun)" ${ }^{\prime 4}$. They are in agreement with the experiment results and with the Theory of General Relativity ${ }^{4}$.

It is demonstrated at the article mentioned the gravitational interaction and the gravitational energy emission which influences the light frequency which is called the gravitational redshift ${ }^{4}$ : Variant Frequency for the Light passing close a Gravitational Field from a Massive Object $^{4}$ (Sun for example). The gravitational energy emission also influences the light deflection passing close to the Sun: a star in a certain position will appear as if it were in another position because the light is deflected when passing near the Sun ${ }^{4}$. Stars that appear near the Sun can only be visible in a total solar eclipse. In 1919, the Royal Society of London organized an expedition to Africa and another to Brazil to observe an eclipse of the sun. The observations showed with great accuracy that the apparent 
deviation of the position of the stars near the Sun corresponded to that predicted by Einstein: light deflection of 1.75 arc seconds approximately ${ }^{4}$.

By using the formula for the light velocity ${ }^{4}$, the value of the light deflection is: $\theta \approx \frac{4 \mathrm{GM}}{\mathrm{Rc}^{2}}$ $\theta=1,75$ arc secons of light deflection. It is in agreement with the result of the General Relativity Theory ${ }^{4}$.

False position of the star True position of the star

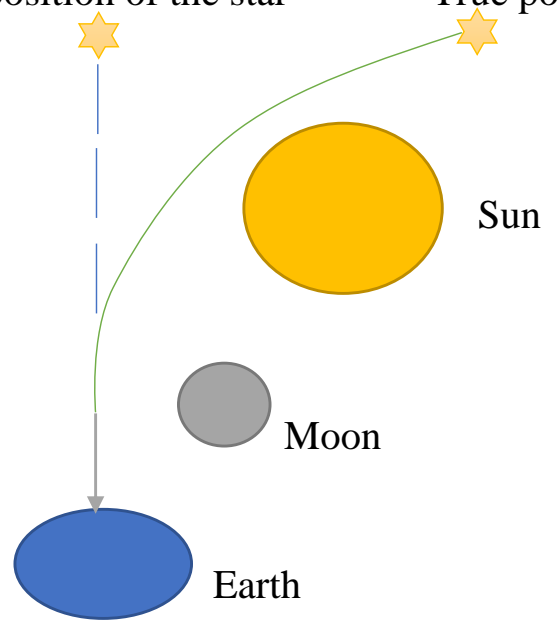

Fig.2. Light Deflection from the stars when passing close to the Sun

The light does not have mass but light has energy and as consequence, it experiments the interaction with the gravitational field which influences the light frequency or gravitational redshift and light deflection ${ }^{4}$. In fact, in a gravitational field, the light has lower velocity, lower rates of the clock-time (less time measured) than the light in a place without gravitational field. Then, the light passing near the Sun experiments the gravitational redshift when the light is observed at the Earth: less frequency measured, deviation to the red, more wavelength, because of the time clock measured and the real lost energy ${ }^{4}$.

Other demonstration of gravitational energy emission and effect of the gravitational interaction is the Perihelion Precession of Mercury ${ }^{4}$. The perihelion or the ellipse of Mercury has a small rotation and changes a small angle $\theta$ after every turn around the Sun. The formula for time dilation and decrease distance are used to calculate the Perihelion Precession of Mercury ${ }^{4}$. The result $\Delta \theta=43,75$ arcoseconds/century is in agreement with the experiment result and with the Relativity Theory with high accuracy ${ }^{4}$.

For other hand, Albert Einstein wrote in an research article entitled: "Does the inertia of a body depend on its energy content?" (Ist die Trägheit eines Körpers von seimen Energienhalt abhängig?): "If a body emits energy E in the form of radiation, its mass decreases by $\mathrm{E} / \mathrm{c}^{2}$. It is not essential that the energy emitted from the body is converted into radiant energy, so we are drawn to the most general conclusion: The mass of a body is a measure of its energy content. If the energy changes in $\mathrm{E}$, the mass also changes at the same rate $\mathrm{E} / \mathrm{c}^{2}$. One must not rule out the possibility of testing this theory using bodies whose energy content is highly variable (radio salts for example). If the theory agrees with the facts, then radiation carries inertia between emitting and absorbing bodies" ${ }^{\prime 4}$. Besides, it is true for any type of emitted radiation (gravitational (gravitons), electromagnetism (photons), for example) ${ }^{5}$. 
The emission of this energy will produce a decrease in the mass of the emitting body. Thus, Maxwell's theory shows that electromagnetic waves are radiated whenever charges accelerate as for example for the electron. Then, this electromagnetic radiation (photons) produces a decrease in the mass of the electron which is given by the formula of the Variant Mass for an accelerated charged particle ${ }^{5}$. This lustrous, simple and symmetric formula for the electromagnetic radiation for an accelerated particle was obtained and demonstrated by myself at the research of Variant Mass for an accelerated charged particle ${ }^{5}$.

Thus, if a particle emits radiation energy E (electromagnetic or gravitational), then the rest energy of the particle decreases in $\mathrm{E}$ and by the mass-energy conservation also the mass of the particle decreases in the value $\Delta \mathrm{m}=\mathrm{E} / \mathrm{c}^{2}$ [2]. Therefore, the mass of a body is a measure of its energy content. The inert mass of a body increase or decrease with energy that it contains. If the initial mass of the particle is $M$ and the final mass of the particle is $M^{\prime}$ after the emission, then it is obtained: $\quad \mathrm{M}^{\prime}-\mathrm{M}^{\prime}=\mathrm{E} / \mathrm{c}^{2} \quad \mathrm{E}=\left(\mathrm{M}^{2}-\mathrm{M}^{\prime}\right) \mathrm{c}^{2} \quad \mathrm{E}=\Delta \mathrm{Mc}^{2}$. Thus, the decrease or increase in mass $\Delta \mathrm{M}=\mathrm{M}-\mathrm{M}^{\prime}$ of the particle is linked to the radiation energy $\mathrm{E}=\Delta \mathrm{Mc}^{2}$ emitted or absorbed. This energy is also the lost energy of the particle for the case of energy emission.

Besides, it is possible to have the next thought experiment: if a mass $\mathrm{M}_{\mathrm{o}}$ is suspended from a spring balance in the $\mathrm{K}$ ' accelerated system with acceleration $\mathrm{g}$, the balance will indicate the apparent weight $\mathrm{M}_{\mathrm{o}} \mathrm{g}$ due the inertia of $\mathrm{M}_{\circ}$ (the balance transmits the acceleration to the mass $M_{o}$ ). If the amount of energy $E$ is transferred to $M_{o}$, the spring balance, by the law of the inertia of the energy (equivalence of mass and energy $E / c^{2}=m$ ), will indicate $M_{o} g+\frac{E}{c^{2}} g$. Exactly, this should happen when the experiment is repeated in the gravitational system $\mathrm{K}$ where the balance transmits the gravity acceleration of the Earth to the mass $\mathbf{M}_{0}$. At the opposite situation, if the mass $\mathrm{M}_{0}$ emits gravitational energy, it decreases the mass ${ }^{4}$. It is also a tough experiment that corroborates that the inertial mass is equivalent to the gravitational mass.

\section{Applied Physics in Football}

\section{Free Fall}

There are some situations when the player kicks the ball and the motion of the ball is in vertical free fall. The ball during the vertical motion is under the action of the gravity field or gravity acceleration. Besides, there are situations where there is a stopped play, and the referee to resume play throws the ball upward or drop it ${ }^{6}$. A member of each team stands next to the referee and waits for the referee to drop the ball between them and then, a player kicks it to the other team ${ }^{6}$. If it occurs, then the motion of the ball performed by the referee is vertical free fall under the action of the gravity acceleration.

The forces that act on the ball when it is in the air are the gravitational force and the friction force due the air resistance. Nevertheless, the objects in free fall do not weigh although there is the gravitational force on the object which is the reason of the free fall with the acceleration of the gravity. Thus, if there is a scale under the ball in free fall, the scale does not feel the force and pressure of the ball because it falls with the same gravity acceleration of the ball and this will mark a weight of $\mathrm{W}=0 \mathrm{~N}$. There is a thought experiment that can be carried out in an elevator 
that falls with the same acceleration of gravity and in which a person is on a scale. The weight of the person in these conditions is $0 \mathrm{~N}$ because both: the person and the scale fall with the same gravity acceleration.

The value of the gravity acceleration for all objects near the surface of the Earth is $g=9.8 \mathrm{~m} / \mathrm{s}^{2}$ which is directed toward the center of the Earth. Then, all the objects fall with the same acceleration of gravity neglecting the air resistance. It is due to the gravitational field exerted by the planet on all objects that have mass and that are within it. The gravitational field which is also directed toward the center of the Earth is equal to the gravity acceleration at surface of the Earth ${ }^{1,2,3}$.

Because the vertical launch up is an uniform accelerated motion, the formulas of this motion can also be used by using the gravity acceleration $\mathrm{a}=-\mathrm{g}$ because the upward vectors are positive $\mathrm{i}^{1,2,3}$. The magnitude of the velocities that are in the same level are equals but they have opposite direction. The velocity is equal to zero at the maximum height of the trajectory. Besides, the rise time is equal to the fall time $e^{1,2,3}$ and then, the total flight time is the double of the rise time or the double of the fall time. The formulas for the vertical launch up are as follows:

$\mathrm{v}_{\mathrm{f}}=\mathrm{v}_{\mathrm{i}}+\mathrm{at}$

$\mathrm{v}_{\mathrm{f}}^{2}=\mathrm{v}_{\mathrm{i}}^{2}+2 \mathrm{a} \Delta \mathrm{y}$

$\Delta \mathrm{y}=\mathrm{v}_{\mathrm{i}} \mathrm{t}+\frac{1}{2} a \mathrm{t}^{2}$

$\Delta \mathrm{y}=\frac{\left(v_{f}+v_{i}\right)}{2} t$

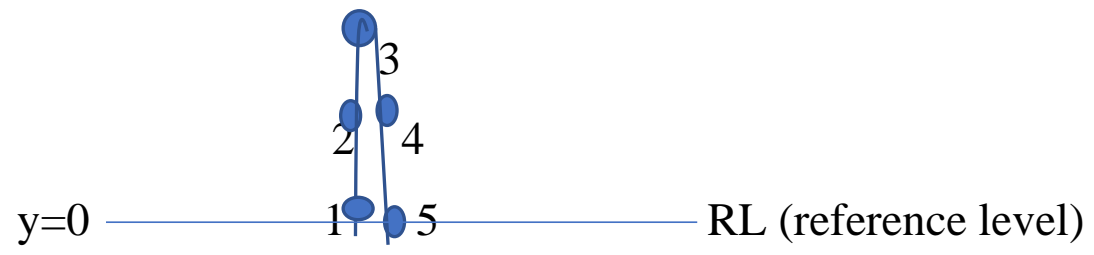

Fig.3. Vertical launch up

In addition, the vertical launch up can be divided in two movements: an upward motion which is decelerated (velocity and acceleration in opposite direction) and a downward motion which is accelerated (velocity and acceleration in the same direction). For the downward motion, the reference level $(y=0)$ can be considered at the point of the maximum height where the initial velocity is $\mathrm{v}=0 \mathrm{~m} / \mathrm{s}$. If the reference level is located at the point of the maximum height and the downward vectors are positive, then all displacements and velocities are positive $e^{1,2,3}$.

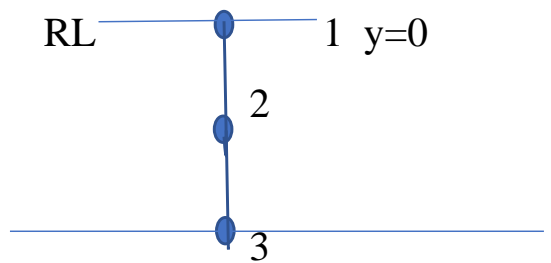

Fig.4. Downward motion for the vertical launch up

Since the acceleration due to gravity is positive $\mathrm{a}=\mathrm{g}$ and by considering an initial velocity $\mathrm{v}_{\mathrm{i}}=0$, the formulas for this movement are as follows: 
$\mathrm{v}_{\mathrm{f}}=\mathrm{v}_{\mathrm{i}}+\mathrm{gt}$

$v_{f}^{2}=v_{i}^{2}+2 g \Delta y$

$\Delta \mathrm{y}=\mathrm{v}_{\mathrm{i}} \mathrm{t}+\frac{1}{2} \mathrm{gt}^{2}$

$\Delta \mathrm{y}=\frac{\left(v_{f}+v_{i}\right)}{2} t$ $\mathrm{v}_{\mathrm{f}}=\mathrm{gt}$

$\mathrm{v}_{\mathrm{f}}^{2}=2 \mathrm{~g} \Delta \mathrm{y}$

$\Delta \mathrm{y}=\frac{1}{2} \mathrm{gt}^{2}$

$\Delta \mathrm{y}=\frac{\left(v_{f}\right)}{2} t$

\section{Parabolic Movement}

There are many examples of parabolic motion of the ball in a Direct or Indirect Free kick, Goalkeeper kick, Corner kick, Penalty, Hand serve ${ }^{6}$. For example, the hand serve is a kind of parabolic motion that occurs when the ball is launched upward with the hand and with an angle of inclination positive ${ }^{6}$. Therefore, the height $h$ of the next graph corresponds to the height of the person which performs the hand serve.

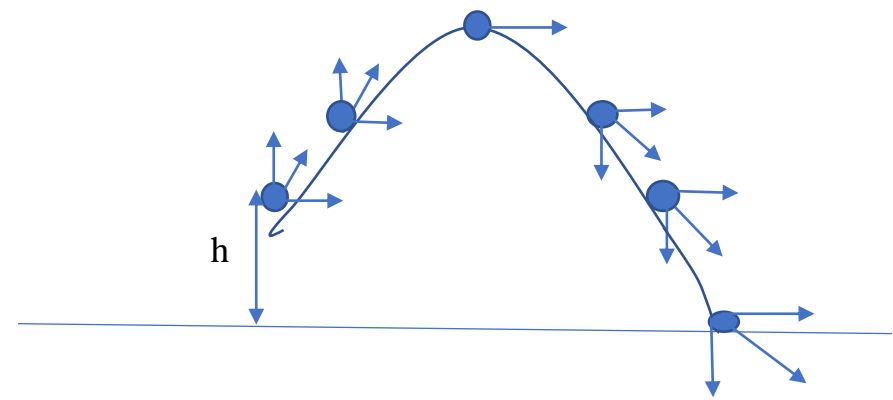

Fig.5. Hand Serve: Ball launched with the hand in a parabolic motion

The Free kick is a type of parabolic movement that occurs when the ball is kicked from the grass. In a free kick, the defenders can form a barrier 10 yards or $9.14 \mathrm{~m}$ away from the point where the ball is kicked. A barrier is formed at the free kick to defend the goal or block a possible goal. and cannot raise their hand to block the free kick. It can be formed with the desired number of players and according to the indications of the goalkeeper and go forward once the ball is touched. The movement of the ball in a free kick is parabolic, in which intervenes the effects of kicking the ball, the gravity and atmospheric pressure of the planet and the effects of air resistance, ${ }^{7,8}$.

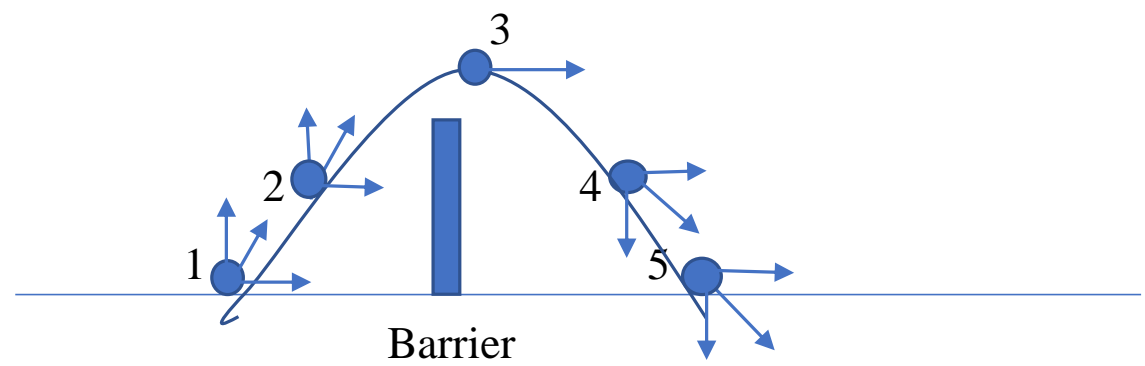

Fig.6. Free kick: Ball kicked from the grass in Parabolic motion

The graph shows the velocity (which are tangential to the path) with its components horizontal and vertical for various points on the path. At point 3, there is only the horizontal component of velocity and there is no vertical component $\mathrm{v}_{\mathrm{y}}=0$. The path of the parabolic movement is a parabola and the acceleration of gravity is directed downward $^{1,2,3}$. The object throughout its trajectory is subject to the Earth's gravitational field which is directed 
towards the center of the Earth. This causes the object to fall after having risen a certain height ${ }^{1,2,3}$. It is analogous to a movement made up of two movements: one horizontal and the other vertical. The horizontal motion corresponds to a straight line motion with constant velocity because there is no horizontal acceleration. The vertical movement corresponds to the launch upward in which the acceleration of gravity intervenes ${ }^{1,2,3}$. The equations used are those of the motion with constant velocity for the horizontal part and those of vertical launch upward for the vertical part ${ }^{1,2,3}$. The object can be launched upward in a parabolic motion with an angle of inclination either from the ground or from a certain height.

The formulas to use for the horizontal part are as follows:

$\Delta \mathrm{x}=\mathrm{v}_{\mathrm{x}} \mathrm{t} \quad \mathrm{v}_{\mathrm{ix}}=\mathrm{v}_{\mathrm{x}}=\mathrm{v}_{\mathrm{i}} \cos \theta_{\mathrm{i}} \quad \mathrm{v}_{\mathrm{x}}$ : horizontal velocities are constants

The formulas to use for the vertical part are as follows:
$\mathrm{v}_{\mathrm{fy}}=\mathrm{v}_{\mathrm{iy}}-\mathrm{gt}$
(1) $\quad \mathrm{v}_{\mathrm{iy}}=\mathrm{v}_{\mathrm{i}} \operatorname{sen} \theta_{\mathrm{i}}$
$v_{\text {fy }}^{2}=v_{i y}^{2}-2 g \Delta y$
$\Delta \mathrm{y}=\mathrm{v}_{\mathrm{iy}} \mathrm{t}-\frac{1}{2} \mathrm{gt}^{2}$
$\Delta \mathrm{y}=\frac{\left(\mathrm{v}_{\mathrm{fy}}+\mathrm{v}_{\mathrm{iy}}\right)}{2} \mathrm{t}$

The formulas for the velocity components are as follows:

$\mathrm{v}_{\mathrm{ix}}=\mathrm{v}_{\mathrm{x}}=\mathrm{v}_{\mathrm{i}} \cos \theta_{\mathrm{i}} \quad \mathrm{v}_{\mathrm{ix}}=\mathrm{v}_{\mathrm{x}}=\mathrm{v} \cos \theta \quad \mathrm{v}_{\mathrm{i}} \cos \theta_{\mathrm{i}}=\mathrm{v} \cos \theta \quad \mathrm{v}_{\mathrm{x}}:$ constant velocity

$\mathrm{v}_{\mathrm{iy}}=\mathrm{v}_{\mathrm{i}} \operatorname{sen} \theta_{\mathrm{i}} \quad \mathrm{v}_{\mathrm{y}}=\mathrm{v} \operatorname{sen} \theta$

$\mathrm{v}_{\mathrm{i}}^{2}=\mathrm{v}_{\mathrm{ix}}{ }^{2}+\mathrm{v}_{\mathrm{iy}}^{2} \quad \tan \theta_{\mathrm{i}}=\left(\mathrm{v}_{\mathrm{iy}} / \mathrm{v}_{\mathrm{x}}\right)$

$\mathrm{v}^{2}=\mathrm{v}_{\mathrm{x}}^{2}+\mathrm{v}_{\mathrm{y}}^{2} \quad \tan \theta=\left(\mathrm{v}_{\mathrm{y}} / \mathrm{v}_{\mathrm{x}}\right)$

By solving for the time $t$ from the equation: $\Delta x=v_{x} t$ and by replacing: $v_{i x}=v_{i} \cos \theta_{i}$, it is obtained: $t=\Delta x / v_{i x} \quad t=$ $\Delta \mathrm{x} /\left(\mathrm{v}_{\mathrm{i}} \cos \theta_{\mathrm{i}}\right)$. By replacing this time $\mathrm{t}$ at the equation: $\Delta \mathrm{y}=\mathrm{v}_{\mathrm{iy}} \mathrm{t}-\frac{1}{2} \mathrm{gt}^{2}$ and $\mathrm{v}_{\mathrm{iy}}=\mathrm{v}_{\mathrm{i}} \operatorname{sen} \theta_{\mathrm{i}}$, the parabolic equation is obtained: $\quad \Delta \mathrm{y}=\Delta \mathrm{x} \tan \theta_{\mathrm{i}}-\frac{1}{2} \mathrm{~g}\left[\frac{\Delta \mathrm{x}}{\mathrm{v}_{\mathrm{i}} \cos \theta_{\mathrm{i}}}\right]^{2}$

If the object is launched horizontally $\theta_{\mathrm{i}}=0^{\circ}$ from a height $\mathrm{h}^{1,2,3}$, then $\mathrm{v}_{\mathrm{iy}}=0 \mathrm{~m} / \mathrm{s}$ and $\mathrm{v}_{\mathrm{ix}}=\mathrm{v}_{\mathrm{i}}$. The constant acceleration of the gravity is directed downward ${ }^{1,2,3}$.

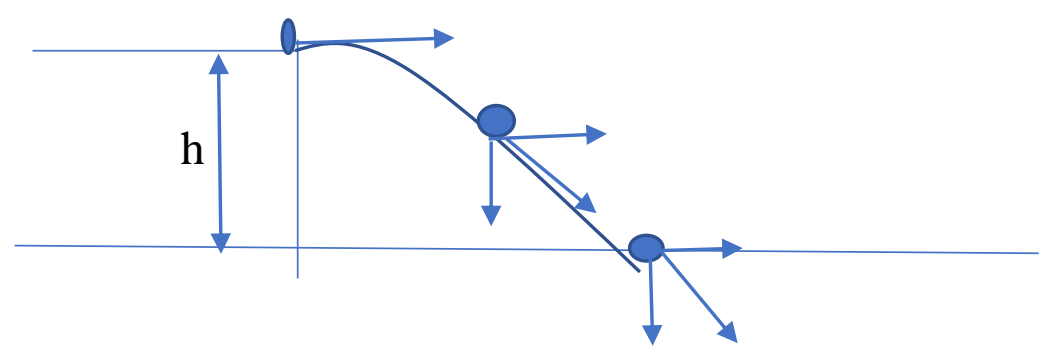

Fig.7. Parabolic movement for an object launched horizontally from a height $h$ 
The formulas to use for the horizontal part are as follows:

$\Delta \mathrm{x}=\mathrm{v}_{\mathrm{x}} \mathrm{t} \quad \mathrm{v}_{\mathrm{x}}=\mathrm{v}_{\mathrm{i}} \cos \theta_{\mathrm{i}}=\mathrm{v}_{\mathrm{i}} \cos (0)=\mathrm{v}_{\mathrm{i}}$

$\mathrm{v}_{\mathrm{iy}}=\mathrm{v}_{\mathrm{i}} \operatorname{sen}(0)=0$

The formulas to use for the vertical part are as follows:

$\mathrm{v}_{\mathrm{fy}}=\mathrm{gt}$

(1) (downward vectors are positive and $\mathrm{v}_{\mathrm{iy}}=0$ )

$v_{\text {fy }}^{2}=2 g \Delta y$

$\Delta \mathrm{y}=\frac{1}{2} \mathrm{gt}^{2}$

$\Delta \mathrm{y}=\frac{\left(\mathrm{v}_{\mathrm{fy}}\right)}{2} \mathrm{t}$

The formulas for the velocity components are as follows:

$\begin{array}{llll}\mathrm{v}_{\mathrm{x}}=\mathrm{v}_{\mathrm{i}} \cos (0)=\mathrm{v}_{\mathrm{i}} & \mathrm{v}_{\mathrm{ix}}=\mathrm{v}_{\mathrm{x}}=\mathrm{v}_{\mathrm{i}} & \mathrm{v}_{\mathrm{i}}=\mathrm{v} \cos \theta & \mathrm{v}_{\mathrm{x}}: \text { constant velocity } \\ \mathrm{v}_{\mathrm{iy}}=\mathrm{v}_{\mathrm{i}} \operatorname{sen}(0)=0 & \mathrm{v}_{\mathrm{iy}}=0 & \mathrm{v}_{\mathrm{y}}=\mathrm{v} \operatorname{sen} \theta \\ \mathrm{v}_{\mathrm{i}}{ }^{2}=\mathrm{v}_{\mathrm{ix}}{ }^{2}+\mathrm{v}_{\mathrm{iy}}^{2} & \mathrm{v}_{\mathrm{i}}=\mathrm{v}_{\mathrm{ix}}=\mathrm{v}_{\mathrm{x}} & \mathrm{v}^{2}=\mathrm{v}_{\mathrm{i}}{ }^{2}+\mathrm{v}_{\mathrm{y}}{ }^{2} \\ \theta_{\mathrm{i}}=0^{\circ} & \tan \theta=\left(\mathrm{v}_{\mathrm{y}} / \mathrm{v}_{\mathrm{x}}\right) & \end{array}$

\section{Newton Laws}

Forces are applied in Football as for example in the contact of the foot with the ball and in the contact between players. Therefore, it is important to analyse the Newton laws because they have effects at the motion of the ball. Thus, the forces are the causes of the ball motions. Besides, the motion of the ball is important to score goals which is one of the most important objective in Football ${ }^{6}$.

The forces have magnitude and direction and thus, they are vectors ${ }^{1,2,3}$. It is important for example the magnitude and direction of the force applied to the ball by the foot in a Goal kick or Goalkeeper kick, Penalty, Corner kick, and Direct or Indirect free kick ${ }^{6}$. The forces that act in a Football ball when it is in the air are: the weight or gravitational force and the friction force due the air resistance. The gravitational field and the gravitational force act on the ball at all time of the free fall of the ball and due this reason, there is the free fall of the Football Ball with the acceleration of the gravity.

Therefore, it is very important to understand the Newton Forces Laws:

Newton's First Law (Law of Inertia): Every body or object tends to remain in a state of rest or motion with constant velocity unless a force acting on it and changes its state of motion with constant velocity or at rest. The object must be analyzed from an inertial frame of reference ${ }^{1,2,3}$.

Regarding Football, the ball tends to remain at rest or with constant velocity after the respective kick to the ball unless a force acts (other force done with the foot of other player to the ball for example) on it and changes its state 
of motion with constant velocity or at rest. Of course, the ball doesn't remain with constant velocity after the respective kick to the ball by the player due the friction force of the ball with the grass or with the wind at the $\operatorname{air}^{6,7,8}$

Newton's Second Law: Every force that is applied to an object gives it an acceleration of equal direction of the applied force ${ }^{1,2,3}$. This is established by means of the following equation: $\mathrm{F}=$ ma. An example of Newton's second law is the weight or gravitational force: $\mathrm{W}=\mathrm{Fg}=\mathrm{mg}$, where $\mathrm{g}$ is the acceleration due to gravity. The weight is the gravitational force that is directed toward the center of the Earth while the gravity is an acceleration that is also directed toward the center of the Earth ${ }^{1,2,3}$

For other hand, the mass of the object or the ball transfers to it a resistance to being accelerated $\mathrm{a}=\mathrm{F} / \mathrm{m}$ : the higher the mass, the higher the gravitational force, the higher the resistance to being accelerated and lower acceleration, the lower the mass, the lower the gravitational force, the less resistance to being accelerated and higher acceleration $^{1,2,3}$. Due this compensation between the gravitational force and the resistance to being accelerated, all objects fall with the same acceleration and reach the ground at the same time neglecting air resistance.

Regarding Football, a force applied to the ball produces an acceleration to the ball $\mathrm{a}=\mathrm{F} / \mathrm{m}$ : the higher the force: the higher the ball acceleration, the lower the force: the lower the ball acceleration and for other hand, the higher the ball mass: the higher the resistance to being accelerated and lower acceleration, the lower the ball mass: the lower the resistance to being accelerated and higher acceleration. There are different sides and weights of balls for Football, Futsal or Indoor football, or Beach football. Therefore, there are different resistances of the balls to being accelerated depending on their weight and size ${ }^{6}$. This Newton law is important to consider in a Goal kick or Goalkeeper kick, Penalty, Corner kick and Direct or Indirect free kick where the magnitude and the direction of the foot force has direct effect in the motion of the ball ${ }^{6,7,8}$.

Newton's Third Law: A reaction force of equal magnitude but in the opposite direction is opposed to every action force $^{1,2,3}$. An example of Newton's third law is when an object rests on the floor, the object exerts on the floor a force equal to the weight, while the floor exerts on the object a reaction force called normal ${ }^{1,2,3}$. Thus, we have $\mathrm{N}=$ $-W$.

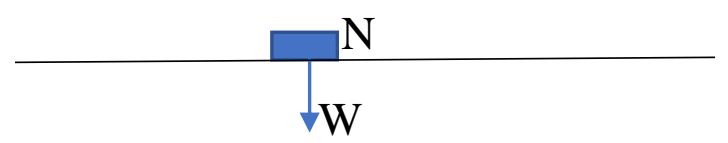

Fig.8. The weight or gravitational force and the normal force

Regarding Football, when the ball rests on the grass, the following pair of forces action reaction act: the ball exerts on the grass a force equal to the weight $\mathrm{W}$ or gravitational force $\mathrm{F}_{\mathrm{g}}$ (downward direction) while the grass exerts on the ball a reaction force which is called the normal force $\mathrm{N}=-\mathrm{W}$ (upward direction). Besides, when the foot of the player kicks the ball, there is the next pair of forces action reaction: the force exerted by the foot on the ball (which produces a small imperceptible temporary deformation of the ball) and the reaction force of the ball on the foot of equal magnitude but opposed to the foot force in the opposite direction. When the ball is in the air, the following 
pairs of forces action reaction act: the gravitational force or weight of the ball and the reaction force of the air (air resistance) on the ball. In addition, there is another pair of action-reaction forces when the player runs which is the backward force of the foot on the grass and the forward friction force that the grass does on the foot ${ }^{6,7,8}$.

\section{Work and Energy}

It is necessary to do the work of kicking the ball to produce the motion of the ball ${ }^{6,7,8}$. Then, the work done by the foot when kicking the ball is converted in kinetic and potential energy of the ball which is in accordance with the principle of energy conservation: "Energy is neither created nor destroyed, it is only transformed"1,2,3.

Then, the work done is converted into kinetic energy, potential energy or elastic energy as it was mentioned before. The work which is scalar quantity has units of energy because it is necessary energy to do the work. If this work is positive, the energy is transferred to the system. On the other hand, if this work is negative, the energy is transferred from the system ${ }^{1,2,3}$. The unit of the work or the energy is Joule $(\mathrm{J})$ in the MKS system or Lb-ft in the English System ${ }^{1,2,3}$.

If the force has an angle $\theta$ with the direction of the displacement, the work is given by the distance times the component of the force in the direction of displacement: $\quad \mathrm{T}=\mathrm{F} d \cos \theta, \mathrm{T}=\mathrm{F} \cdot \mathrm{d}$ (the $\cdot$ represents the dot product between two vectors $)^{1,2,3}$. If $\theta=0^{\circ}$, the the work is: $\mathrm{T}=\mathrm{Fd}$.

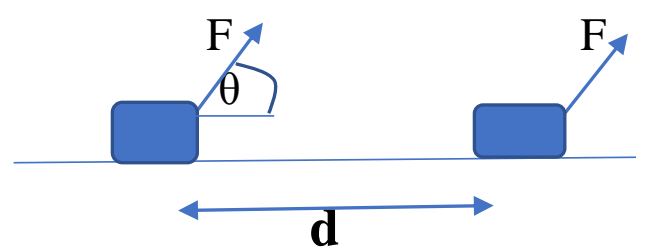

Fig.9. The work done by a constant force which has an angle $\theta$ with

the direction of the displacement $\mathrm{d}$

If the work is done by a variable force, then the work is obtained as follows: $T=\int_{x_{i}}^{x_{f}} F d x$. Thus, the work represents the area under the curve of $\mathrm{F}$ versus $\mathrm{x}$. In the case of a constant force, the work is the area of the rectangle $\mathrm{T}=\mathrm{Fd}$ :

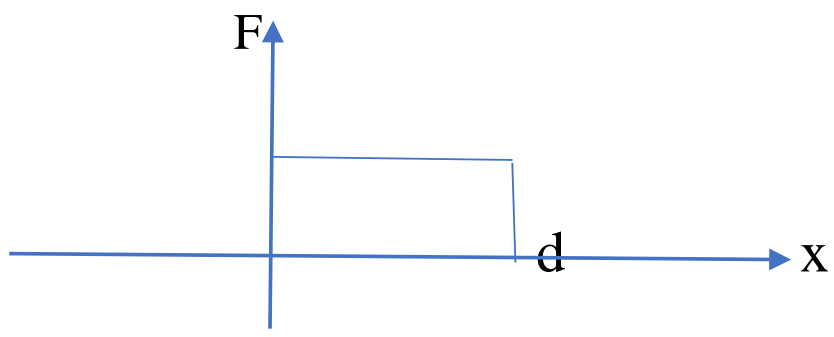

Fig.10. The constant force $F$ versus the displacement $d$

A variable force is for example the elastic force in a spring. It is considered the Hooke's law that establishes a relationship between the elastic force and the displacement: $\mathrm{F}=\mathrm{kx}$, where $\mathrm{k}$ is the elastic constant of the spring ${ }^{1,2,3}$. The elastic potential energy or the work done by a spring is: 
$\mathrm{T}=\int_{0}^{\mathrm{x}} \mathrm{Fdx}=\int_{0}^{\mathrm{x}} \mathrm{kxdx}=\frac{1}{2} \mathrm{kx}^{2}$. This result could also be obtained through the area of the triangle of the graph $\mathrm{F}$ versus $\mathrm{x}$.

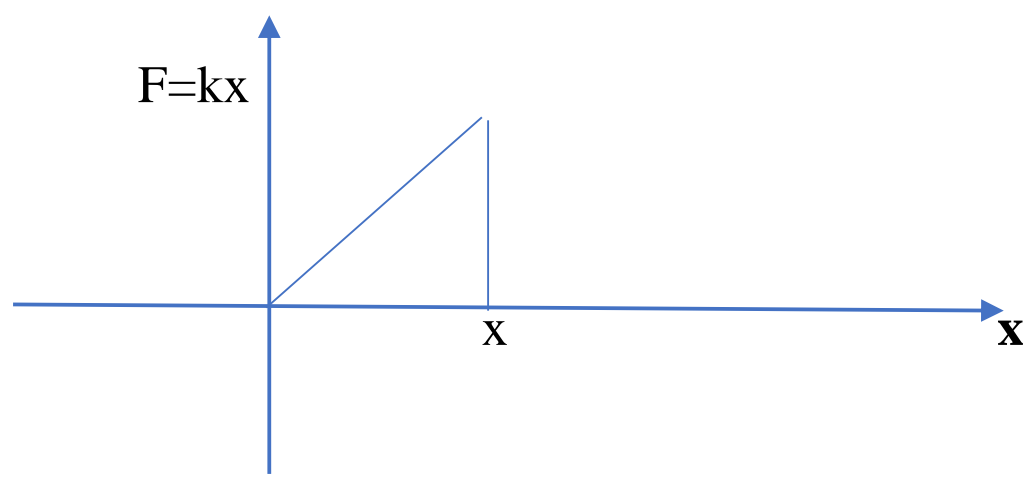

Fig.11. The variable force $\mathrm{F}=\mathrm{kx}$ versus the displacement $\mathrm{x}$

\section{Kinetic Energy}

The work of kicking the ball is transformed into a variation of the kinetic energy which produces the motion of the ball ${ }^{6,7,8}$. Thus, there is kinetic energy when there is movement of the object ${ }^{1,2,3}$. The unit of kinetic energy is the same unit of work, as for example Joule for the MKS System and Lb-ft for the English System. The formula of the kinetic energy is:

$\mathrm{T}=\int \mathrm{Fdx}=\int \mathrm{madx}=\int_{\mathrm{v}_{\mathrm{i}}}^{\mathrm{v}_{\mathrm{f}}} \mathrm{m} \frac{\mathrm{dv}}{\mathrm{dt}} \mathrm{dx}=\int_{\mathrm{v}_{\mathrm{i}}}^{\mathrm{v}_{\mathrm{f}}} \mathrm{mv} \mathrm{dv}=\frac{1}{2} \mathrm{mv}_{\mathrm{f}}^{2}-\frac{1}{2} \mathrm{mv}_{\mathrm{i}}^{2}$

$\Delta \mathrm{K}=\frac{1}{2} \mathrm{mv}_{\mathrm{f}}^{2}-\frac{1}{2} \mathrm{mv}_{\mathrm{i}}^{2}$

If the object part of rest, then the formula to use is: $\Delta \mathrm{K}=\frac{1}{2} \mathrm{mv}_{\mathrm{f}}{ }^{2}$ because $\mathrm{v}_{\mathrm{i}}=0 \mathrm{~m} / \mathrm{s}$ (ball from rest). This formula is valid not only for rectilinear motion with constant acceleration, but for all types of motion.

\section{Gravitational Potential Energy}

There is gravitational potential energy when there is a vertical position change or height of the ball respect to the grass which is the reference level. This variation of the gravitational potential energy occurs during the parabolic motion of the Football ball. It is produced in a Direct or Indirect Free kick, Corner kick, Goalkeeper kick, Penalty for example ${ }^{6}$. In a Free kick, it occurs when the ball is kicked and it is necessary to pass the barrier made by the players $^{6,7,8}$. The unit is also the Joule and the symbol is $\mathrm{E}_{\mathrm{g}}$.

Thus, the gravitational potential energy is produced when there is a vertical position change or height of the object with respect to a reference level (position (1) in the graph) ${ }^{1,2,3}$. Besides, heights above the reference level are positive and below the reference level are negative $e^{1,2,3}$.

If we want to change the vertical position of an object or the ball to a height $h$, work must be done to overcome the weight $\mathrm{W}$ or gravitational force $\mathrm{F}_{\mathrm{g}}$. Thus, an external force $\mathrm{F}=\mathrm{W}$ (weight) needs to be applied and it is obtained: $\mathrm{T}$ $=\mathrm{Wh}, \mathrm{T}=\mathrm{E}_{\mathrm{g}}=\mathrm{mgh}$ where $\mathrm{m}$ is the mass of the object or the ball. This equation is valid for objects near the Earth's surface, where the gravity is considered approximately constant ${ }^{1,2,3}$. 


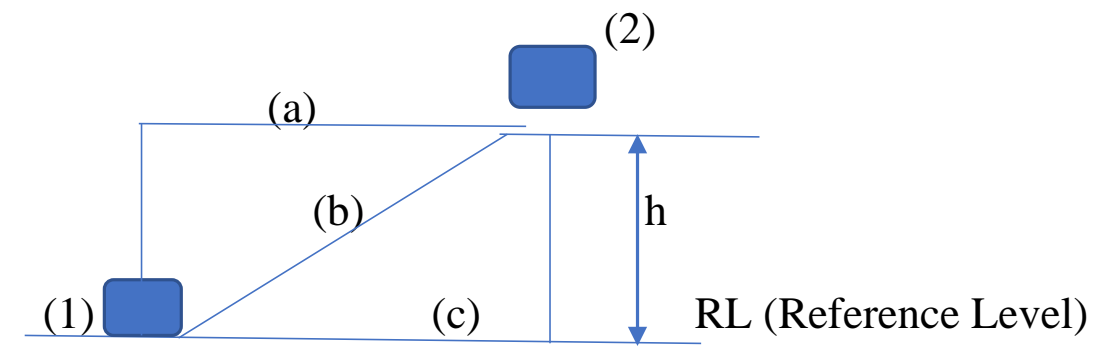

Fig.12. Work $\mathrm{T}=\mathrm{E}_{\mathrm{g}}=\mathrm{mgh}$ to bring the object from position (1) to (2) which is independent of the paths (a), (b) or (c)

The work to bring the object from position (1) to position (2) is independent of the path (a, b or c). The gravitational potential energy depends only of the vertical positions of the points (1) and (2). This work is equal to the change in gravitational potential energy $\mathrm{T}=\mathrm{E}_{\mathrm{g}}=\mathrm{mgh}$ where $\mathrm{h}$ is the difference between vertical positions of (1) and (2). The work that is done to move the object from position (1) to position (2) is stored in position (2) as gravitational potential energy $y^{1,2,3}$. Moreover, the variation of gravitational potential energy is independent of the reference level ${ }^{1,2,3}$ :

NR1: $E_{\mathrm{ga}}=0 \quad \mathrm{E}_{\mathrm{gb}}=\mathrm{mgh} \quad \Delta \mathrm{E}_{\mathrm{g}}=\mathrm{mgh}$

NR2: $E_{g a}=m g y \quad E_{g b}=m g(h+y) \quad \Delta E_{g}=m g h$

(b)

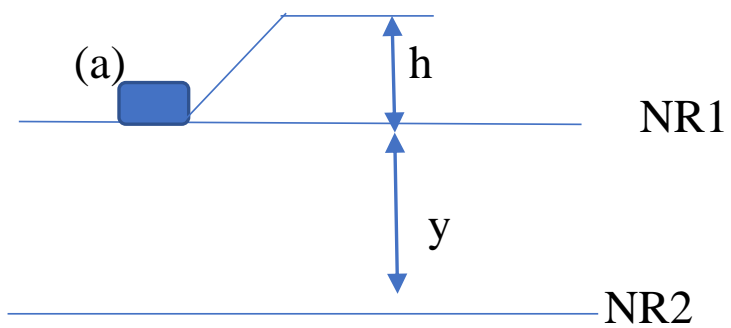

Fig.13. Variation of the gravitational potential energy which is

independent of the reference level

For other hand, if a particle with mass $m$ changes a small distance by increasing the height ( $\mathrm{R}$ increases) near the surface of the Earth with radius $R_{e}$ and mass $M_{e}$, it is obtained the following for the gravitational potential energy $^{1,2,3}: E_{g}=-G \frac{M_{e} m}{R} \quad E_{g}$ : gravitational potential energy

$$
\begin{aligned}
& \Delta \mathrm{E}_{\mathrm{g}}=\mathrm{E}_{\mathrm{gf}}-\mathrm{E}_{\mathrm{gi}} \quad \Delta \mathrm{E}_{\mathrm{g}}=-\mathrm{GM}_{\mathrm{e}} \mathrm{m}\left(\frac{1}{\mathrm{R}_{\mathrm{f}}}-\frac{1}{\mathrm{R}_{\mathrm{i}}}\right) \\
& \Delta E_{g}=G_{e} m\left(\frac{R_{f}-R_{i}}{R_{f} R_{i}}\right) \quad R_{f}-R_{i}=\Delta y \quad R_{f} R_{i} \approx R_{e}^{2} \quad g=G \frac{M_{e}}{R_{e}{ }^{2}}
\end{aligned}
$$

$\Delta \mathrm{E}_{\mathrm{g}}=\mathrm{mg} \Delta \mathrm{y}$ (the gravitational potential energy inside of the Earth) which is equal to the formula obtained before and valid for objects near the surface of the Earth where the gravity accelerations is considered approximately constant. 


\section{Principle of energy conservation}

When the player kicks the ball in a Direct or Indirect free kick for example, the work done by the foot at the kicking of the ball is transformed into a variation of the kinetic energy (which produces a motion of the ball) and/or in a variation of the potential energy (the ball gets a height $h$ respect to the reference level or grass) ${ }^{6,7,8}$.

Thus, if work is done on a system, this work is transformed into an increase in kinetic energy or gravitational potential energy or other kind of energy. For other hand, if the system does the work, this results in a decrease in its kinetic energy or its gravitational potential energy. It is also possible that if no work is done on the system, there may be a transformation from kinetic energy to gravitational energy or from gravitational energy to kinetic energy. Thus, there is a transformation from one type of energy to another. This can be stated in the following way: "Energy is neither created nor destroyed, it is only transformed"1,2,3. An example of energy transformation is what occurs in an electrical dam. The principle of energy conservation can be expressed mathematically in the following way: $\Delta \mathrm{K}+\Delta \mathrm{E}_{\mathrm{g}}=0$ or $\mathrm{T}+\mathrm{T}_{\mathrm{p}}=\Delta \mathrm{K}+\Delta \mathrm{E}_{\mathrm{g}}$ if there is a work $\mathrm{T}$ done on the system or if there is lost energy $\mathrm{T}_{\mathrm{p}}$ due the friction force $\mathrm{F}_{\mathrm{f}}$.

Furthermore, the sum of the kinetic $(\mathrm{K})$ and potential energies $\left(\mathrm{E}_{\mathrm{p}}\right)$ is equal to the mechanical energy of the system: $E_{m e c}=K+E_{p}$, where $K$ is the kinetic energy, $E_{p}$ is the potential energy: $E_{p}=E_{g}+E_{e}$ (gravitational potential energy more elastic potential energy of a spring) $\mathrm{K}=\frac{1}{2} \mathrm{mv}^{2} \quad \mathrm{E}_{\mathrm{g}}=\mathrm{mgh} \quad \mathrm{E}_{\mathrm{e}}=\frac{1}{2} \mathrm{kx}^{2}$.

\section{Friction work and friction forces}

There are friction forces at the contact of the ball with the grass and with the air due the air resistance or winding ${ }^{6,7,8}$. The friction work or work done by the friction force $F_{f}$ can be included in the energy conservation formula ${ }^{1,2,3}: T_{p}=F_{f} d$. If the friction force is due the contact of the ball with the grass, the formula is: $F_{f}=-\mu N$ where $\mathrm{N}$ is the normal force and $\mu(\mu>0)$ is the friction coefficient which can be static $\mu_{\mathrm{s}}$ (static ball) or kinetic $\mu_{\mathrm{k}}$ (ball in motion). The minus sign is because the friction force is opposite to the displacement of the object. The work done by the friction force is always negative: $\mathrm{T}_{\mathrm{p}}=-\mu \mathrm{Nd}$. Then, the energy conservation is:

$\mathrm{T}+\mathrm{T}_{\mathrm{p}}=\Delta \mathrm{K}+\Delta \mathrm{E}_{\mathrm{g}} \quad \mathrm{T}=\mathrm{Fd} \quad \mathrm{T}_{\mathrm{p}}=-\mu \mathrm{Nd}$

Another way to state the energy conservation is as follows:

$\mathrm{E}_{\mathrm{i}}=\mathrm{E}_{\mathrm{f}}$

$\mathrm{K}_{\mathrm{i}}+\mathrm{E}_{\mathrm{gi}}+\mathrm{T}+\mathrm{T}_{\mathrm{p}}=\mathrm{K}_{\mathrm{f}}+\mathrm{E}_{\mathrm{gf}} \quad$ where $\mathrm{T}=\mathrm{F}$ d or $\mathrm{T}=\mathrm{F} \mathrm{d} \cos \theta$ and $\mathrm{T}_{\mathrm{p}}=\mathrm{F}_{\mathrm{f}} \mathrm{d}=-\mu \mathrm{Nd}$

If the system is isolated, then $\mathrm{F}=0$ and $\mathrm{T}=0$ and the principle of energy conservation is as follows: $\mathrm{T}_{\mathrm{p}}=\Delta \mathrm{K}+\Delta \mathrm{E}_{\mathrm{g}}$

\section{Dissipative and Conservative Forces}

Dissipative or non-conservative forces are those forces that perform work that depend on the path traveled. An example of this force is the friction force. In this case, the work invested by the dissipative force along a closed path is not zero. In an isolated system (external force is equal to zero) with non-conservative forces (as the friction force for example), the total energy is conserved but the mechanical energy is not conserved ${ }^{1,2,3}$. 
$\mathrm{E}_{\text {mec }} \neq$ constant $\quad \Delta \mathrm{E}_{\text {mec }} \neq 0 \quad \mathrm{E}_{\text {total }}=$ constant $\quad \Delta \mathrm{E}_{\text {total }}=0 \quad \mathrm{~T}_{\mathrm{p}}=\Delta \mathrm{E}_{\text {mec }}=\Delta \mathrm{K}+\Delta \mathrm{E}_{\mathrm{p}}$

In Football, there are dissipative forces as the friction force at the contact of the ball with the grass and in the air due the air resistance. Therefore, the mechanical energy is not conserved in Football but the total energy is conserved as in all system. There is only energy transformation as we have mentioned before: the work done by the foot with the ball is transformed in a variation of the kinetical energy and/or variation of the gravitational potential energy with the interaction with the friction force. Thus, there is lost energy due the friction with the grass or with the air: $\mathrm{T}+\mathrm{T}_{\mathrm{p}}=\Delta \mathrm{K}+\Delta \mathrm{E}_{\mathrm{g}}$

For other hand, conservative forces are those forces that perform work that is independent of the path traveled and depends only on the start and end points. Examples of these forces are the gravitational force. Furthermore, the work invested by a conservative force along any closed path is zero ${ }^{1,2,3}$. Besides, in an isolated system where the external force is zero and only with conservative forces, the mechanical energy and the total energy are conserved. Thus, the sum of the kinetic and potential energies is a constant ${ }^{1,2,3}: \mathrm{E}_{\mathrm{mec}}=\mathrm{K}+\mathrm{E}_{\mathrm{p}}=$ constant $\quad \Delta \mathrm{E}_{\mathrm{mec}}=\Delta \mathrm{K}+\Delta \mathrm{E}_{\mathrm{p}}=0$ $\Delta \mathrm{E}_{\mathrm{p}}=\Delta \mathrm{E}_{\mathrm{g}}+\Delta \mathrm{E}_{\mathrm{e}}$

$\mathrm{E}_{\text {total }}=$ constant $\quad \Delta \mathrm{E}_{\text {total }}=0 \quad \Delta \mathrm{K}+\Delta \mathrm{E}_{\mathrm{p}}=0$

\section{Power (Potency)}

Sometimes, it is mentioned in Football for example, that the Direct Free kick or Penalty was potent which depends of the foot force with which the ball was kicked ${ }^{6,7,8}$. This potency has direct effect in the velocity of the ball and of course, it is important to do a goal as for example in a Direct Free kick or Penalty ${ }^{6,7,8}$. The power is given by the quotient of the work done divided by the time during which the work was done or the force was acting ${ }^{1,2,3}$ : $\mathrm{P}=\frac{\mathrm{T}}{\mathrm{t}}=\frac{\mathrm{Fd}}{\mathrm{t}}=\mathrm{Fv}$. The power units are Watt $=\mathrm{J} / \mathrm{s}$ for the MKS system or Lbs- $\mathrm{ft} / \mathrm{s}$ for the English system ${ }^{1,2,3}$. For other hand, there is the Horse Power unit (HP) which is equivalent to 746 Watts or $550 \mathrm{lbs}-\mathrm{ft} / \mathrm{s}$.

\section{Impulse and Momentum}

The impulse done at the ball due the external force $\mathrm{F}$ of the foot in a short time $\Delta \mathrm{t}$, is transformed into a variation in the amount of ball motion or momentum during the contact of the ball. If the ball at the beginning is at rest as in a direct kick for example, then $\mathrm{v}_{\mathrm{i}}=0$ and the impulse is equal to the variation in momentum: $\mathrm{I}=\Delta \mathrm{p}=\mathrm{m} \Delta \mathrm{v}=\mathrm{m}\left(\mathrm{v}_{\mathrm{f}}-\mathrm{v}_{\mathrm{i}}\right)=\mathrm{mv}_{\mathrm{f}}=\mathrm{mv}$

where $\mathrm{v}_{\mathrm{i}}=0$ and $\mathrm{v}_{\mathrm{f}}=\mathrm{v}$ is the final velocity of the ball after the kicking of the ball or the initial velocity of the parabolic motion of the ball. The impulse is also given by the next formula: $I=\bar{F} \Delta t$ where $\bar{F}$ : average constant force and $\Delta \mathrm{t}=\mathrm{t}_{\mathrm{f}}-\mathrm{t}_{\mathrm{i}}=\mathrm{t}_{\mathrm{f}}=\mathrm{t} \quad \mathrm{t}_{\mathrm{i}}=0$ and $\mathrm{t}$ is the time duration of the contact of the foot with the ball ${ }^{6,7,8}$. Therefore, it is obtained: $\mathrm{I}=\Delta \mathrm{p} \quad \overline{\mathrm{F}} \Delta \mathrm{t}=\mathrm{m} \Delta \mathrm{v} \quad \overline{\mathrm{F}} \mathrm{t}=\mathrm{mv} \quad \mathrm{v}_{\mathrm{i}}=0 \mathrm{~m} / \mathrm{s}$

$\mathrm{v}=\frac{\overline{\mathrm{F}} \mathrm{m}}{\mathrm{m}}$

Therefore, the velocity of the ball depends of the next physics variables: the external average force $\overline{\mathrm{F}}$ of the foot, the short time $t$ during which the force of the foot kicks the ball and the mass of the ball. 
It is possible to apply technology and electronic sensors to measure the impulse and force of the foot by doing the measurement of the time duration $\Delta \mathrm{t}$ of the contact of the foot with the ball and the initial velocity of the parabolic motion. It is necessary to measure the maximum distance $x$ of the ball and the initial angle $\theta_{i}: \quad x=\frac{v_{i}^{2} \text { sen } 2 \theta_{i}}{g}$ which are possible to obtain on the spot or by video software program.

Therefore, it is possible to obtain the initial velocity of the parabolic motion which is the final velocity after the kicking to the ball. Then, it is possible to know the average force of the kicking to the ball: $\mathrm{I}=\overline{\mathrm{F}} \mathrm{t}=\mathrm{mv}$

$\overline{\mathrm{F}}=\frac{\mathrm{mv}}{\mathrm{t}}$ where $\Delta \mathrm{t}=\mathrm{t}$. Actually, it is possible to obtain the average velocities reached by the players and the velocity of the ball in Direct kick and Penalty by using the technology $6,7,8$.

The formula for impulse and momentum can be obtained from Newton's second law as follows $s^{1,2,3}: F=\frac{d p}{d t}$ second Newton law where $\mathrm{p}$ is the momentum $\mathrm{p}=\mathrm{mv}$. If the mass is constant which is possible to consider for low velocities, then: $\quad F=m \frac{d v}{d t} \quad F d t=m d v \quad$ where $d I=F d t \quad$ and $d p=m d v$

In the case of a variable force, the impulse is: $I=\int F d t$. Therefore: $\mathrm{I}=\int \mathrm{Fdt}=\int \mathrm{mdv}=\mathrm{m} \Delta \mathrm{v}=$ $\mathrm{m}\left(\mathrm{v}_{\mathrm{f}}-\mathrm{v}_{\mathrm{i}}\right)$ where $\mathrm{m}$ is considered a constant.

It is possible to consider an average constant force $\overline{\mathrm{F}}$ (constant) during the short time $\Delta \mathrm{t}$ and $\mathrm{I}=\int \mathrm{Fdt}=\overline{\mathrm{F}} \Delta \mathrm{t}$ which is equal to the variation in momentum $\mathrm{I}=\overline{\mathrm{F}} \Delta \mathrm{t}=\mathrm{m} \Delta \mathrm{v}$ where $\mathrm{I}$ is known as the impulse and $\overline{\mathrm{F}}$ is the average external force, while $p=m \Delta v$ is known as the momentum.

The equation $\mathrm{I}=\Delta \mathrm{p}$ means that the impulse carried out by a force external to the system during a short time $\Delta \mathrm{t}$ is equal to the variation in the amount of movement of the system or momentum ${ }^{1,2,3}$. This is known as the conservation of momentum principle. If there are no external forces, then $\Delta \mathrm{p}=0$, or $\mathrm{p}_{\mathrm{i}}=\mathrm{p}_{\mathrm{f}}$. For other hand, the impulse represents the area under the curve on an Force versus time graph $^{1,2,3}$.

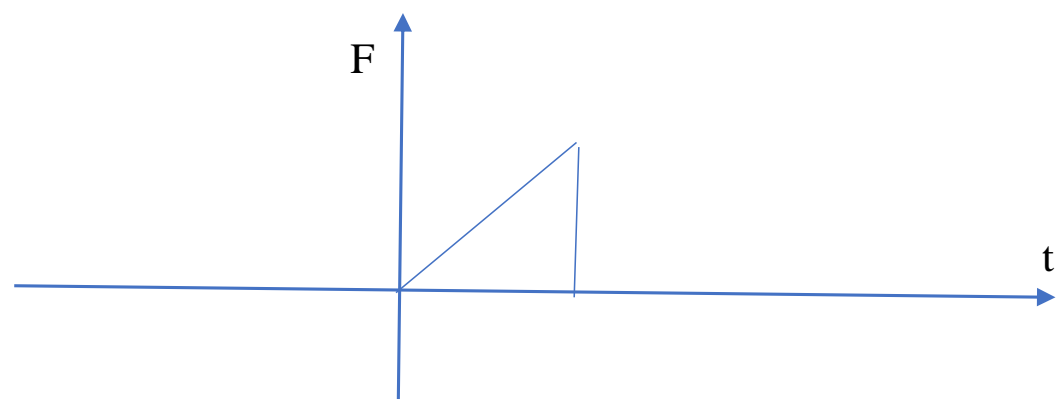

Fig.14. Variable force versus time where the impulse is the area under the curve

For example, if in the previous graph the external force is given by $\mathrm{F}=\mathrm{kt}$ where $\mathrm{k}$ is a constant, the impulse is:

$\mathrm{I}=\int \mathrm{Fdt}=\int_{0}^{\mathrm{t}} \mathrm{kt} \mathrm{dt}=\mathrm{k} \frac{\mathrm{t}^{2}}{2}$

Both impulse and momentum are vector quantities. The impulse units for the different unit systems are: N-s for MKS or Lbf-s for English system. The units of momentum are: $\mathrm{kg}-\mathrm{m} / \mathrm{s}$ for MKS or slug-feet/s for English system $^{1,2,3}$. The units of impulse and momentum coincide if it is replaced $\mathrm{N}$ by $\mathrm{kg}-\mathrm{m} / \mathrm{s}^{2}$. 


\section{Thought Experiment I (Gedanken experiment I)}

A Football ball with a mass of 450 grams is kicked. The force exerted by the foot on the ball varies from zero to a maximum value (where the ball temporarily deforms) and returns to zero when it stops making contact with the ball. The force versus time curve is described in the next figure.

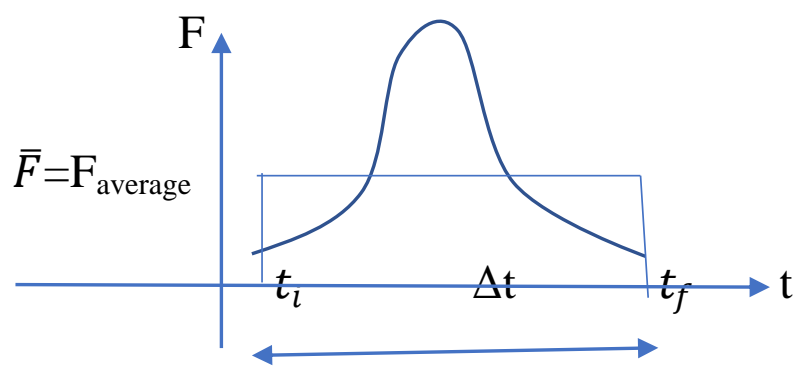

Fig.15. Force $\mathrm{F}$ versus time $\mathrm{t}$

$\mathrm{I}=\int_{\mathrm{t}_{\mathrm{i}}}^{\mathrm{t}_{\mathrm{f}}} \mathrm{Fdt}=\overline{\mathrm{F}} \Delta \mathrm{t}=\mathrm{m} \Delta \mathrm{v}$

If the ball travels a distance of $15 \mathrm{~m}$ and it is the maximum distance for any initial angle $\left(\theta_{\mathrm{i}}=45^{\circ}\right)$, the final velocity after the foot makes contact with the ball or the initial velocity of the parabolic movement is:

$\mathrm{x}=\frac{\mathrm{v}_{\mathrm{i}}{ }^{2} \operatorname{sen} 2 \theta_{\mathrm{i}}}{\mathrm{g}} \quad \mathrm{V}_{\mathrm{i}}=\sqrt{\mathrm{xg}} \quad \mathrm{x}=15 \mathrm{~m} \quad \mathrm{v}_{\mathrm{i}}=12.12 \mathrm{~m} / \mathrm{s}$

The average impulse is:

$\mathrm{I}=\Delta \mathrm{p}=\mathrm{m}\left(\mathrm{v}_{\mathrm{f}}-\mathrm{v}_{\mathrm{i}}\right)=(0.45)(12.12-0)=5.46 \mathrm{~kg}(\mathrm{~m} / \mathrm{s})$

The collision time is: $\Delta \mathrm{t}=\Delta \mathrm{x} / \mathrm{v}$ where $\Delta \mathrm{x}$ is approximately the ball radius which is approximately the distance traveled by the ball on the grass $\Delta x=11.14 \mathrm{~cm}$ (ball radius) and $\mathrm{v}$ is the average velocity $\mathrm{v}=12.12 \mathrm{~m} / \mathrm{s}$ : $\Delta \mathrm{t}=9.2 * 10^{-3} \mathrm{~s}$. The average force exerted by the foot on the ball is:

$\overline{\mathrm{F}}=\mathrm{mv} / \Delta \mathrm{t} \quad$ where $\mathrm{m}=0.450 \mathrm{~kg}, \mathrm{v}=12.12 \mathrm{~m} / \mathrm{s}$ and $\Delta \mathrm{t}=9.2 * 10^{-3} \mathrm{~s}$

$\overline{\mathrm{F}}=593.76 \mathrm{~N}$

This force is very large compared with the weight of the ball which is $\mathrm{W}=\mathrm{mg}=(0.45)(9.8)=4.41 \mathrm{~N}$.

\section{Collisions}

In Football, there are examples of collisions as the collision of the Football ball with the grass and between Football players. It is applied the principle of conservation of momentum: $\Delta p=0\left(p_{i}=p_{f}\right)$ if the external force is considered to be zero: $\mathrm{F}=0$ or the time duration of the force is very small $\Delta \mathrm{t} \approx 0$. There are internal forces ${ }^{1,2,3}$ during the collision but they don't affect the total movement of the system and thus: $\Delta p=0$.

But in some collisions, very large forces are produced that have a minimum duration, which are called impact forces and they are external forces to the system ${ }^{1,2,3}$. The equation $I=\int F d t=\Delta p$ is applied to solve problems of this type where it is considered an external force F. 
Collisions can be of three types: inelastic, perfectly elastic, and perfectly inelastic. Collisions are perfectly elastic when colliding bodies retain their kinetic energy before and after the collision. This type of collision does not occur in nature, except between subatomic particles. Besides, collisions between billiard balls are considered perfectly elastic too ${ }^{1,2,3}$. For other hand, the collision is perfectly inelastic when the objects after the collision are completely joined. The kinetic energy before and after the collision are not equals ${ }^{1,2,3}$.

For a perfectly elastic collision, it is obtained:

$\mathrm{p}_{\mathrm{i}}=\mathrm{p}_{\mathrm{f}}$

$\mathrm{K}_{\mathrm{i}}=\mathrm{K}_{\mathrm{f}} \quad($ where $\mathrm{K}$ is the kinetic energy)

For inelastic collisions, it is obtained:

$p_{i}=p_{f}$

$\mathrm{K}_{\mathrm{i}} \neq \mathrm{K}_{\mathrm{f}}$

For a perfectly inelastic collision where objects after the collision are completely joined, it is obtained:

$\mathrm{p}_{\mathrm{i}}=\mathrm{p}_{\mathrm{f}}$

$\mathrm{K}_{\mathrm{i}} \neq \mathrm{K}_{\mathrm{f}}$

However, it is always possible to apply the energy conservation in all the collision cases: $T+T_{p}=\Delta K+\Delta E_{p}$ where $\Delta \mathrm{E}_{\mathrm{p}}=\Delta \mathrm{E}_{\mathrm{g}}+\Delta \mathrm{E}_{\mathrm{e}}$. Besides, many times in collisions the restitution coefficient is mentioned, which is given by the following formula: $e=-\frac{V_{1 f}-V_{2 f}}{V_{1 i}-V_{2 i}}$

$V_{1 f}-V_{2 f}$ : is the relative velocity of the first object relative to the second object after the collision.

$\mathrm{V}_{1 \mathrm{i}}-\mathrm{V}_{2 \mathrm{i}}$ : is the relative velocity of the first object with respect to the second object before the collision.

For perfectly inelastic collisions, the coefficient of restitution is 0 , for perfectly elastic collisions, the coefficient of restitution is 1 , while for inelastic collisions the coefficient of restitution is between 0 and 1 .

Regarding Football, and in the case of a ball bouncing off the grass, the bodies that collide are the ball and the grass. The earth or the grass is not affected by the ball colliding and its velocity before and after are zero $\mathrm{v}_{2 \mathrm{i}}=0$ and $\mathrm{v}_{2 \mathrm{f}}=0$. Thus, there are only the velocities of the ball before and after, and so the coefficient of restitution is: $\mathrm{e}=-\frac{\mathrm{v}_{1 \mathrm{f}}}{\mathrm{v}_{1 \mathrm{i}}}$

$\mathrm{v}_{1 \mathrm{f}}=\sqrt{2 \mathrm{gh}_{2}} \quad \mathrm{v}_{1 \mathrm{i}}=-\sqrt{2 \mathrm{gh}_{1}}$, the negative sign is because the velocity is in the downward direction.

In this form, the coefficient of restitution is: $e=\sqrt{\frac{h_{2}}{h_{1}}}$

Thus, it is possible to obtain the coefficient of restitution by doing the respective measurement of the height $\mathrm{h}_{1}$ and $h_{2}$ where $h_{1}$ is the initial height of the ball respect to the grass and $h_{2}$ is the final height of the ball respect to the grass. 
As it was mentioned before, for perfectly inelastic collisions, the coefficient of restitution is 0 , for perfectly elastic collisions, the coefficient of restitution is 1 since the kinetic energy is conserved and $h_{1}=h_{2}$ for a ball bouncing off the ground but it is an ideal case, while for inelastic collisions which is the case of the Football ball the coefficient of restitution is between 0 and 1 because the ball does not retain their kinetic energy before and after the collision: $\mathrm{K}_{\mathrm{i}} \neq \mathrm{K}_{\mathrm{f}} \mathrm{h}_{1} \neq \mathrm{h}_{2}$. Besides, the coefficient of restitution changes if the ball is made of a different material. There are different sides. weights and materials of the ball with different coefficient of restitution for Football, Futsal or Indoor football, or Beach football ${ }^{6,7,8}$. The coefficient of restitution and the weight of Football balls have been changing in the world championships, which directly affects the rebound and effects of the ball. The rebound of the ball affects directly the velocity of the match and thus, the coefficient of restitution and weight of the Football ball are important factors to be considered.

\section{Thought Experiment II (Gedanken experiment II)}

The 450 gram Football ball is dropped from a height of $1.7 \mathrm{~m}$ above the floor. The ball bounces vertically to a height of $1.3 \mathrm{~m}$ after hitting the ground. The momentum before and after the ball hits the ground is:

$$
\Delta \mathrm{y}=\frac{1}{2} \mathrm{gt}^{2} \quad \Delta \mathrm{y}=\mathrm{h}_{1} \quad \mathrm{t}_{1}=\sqrt{\frac{2 \mathrm{~h}_{1}}{\mathrm{~g}}}
$$

$\mathrm{v}_{\mathrm{f}}^{2}=2 \mathrm{~g} h_{1} \quad \mathrm{v}_{\mathrm{i}}=0$

$\mathrm{v}_{\mathrm{f}}=-\sqrt{2 \mathrm{gh}_{1}}:$ the minus sign is because the ball is in the downward motion and vectors are negative in the downward motion. It is possible to obtain the same expression by applying energy conservation:

$\frac{1}{2} \mathrm{mv}_{\mathrm{f}}^{2}=\mathrm{mgh}_{1} \mathrm{v}_{\mathrm{f}}^{2}=2 \mathrm{gh}$

$\mathrm{v}_{\mathrm{f}}=-\sqrt{2 \mathrm{gh}_{1}} \quad \mathrm{v}_{\mathrm{f}}=-5.77 \mathrm{~m} / \mathrm{s}$

It is the initial velocity for momentum conservation: $v_{i}=-5.77 \mathrm{~m} / \mathrm{s}$. Therefore, it is obtained: $\mathrm{p}_{\mathrm{i}}=\mathrm{mv}_{\mathrm{i}} \mathrm{m}=0.450 \mathrm{~kg}$ $\mathrm{p}_{\mathrm{i}}=-2.59 \mathrm{~kg}-\mathrm{m} / \mathrm{s}$

For the upward motion, it is obtained:

$\mathrm{v}_{\mathrm{f}}^{2}=\mathrm{v}_{\mathrm{i}}^{2}-2 \mathrm{~g} \Delta \mathrm{y} \quad \mathrm{v}_{\mathrm{f}}=0 \quad \Delta \mathrm{y}=\mathrm{h}_{2}$

$\mathrm{v}_{\mathrm{i}}=\sqrt{2 \mathrm{gh}_{2}}:$ the velocity is positive because the ball is in the upward motion and vectors are positive in the upward motion.

$\mathrm{v}_{\mathrm{f}}=\mathrm{v}_{\mathrm{i}^{-}} \mathrm{gt} \quad \mathrm{v}_{\mathrm{f}}=0 \quad \mathrm{v}_{\mathrm{i}}=\sqrt{2 \mathrm{gh}_{2}}$

$\mathrm{t}_{2}=\frac{\sqrt{2 \mathrm{gh}_{2}}}{\mathrm{~g}} \quad \mathrm{t}_{2}=\sqrt{\frac{2 \mathrm{~h}_{2}}{\mathrm{~g}}}$

It is possible to obtain the same expression by applying energy conservation:

$\frac{1}{2} \mathrm{mv}_{\mathrm{i}}^{2}=\mathrm{mgh}_{2}$ 
$\mathrm{v}_{\mathrm{i}}^{2}=2 \mathrm{~g} h_{2}$

$\mathrm{v}_{\mathrm{i}}=\sqrt{2 \mathrm{gh}_{2}} \quad \mathrm{v}_{\mathrm{i}}=5.05 \mathrm{~m} / \mathrm{s}$

It is the final velocity for momentum conservation: $v_{f}=5.05 \mathrm{~m} / \mathrm{s}$. Therefore, it is obtained: $\mathrm{p}_{\mathrm{f}}=\mathrm{mv}_{\mathrm{f}} \mathrm{m}=0.450 \mathrm{~kg}$ $\mathrm{p}_{\mathrm{f}}=2.27 \mathrm{~kg}-\mathrm{m} / \mathrm{s}$

The impulse is: $\mathrm{I}=\overline{\mathrm{F}} \Delta \mathrm{t}=\mathrm{m} \Delta \mathrm{v}=\mathrm{m}\left(\mathrm{v}_{\mathrm{f}}-\mathrm{v}_{\mathrm{i}}\right)=\mathrm{p}_{\mathrm{f}}-\mathrm{p}_{\mathrm{i}}=2.27+2.59=4.86 \mathrm{~kg}-\mathrm{m} / \mathrm{s}$

The average force exerted by the ground on the ball is obtained as follows:

$\Delta \mathrm{t}=\Delta \mathrm{y} / \mathrm{v}$ where $\Delta \mathrm{y}$ is approximately the ball radius which is approximately the distance traveled by the ball on the grass $\Delta \mathrm{y}=11.14 \mathrm{~cm}$ (ball radius) and $\mathrm{v}$ is the average velocity. For $\mathrm{v}=5.77 \mathrm{~m} / \mathrm{s}: \Delta \mathrm{t}_{1}=0.0193 \mathrm{~s}$. For $\mathrm{v}=5.05 \mathrm{~m} / \mathrm{s}$, $\Delta \mathrm{t}_{2}=0.022 \mathrm{~s}$

$\Delta \mathrm{t}=\Delta \mathrm{t}_{1}+\Delta \mathrm{t}_{2}=0.0413 \mathrm{~s}$

$\overline{\mathrm{F}}=\mathrm{I} / \Delta \mathrm{t} \quad$ where $\mathrm{m}=0.450 \mathrm{~kg} \quad \mathrm{I}=4.86 \mathrm{~kg}-\mathrm{m} / \mathrm{s} \quad \Delta \mathrm{t}=0.0413 \mathrm{~s}$

$\overline{\mathrm{F}}=1117.49 \mathrm{~N}$

This force is very large compared with the weight of the ball which is $\mathrm{W}=\mathrm{mg}=(0.45)(9.8)=4.41 \mathrm{~N}$. The total flight time of the ball is:

$\mathrm{t}_{\mathrm{t}}=\mathrm{t}_{1}+\mathrm{t}_{2}+\Delta \mathrm{t}$

$\mathrm{t}_{\mathrm{t}}=\sqrt{\frac{2 \mathrm{~h}_{1}}{\mathrm{~g}}}+\sqrt{\frac{2 \mathrm{~h}_{2}}{\mathrm{~g}}}+\Delta \mathrm{t}$

$\mathrm{t}_{\mathrm{t}}=0.58+0.52+0.0413=1.14 \mathrm{~s}$

The coefficient of restitution is: $e=\sqrt{\frac{h_{2}}{h_{1}}}$

$\mathrm{e}=0.87$

\section{Free Fall and Parabolic Movement with air resistance}

Free Fall with air resistance: $F_{f}=-k v$

It is considered a friction force of the air with the ball proportional to the instantaneous velocity of the object: $F_{f} \propto$ $\mathrm{v} \quad \mathrm{F}_{\mathrm{f}}=-\mathrm{kv}$ where $\mathrm{k}$ is a positive proportional constant. The minus sign is because the friction force is opposite to the velocity or to the movement of the object.

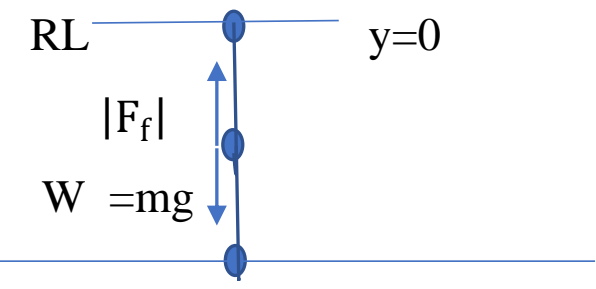

Fig.16. Free fall with air resistance 
The second Newton law is established as follows:

$\mathrm{m} \frac{\mathrm{dv}}{\mathrm{dt}}=\mathrm{mg}-\mathrm{kv}$ (downward vectors are considered positive)

$\frac{d v}{\frac{m}{k} g-v}=\frac{k}{m} d t \quad \mathrm{t}=0 \quad \mathrm{v}_{\mathrm{i}}=0$ or $\mathrm{v}(0)=0$

$-\ln \left(\frac{m}{k} g-v\right)=\frac{k}{m} t+C \quad \mathrm{C}=-\ln \left(\frac{m}{k} g\right)$

$\ln \left(\frac{m}{k} g-v\right)=-\frac{k}{m} t+\ln \left(\frac{m}{k} g\right)$

$\mathbf{v}=\frac{\mathbf{m g}}{\mathbf{k}}\left(\mathbf{1}-\mathbf{e}^{-\mathbf{k t} / \mathbf{m}}\right)$

If the resistance coefficient of the medium is very small, then the exponential function can be approximate in power series up to third order:

$\mathrm{v}=\frac{\mathrm{mg}}{\mathrm{k}}\left(1-1+\frac{\mathrm{k}}{\mathrm{m}} \mathrm{t}-\frac{\mathrm{k}^{2}}{2 \mathrm{~m}^{2}} \mathrm{t}^{2}+\frac{\mathrm{k}^{3}}{6 \mathrm{~m}^{3}} \mathrm{t}^{3}\right)$ other terms are neglected

$v=g t-\frac{k g}{2 m} t^{2}+\frac{k^{2} g}{6 m^{2}} t^{3}$

It is possible to observe at the formula that for resistance coefficient much smaller, then it is obtained the formula for the velocity for free fall without air resistance: $v_{\mathrm{f}}=\mathrm{gt}$

Besides, when $t->\infty$, the limit velocity is obtained:

$\mathrm{v}=\frac{\mathrm{mg}}{\mathrm{k}}\left(1-\mathrm{e}^{-\mathrm{kt} / \mathrm{m}}\right) \quad$ when $\mathrm{t}->\infty \quad \mathbf{v}_{\text {limit }}=\frac{\mathbf{m g}}{\mathbf{k}}$

The limit velocity does not depend of the initial conditions and only depends of the mass of the object and the resistance coefficient of the medium. It is also the limit velocity that the sky drivers experience. After, they get this limit velocity, they continue the downward movement with this constant velocity and the acceleration is equal to zero.

Therefore, when it is reached the limit velocity, the resistive force or friction force is equal to the weight and the acceleration is approximately equal to zero: $\mathrm{m} \frac{\mathrm{dv}}{\mathrm{dt}}=\mathrm{mg}-\mathrm{kv} \quad \mathrm{a}=\frac{d v}{d t}=0 \quad \mathrm{mg}-\mathrm{kv}=0 \quad \mathbf{v}_{\text {limit }}=\frac{\mathbf{m g}}{\mathbf{k}}$

$\frac{d y}{d t}=\frac{m g}{k}\left(1-\mathrm{e}^{-\mathrm{kt} / \mathrm{m}}\right) \quad \mathrm{t}=0 \quad \mathrm{y}=0$

$y=\frac{m g}{k} t+\frac{m^{2} g}{k^{2}} \mathrm{e}^{-\frac{\mathrm{kt}}{\mathrm{m}}}+C \quad C=-\frac{m^{2} g}{k^{2}}$

$\mathbf{y}=\frac{\mathrm{mg}}{\mathrm{k}} \mathbf{t}-\frac{\mathrm{m}^{2} \mathrm{~g}}{\mathrm{k}^{2}}\left(1-\mathbf{e}^{-\frac{\mathrm{kt}}{\mathrm{m}}}\right)$

If the resistance coefficient of the medium is very small, then the exponential function can be approximate in power series up to third order:

$y=\frac{m g}{k} t-\frac{m^{2} g}{k^{2}}\left(1-1+\frac{k}{m} t-\frac{k^{2}}{2 m^{2}} t^{2}+\frac{k^{3}}{6 m^{3}} t^{3}\right)$ other terms are neglected 
$y \approx \frac{1}{2} g t^{2}-\frac{k g}{6 m} t^{3}$

It is possible to observe at the formula that for resistance coefficient much smaller, then it is obtained the formula for the height $\mathrm{y}$ for free fall without air resistance: $\Delta \mathrm{y}=\mathrm{v}_{\mathrm{i}} \mathrm{t}+\frac{1}{2} \mathrm{gt}^{2} \quad \mathrm{v}_{\mathrm{i}}=0 \quad \Delta \mathrm{y}=\frac{1}{2} \mathrm{gt}^{2}$

Vertical Launch $U p$ with air resistance: $F_{f}=-k v$

If the object is launched vertically upwards, then it is obtained the next equations:
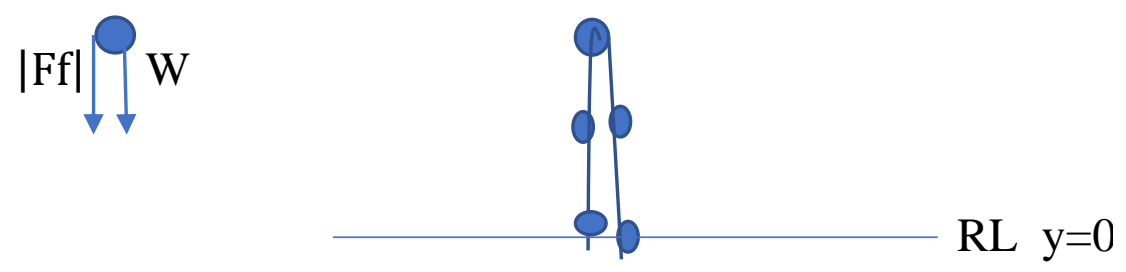

Fig.17. Vertical launch up with air resistance

$\mathrm{m} \frac{\mathrm{dv}}{\mathrm{dt}}=-\mathrm{mg}-\mathrm{kv} \quad$ (upward vectors are considered positive)

$\frac{d v}{\frac{m}{k} g+v}=-\frac{k}{m} d t \quad \mathrm{t}=0 \quad \mathrm{v}=\mathrm{v}_{\mathrm{i}}$ or $\mathrm{v}(0)=\mathrm{v}_{\mathrm{i}}$

$\ln \left(\frac{\mathrm{m}}{\mathrm{k}} \mathrm{g}+\mathrm{v}\right)=-\frac{\mathrm{k}}{\mathrm{m}} \mathrm{t}+\mathrm{C} \quad \mathrm{C}=\ln \left(\frac{\mathrm{m}}{\mathrm{k}} \mathrm{g}+v_{i}\right)$

$\ln \left(\frac{m}{k} g+v\right)=-\frac{k}{m} t+\ln \left(\frac{\mathrm{m}}{\mathrm{k}} \mathrm{g}+v_{i}\right)$

$\mathrm{v}=\left(\frac{m g}{k}+\mathrm{v}_{\mathrm{i}}\right) \mathrm{e}^{-\frac{\mathrm{kt}}{\mathrm{m}}}-\frac{\mathrm{mg}}{\mathrm{k}} \quad \mathrm{t}=0 \quad \mathrm{v}=\mathrm{v}_{\mathrm{i}}$

$\frac{d y}{d t}=\left(\frac{m g}{k}+\mathrm{v}_{\mathrm{i}}\right) \mathrm{e}^{-\frac{\mathrm{kt}}{\mathrm{m}}}-\frac{\mathrm{mg}}{\mathrm{k}} \quad \mathrm{t}=0 \quad \mathrm{y}=0$

$y=-\frac{m}{k}\left(\frac{m g}{k}+\mathrm{v}_{\mathrm{i}}\right) \mathrm{e}^{-\frac{\mathrm{kt}}{\mathrm{m}}}-\frac{\mathrm{mg}}{\mathrm{k}} t+C \quad \mathrm{C}=\frac{m}{k}\left(\frac{m g}{k}+\mathrm{v}_{\mathrm{i}}\right)$

$y=-\frac{m}{k}\left(\frac{m g}{k}+\mathrm{v}_{\mathrm{i}}\right) \mathrm{e}^{-\frac{\mathrm{kt}}{\mathrm{m}}}-\frac{\mathrm{mg}}{\mathrm{k}} t+\frac{m}{k}\left(\frac{m g}{k}+\mathrm{v}_{\mathrm{i}}\right)$

$y=\frac{m}{k}\left(\frac{m g}{k}+\mathrm{v}_{\mathrm{i}}\right)\left(1-\mathrm{e}^{-\frac{\mathrm{kt}}{\mathrm{m}}}\right)-\frac{m g}{k} t \quad \mathrm{t}=0 \quad \mathrm{y}=0$

The time for the maximum height is:

$\mathrm{v}=0 \quad \mathrm{v}=\left(\frac{m g}{k}+\mathrm{v}_{\mathrm{i}}\right) \mathrm{e}^{-\frac{\mathrm{kt}}{\mathrm{m}}}-\frac{\mathrm{mg}}{\mathrm{k}}$

$\frac{\frac{\mathrm{mg}}{\mathrm{k}}}{\left(\frac{m g}{k}+\mathrm{v}_{\mathrm{i}}\right)}=\mathrm{e}^{-\mathrm{kt} / \mathrm{m}} \quad \ln \left(\frac{m g}{m g+k v_{i}}\right)=-\frac{k t}{m}$ 
$t_{\max }=\frac{m}{k} \ln \left(\frac{m g+k v_{i}}{m g}\right) \quad$ time of the maximum height

By replacing this time at the formula of $y$, the maximum height $\mathrm{h}$ is obtained:

$\mathrm{h}=\frac{\mathrm{m}}{\mathrm{k}}\left(\frac{\mathrm{mg}}{\mathrm{k}}+\mathrm{v}_{\mathrm{i}}\right)\left(1-\frac{\mathrm{mg}}{\mathrm{mg}+\mathrm{kv} \mathrm{v}_{\mathrm{i}}}\right)-\mathrm{g} \frac{\mathrm{m}^{2}}{\mathrm{k}^{2}} \ln \left(\frac{\mathrm{mg}+\mathrm{kv} v_{\mathrm{i}}}{\mathrm{mg}}\right)$

$\mathrm{h}=\frac{\mathrm{mv}}{\mathrm{k}}-\mathrm{g} \frac{\mathrm{m}^{2}}{\mathrm{k}^{2}} \ln \left(1+\frac{k v_{i}}{m g}\right) \quad$ maximum height

If the resistance coefficient of the medium is very small, then the logarithmic function can be approximate in power series up to third order:

$\mathrm{h}=\frac{\mathrm{mv}_{\mathrm{i}}}{\mathrm{k}}-\mathrm{g} \frac{\mathrm{m}^{2}}{\mathrm{k}^{2}}\left[\frac{k v_{i}}{m g}-\frac{1}{2}\left(\frac{k v_{i}}{m g}\right)^{2}+\frac{1}{3}\left(\frac{k v_{i}}{m g}\right)^{3}\right]:$ other terms are neglected.

$\mathrm{h}=\frac{1}{2} \frac{v_{i}^{2}}{g}-\frac{1}{3} \frac{k v_{i}^{3}}{m g^{2}}$

It is possible to observe at the formula that for resistance coefficient much smaller, then it is obtained the formula for the maximum height $y$ for the vertical launch up without air resistance:

$\mathrm{v}_{\mathrm{f}}^{2}=\mathrm{v}_{\mathrm{i}}^{2}-2 \mathrm{~g} \Delta \mathrm{y} \quad \mathrm{v}_{\mathrm{f}}=0 \quad \mathrm{v}_{\mathrm{i}}^{2}=2 \mathrm{gy} \quad y=\frac{1}{2} \frac{v_{i}^{2}}{g}$

The time for the maximum height is: $t_{\max }=\frac{m}{k} \ln \left(1+\frac{k v_{i}}{m g}\right)$

If the resistance coefficient of the medium is very small, then the logarithmic function can be approximate in power series up to third order:

$t=\frac{m}{k}\left[\frac{k v_{i}}{m g}-\frac{1}{2}\left(\frac{k v_{i}}{m g}\right)^{2}+\frac{1}{3}\left(\frac{k v_{i}}{m g}\right)^{3}\right]$

$t=\frac{v_{i}}{g}-\frac{k}{2 m}\left(\frac{v_{i}}{g}\right)^{2}+\frac{1}{3}\left(\frac{k}{m}\right)^{2}\left(\frac{v_{i}}{g}\right)^{3}$

It is possible to observe at the formula that for resistance coefficient much smaller, then it is obtained the formula for the time of the maximum height for the vertical launch up without air resistance:

$\mathrm{v}_{\mathrm{f}}=\mathrm{v}_{\mathrm{i}^{-}} \mathrm{gt} \quad \mathrm{v}_{\mathrm{f}}=0 \quad \mathrm{v}_{\mathrm{i}}=\mathrm{gt} \quad \mathrm{t}=\mathrm{v}_{\mathrm{i}} / \mathrm{g}$ time of the maximum height

Free Fall with air resistance: $F_{f}=-k v^{2}$

It is considered a friction force of the air with the ball proportional to the square of the of the object velocity: $F_{f} \propto$ $v^{2} \quad F_{f}=-k v^{2}$ where $\mathrm{k}$ is a positive proportional constant. The minus sign is because the friction force is opposite to the velocity or to the movement of the object.

$\mathrm{m} \frac{\mathrm{dv}}{\mathrm{dt}}=\mathrm{mg}-\mathrm{kv}^{2} \quad$ (downward vectors are considered positive)

$\frac{d v}{\frac{m}{k} g-v^{2}}=\frac{k}{m} d t$ 
By applying partial fractions, it is obtained:

$\frac{\frac{1}{2} \sqrt{\frac{k}{m g}} d v}{\sqrt{\frac{m}{k} g}+v}+\frac{\frac{1}{2} \sqrt{\frac{k}{m g}} d v}{\sqrt{\frac{m}{k} g}-v}=\frac{k}{m} d t$

$\frac{1}{2} \sqrt{\frac{k}{m g}} \ln \left(\sqrt{\frac{m}{k} g}+v\right)-\frac{1}{2} \sqrt{\frac{k}{m g}} \ln \left(\sqrt{\frac{m}{k} g}-v\right)=\frac{k}{m} \mathrm{t}+\mathrm{C} \quad \mathrm{t}=0 \quad \mathrm{v}=0 \quad \mathrm{C}=0$

$\ln \left(\frac{\sqrt{\frac{m}{k} g}-v}{\sqrt{\frac{m}{k} g}+v}\right)=-2 \sqrt{\frac{k g}{m}} t$

$\sqrt{\frac{m}{k} g}-v=e^{-2 \sqrt{\frac{k g}{m}} t}\left(\sqrt{\frac{m}{k} g}+v\right)$

$v=\sqrt{\frac{m}{k} g} \frac{\left(1-e^{-2 \sqrt{\frac{k g}{m}}}\right)}{\left(1+e^{-2 \sqrt{\frac{k g}{m}}}\right)} \quad v=\sqrt{\frac{m}{k} g} \tanh \left(\sqrt{\frac{k g}{m}} t\right)$

Besides, when $\mathrm{t}->\infty$, the limit velocity is obtained: $v_{\text {limit }}=\sqrt{\frac{\boldsymbol{m}}{\boldsymbol{k}} \boldsymbol{g}}$

The limit velocity does not depend of the initial conditions and only depends of the mass of the object and the constant $\mathrm{k}$ which depends of the medium. After, they get this limit velocity, they continue the downward movement with this constant velocity and the acceleration is equal to zero.

Therefore, when it is reached the limit velocity, the resistive force or friction force is equal to the weight and the acceleration is approximately equal to zero: $\mathrm{m} \frac{\mathrm{dv}}{\mathrm{dt}}=\mathrm{mg}-\mathrm{k} v^{2} \quad \mathrm{a}=\frac{d v}{d t}=0 \quad \mathrm{mg}-\mathrm{k} v^{2}=0 \quad \mathrm{v}_{\text {limit }}=\sqrt{\frac{m}{k}} g$

The constant $\mathrm{k}$ is: $\mathrm{k}=\frac{1}{2} \mathrm{C} \rho \mathrm{A}$ where $\rho$ is the air density $\rho=1.29 \mathrm{~kg} / \mathrm{m}^{3}$, A is the cross-sectional area of the object and $\mathrm{C}$ is an empiric quantity known as resistance coefficient which is 0.5 for spherical objects but it can have the value of 2 for irregular objects. The terminal velocities for different objects falling in the air are shown below:

Table 1. Terminal velocities for different objects falling in the air by using the model of friction force $\mathrm{F}_{\mathrm{f}}=-\mathrm{kv}^{2}$

\begin{tabular}{|c|c|c|c|c|}
\hline Object & Mass $(\mathrm{Kg})$ & Area $(\mathrm{m} 2)$ & $\mathrm{k}$ & $\operatorname{vlimit}(\mathrm{m} / \mathrm{s})$ \\
\hline skydriver & 75 & 0,7 & 0,2275 & 56,839856 \\
\hline Baseball ball $r=3,66 \mathrm{~cm}$ & 0,145 & 0,0042 & 0,001365 & 32,264929 \\
\hline Golf ball $\quad \mathrm{r}=2,1 \mathrm{~cm}$ & 0,046 & 0,0014 & 0,000455 & 31,476487 \\
\hline $\mathrm{r}=0,5 \mathrm{~cm}$ & 0,00048 & 0,000079 & $2,5675 \mathrm{E}-05$ & 13,5356286 \\
\hline Rain drop $\mathrm{r}=0,2 \mathrm{~cm}$ & 0,000034 & 0,000013 & $4,225 \mathrm{E}-06$ & 8,88053519 \\
\hline Football ball $\mathrm{r}=11,1 \mathrm{~cm}$ & 0,45 & 0,0387 & 0,0125775 & 18,7250132 \\
\hline
\end{tabular}

$v=\sqrt{\frac{m}{k} g} \tanh \left(\sqrt{\frac{k g}{m}} t\right) \quad \frac{d y}{d t}=\sqrt{\frac{m}{k} g} \tanh \left(\sqrt{\frac{k g}{m}} t\right)$ 
$\mathrm{y}=\frac{\mathrm{m}}{\mathrm{k}} \ln \cosh \left(\sqrt{\frac{\mathrm{kg}}{\mathrm{m}}} \mathrm{t}\right)+C \quad \mathrm{t}=0 \quad \mathrm{y}=0 \quad \mathrm{C}=0$

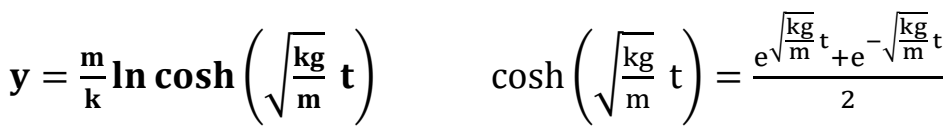

Vertical Launch Up: $F_{f}=-k v^{2}$

If the object is is launched vertically upwards, then it is obtained the next equations:

$\mathrm{m} \frac{\mathrm{dv}}{\mathrm{dt}}=-\mathrm{mg}-\mathrm{k} v^{2} \quad$ (upward vectors are considered positive)

$\frac{d v}{\frac{m}{k} g+\mathrm{v}^{2}}=-\frac{k}{m} d t \quad v=\sqrt{\frac{m g}{k}} \tan \theta \quad \mathrm{dv}=\sqrt{\frac{m g}{k}} \sec ^{2} \theta d \theta$

$\sqrt{\frac{\mathrm{k}}{\mathrm{mg}}} \arctan \left(\sqrt{\frac{\mathrm{k}}{\mathrm{mg}}} \mathrm{v}\right)=-\frac{\mathrm{k}}{\mathrm{m}} \mathrm{t}+\mathrm{C} \quad \mathrm{t}=0 \quad \mathrm{v}=\mathrm{v}_{\mathrm{i}} \quad \mathrm{C}=\sqrt{\frac{k}{m g}} \arctan \left(\sqrt{\frac{k}{m g}} v_{i}\right)$

$\sqrt{\frac{k}{m g}} \arctan \left(\sqrt{\frac{k}{m g}} v\right)=-\frac{k}{m} t+\sqrt{\frac{k}{m g}} \arctan \left(\sqrt{\frac{k}{m g}} v_{i}\right)$

$v=\sqrt{\frac{m g}{k}} \tan \left[\arctan \left(\sqrt{\frac{k}{m g}} v_{i}\right)-\sqrt{\frac{k g}{m}} t\right] \quad \mathrm{t}=0 \quad \mathrm{v}=\mathrm{v}_{\mathrm{i}}$

$v=\sqrt{\frac{m g}{k}}\left(\frac{\sqrt{\frac{k}{m g}} v_{i}-\tan \sqrt{\frac{k g}{m}} t}{1+\sqrt{\frac{k}{m g}} v_{i} \tan \sqrt{\frac{k g}{m}} t}\right)$

$\frac{d y}{d t}=\sqrt{\frac{m g}{k}} \tan \left[\arctan \left(\sqrt{\frac{k}{m g}} v_{i}\right)-\sqrt{\frac{k g}{m}} t\right]$

$\theta=\arctan \left(\sqrt{\frac{k}{m g}} v_{i}\right)-\sqrt{\frac{k g}{m}} t \quad \mathrm{~d} \theta=-\sqrt{\frac{k g}{m}} d t$

$y=-\sqrt{\frac{m g}{k}} \sqrt{\frac{m}{k g}} \ln \sec \left[\arctan \left(\sqrt{\frac{k}{m g}} v_{i}\right)-\sqrt{\frac{k g}{m}} t\right]+C \quad \mathrm{t}=0 \quad \mathrm{y}=0$

$\mathrm{C}=\sqrt{\frac{m g}{k}} \sqrt{\frac{m}{k g}} \ln \sec \left[\arctan \left(\sqrt{\frac{k}{m g}} v_{i}\right)\right]$

$y=\frac{m}{k} \ln \frac{\sec \left[\arctan \left(\sqrt{\frac{k}{m g}} v_{i}\right)\right]}{\sec \left[\arctan \left(\sqrt{\frac{k}{m g}} v_{i}\right)-\sqrt{\frac{k g}{m}} t\right]}$

$y=\frac{m}{k} \ln \frac{\cos \left[\arctan \left(\sqrt{\frac{k}{m g}} v_{i}\right)-\sqrt{\frac{k g}{m}} t\right]}{\cos \left[\arctan \left(\sqrt{\frac{k}{m g}} v_{i}\right)\right]}$

The time for the maximum height is: 
$\mathrm{v}=0 \quad v=\sqrt{\frac{m g}{k}} \tan \left[\arctan \left(\sqrt{\frac{k}{m g}} v_{i}\right)-\sqrt{\frac{k g}{m}} t\right]$

$\arctan \left(\sqrt{\frac{k}{m g}} v_{i}\right)-\sqrt{\frac{k g}{m}} t=0$

$\mathbf{t}_{\max }=\sqrt{\frac{m}{k g}} \arctan \left(\sqrt{\frac{k}{m g}} v_{i}\right)$

The maximum height $\mathrm{h}$ is: $\mathrm{h}=\frac{\mathrm{m}}{\mathrm{k}} \ln \left(\frac{1}{\cos \left[\arctan \left(\sqrt{\left.\frac{\mathrm{k}}{\mathrm{mg}} \mathrm{v}_{\mathrm{i}}\right)}\right)\right.}\right.$

\section{Thought Experiment III (Gedanken experiment III)}

\section{Analysis of Free fall without air resistance}

A Football ball is dropped by the referee $\left(\mathrm{v}_{\mathrm{i}}=0 \mathrm{~m} / \mathrm{s}\right)$ from a height $\mathrm{h}_{1}=1.7 \mathrm{~m}$ above the floor. In the first bounce the ball reaches a height $h_{2}=1.3 \mathrm{~m}$, where it is hit with the head or with the foot by a Football player. The velocity of the ball just as it makes contact with the floor at the downward motion is: $v_{\mathrm{f}}^{2}=2 \mathrm{gh}_{1}$

$\mathrm{v}_{\mathrm{f}}=-\sqrt{2 \mathrm{gh}_{1}}$. The minus sign is because the ball is in the downward motion and vectors are negative in the downward motion.

$\mathrm{v}_{\mathrm{f}}=-5.77 \mathrm{~m} / \mathrm{s}$

The velocity of the ball just as it bounces off the floor at the upward motion is: $\quad v_{f}^{2}=v_{i}^{2}-2 g \Delta y \quad v_{f}=0 \quad \Delta y=h_{2}$ $\mathrm{v}_{\mathrm{i}}=\sqrt{2 \mathrm{gh}_{2}}$. The velocity is positive because the ball is in the upward motion and vectors are positive in the upward motion.

$\mathrm{v}_{\mathrm{i}}=5.05 \mathrm{~m} / \mathrm{s}$

Neglecting the time the ball makes contact with the ground, the total time spent from the point where the ball was dropped to the point where it was hit with the head is: $t_{t}=t_{1}+t_{2}$ where $t_{1}$ is the fall time and $t_{2}$ is the rise time.

Then, for the downward motion, the fall time is:

$\Delta \mathrm{y}=\frac{1}{2} \mathrm{gt}^{2} \quad \Delta \mathrm{y}=\mathrm{h}_{1}$

$\mathrm{t}_{1}=\sqrt{\frac{2 \mathrm{~h}_{1}}{\mathrm{~g}}} \quad \mathrm{t}_{1}=0.58 \mathrm{~s}$

For the upward motion, the rise time is:

$v_{f}=v_{i^{-}}$gt $\quad v_{f}=0 \quad v_{i}=\sqrt{2 g h_{2}}$

$\mathrm{t}_{2}=\frac{\sqrt{2 \mathrm{gh}_{2}}}{\mathrm{~g}}=\sqrt{\frac{2 \mathrm{~h}_{2}}{\mathrm{~g}}}$

$\mathrm{t}_{2}=0.52 \mathrm{~s}$ 
$\mathrm{t}_{\mathrm{t}}=0.58+0.52=1.10 \mathrm{~s}$

Analysis of Free fall with the Friction force of the air: $F_{f}=-k v$

\section{Downward movement}

If the air resistance is considered, it is obtained:

$\mathbf{v}=\frac{\mathbf{m g}}{\mathbf{k}}\left(\mathbf{1}-\mathbf{e}^{-\mathbf{k t} / \mathbf{m}}\right) \mathrm{k}=0.0126 \mathrm{~m}=0.450 \mathrm{~kg} \mathrm{r}=11.1 \mathrm{~cm}$

$\mathrm{k}$ is very small and it it possible to approximate the exponential function:

$\mathrm{v} \approx \mathrm{gt}-\frac{\mathrm{kg}}{2 \mathrm{~m}} \mathrm{t}^{2}+\frac{\mathrm{k}^{2} \mathrm{~g}}{6 \mathrm{~m}^{2}} \mathrm{t}^{3}$

$y=\frac{m g}{k} t-\frac{m^{2} g}{k^{2}}\left(1-\mathrm{e}^{-\frac{\mathrm{kt}}{\mathrm{m}}}\right)$

$\mathrm{k}$ is very small and it it possible to approximate the exponential function:

$\mathbf{y} \approx \frac{1}{2} \mathbf{g t}^{2}-\frac{\mathbf{k g}}{6 \mathbf{m}} \mathbf{t}^{3} \quad \mathrm{y}=4.9 \mathrm{t}^{2}-0.046 \mathrm{t}^{3}$

$\mathrm{y}=\mathrm{h}_{1}=1.7 \mathrm{~m} \quad \mathrm{t}_{1}=0.59 \mathrm{~s} \quad \mathrm{v}=-5.73 \mathrm{~m} / \mathrm{s}$

Therefore, it requires $0.01 \mathrm{~s}$ more with air resistance to get the height $\mathrm{h}_{1}$ and the impact velocity is little less $5.73<5.77$ due the air resistance.

\section{Upward movement}

If the air resistance is considered, it is obtained:

$\mathbf{v}=\left(\frac{\boldsymbol{m g}}{\boldsymbol{k}}+\mathbf{v}_{\mathbf{i}}\right) \mathbf{e}^{-\frac{\mathbf{k t}}{\mathbf{m}}}-\frac{\mathbf{m g}}{\mathbf{k}} \quad \mathrm{k}=0.0126 \mathrm{~m}=0.450 \mathrm{~kg} \mathrm{r}=11.1 \mathrm{~cm}$

$y=\frac{m}{k}\left(\frac{m g}{k}+\mathrm{v}_{\mathrm{i}}\right)\left(1-\mathrm{e}^{-\frac{\mathrm{kt}}{\mathrm{m}}}\right)-\frac{m g}{k} t$

The time for the maximum height is:

$t_{\max }=\frac{m}{k} \ln \left(\frac{m g+k v_{i}}{m g}\right) \quad$ time of the maximum height $v=0$

$\mathrm{k}$ is very small and it it possible to approximate the logarithmic function:

$t=\frac{v_{i}}{g}-\frac{k}{2 m}\left(\frac{v_{i}}{g}\right)^{2}+\frac{1}{3}\left(\frac{k}{m}\right)^{2}\left(\frac{v_{i}}{g}\right)^{3}$

The maximum height is:

$\mathrm{h}=\frac{\mathrm{mv}}{\mathrm{k}}-\mathrm{g} \frac{\mathrm{m}^{2}}{\mathrm{k}^{2}} \ln \left(1+\frac{k v_{i}}{m g}\right) \quad$ maximum height

$\mathrm{k}$ is very small and it possible to approximate the logarithmic function:

$\mathbf{h}=\frac{1}{2} \frac{\mathbf{v}_{\mathbf{i}}^{2}}{\mathrm{~g}}-\frac{1}{3} \frac{\mathrm{kv}_{\mathrm{i}}{ }^{3}}{\mathbf{m g}^{2}} \quad \mathrm{~h}=0.051 \mathrm{v}_{\mathrm{i}}^{2}-0.0000972 \mathrm{v}_{\mathrm{i}}^{3}$ 
$\mathrm{y}=\mathrm{h}_{2}=1.3 \mathrm{~m} \quad \mathrm{v}_{\mathrm{i}}=5.07 \mathrm{~m} / \mathrm{s}$

Therefore, it requires a little more velocity 5.07>5.05 to get the height $h_{2}$ due the air resistance.

If the initial velocity is $\mathrm{v}_{\mathrm{i}}=5.05 \mathrm{~m} / \mathrm{s}$, it is obtained a maximum height of $\mathrm{h}=1.29 \mathrm{~m}$. Thus, the air resistance almost does not affect for small heights.

$\mathbf{t}=\frac{\mathbf{v}_{\mathbf{i}}}{\mathbf{g}}-\frac{\mathbf{k}}{2 \mathrm{~m}}\left(\frac{\mathbf{v}_{\mathbf{i}}}{\mathrm{g}}\right)^{2}+\frac{\mathbf{1}}{3}\left(\frac{\mathbf{k}}{\mathbf{m}}\right)^{2}\left(\frac{\mathbf{v}_{\mathbf{i}}}{\mathbf{g}}\right)^{3} \quad \mathrm{v}_{\mathrm{i}}=5.07 \mathrm{~m} / \mathrm{s}$

$\mathrm{t}_{2}=0.52-0.0000390+0.0000361 \quad \mathrm{t}_{2} \approx 0.52 \mathrm{~s}$

Neglecting the time the ball makes contact with the ground, the total time spent from the point where the ball was dropped to the point where it was hit with the head is: $t_{t}=t_{1}+t_{2}$ where $t_{1}$ is the fall time and $t_{2}$ is the rise time.

$\mathrm{t}_{\mathrm{t}}=0.59+0.52=1.11 \mathrm{~s}$

It is possible to conclude that the air resistance almost does not affect to obtain the results by using this model of friction force $\mathrm{F}_{\mathrm{f}}=-\mathrm{kv}$ and it can be neglected for small heights.

Analysis of Free fall with the Friction force of the air: $F_{f}=-k v^{2}$

\section{Downward movement}

If the air resistance is considered, it is obtained:

$v=\sqrt{\frac{m}{k} g} \frac{\left(1-e^{-2 \sqrt{\frac{k g}{m}} t}\right)}{\left(1+e^{-2 \sqrt{\frac{k g}{m}} t}\right)} \quad v=\sqrt{\frac{m}{k} g} \tanh \left(\sqrt{\frac{k g}{m}} t\right)$

$\boldsymbol{y}=\frac{\boldsymbol{m}}{\boldsymbol{k}} \ln \cosh \left(\sqrt{\frac{\mathrm{kg}}{\boldsymbol{m}}} \boldsymbol{t}\right) \quad \mathrm{k}=0.0126 \mathrm{~m}=0.450 \mathrm{~kg} \mathrm{r}=11.1 \mathrm{~cm}$

$\mathrm{y}=\mathrm{h}_{1}=1.7 \mathrm{~m} \quad \mathrm{t}=0.6 \mathrm{~s}$

Therefore, it requires $0.02 \mathrm{~s}$ more with air resistance to get the height $h_{1}$.

The impact velocity is $5.65 \mathrm{~m} / \mathrm{s}$ which is little less $5.65<5.77$ due the air resistance.

\section{Upward movement}

If the air resistance is considered, it is obtained:

$v=\sqrt{\frac{m g}{k}} \tan \left[\arctan \left(\sqrt{\frac{k}{m g}} v_{i}\right)-\sqrt{\frac{k g}{m}} t\right]$

$v=\sqrt{\frac{m g}{k}}\left(\frac{\sqrt{\frac{k}{m g}} v_{i}-\tan \sqrt{\frac{k g}{m}} t}{1+\sqrt{\frac{k}{m g}} v_{i} \tan \sqrt{\frac{k g}{m}} t}\right)$

$y=\frac{m}{k} \ln \frac{\cos \left[\arctan \left(\sqrt{\frac{k}{m g}} v_{i}\right)-\sqrt{\frac{k g}{m}} t\right]}{\cos \left[\arctan \left(\sqrt{\frac{k}{m g}} v_{i}\right)\right]} \quad \mathrm{k}=0.0126 \mathrm{~m}=0.450 \mathrm{~kg} \mathrm{r}=11.1 \mathrm{~cm}$ 
The time for the maximum height is:

$\mathrm{t}_{\max }=\sqrt{\frac{m}{k g}} \arctan \left(\sqrt{\frac{k}{m g}} v_{i}\right) \quad \mathrm{v}=0$

The maximum height $h$ is:

$\mathrm{h}=\frac{\mathrm{m}}{\mathrm{k}} \ln \left(\frac{1}{\cos \left[\arctan \left(\sqrt{\frac{\mathrm{k}}{\mathrm{mg}}} \mathrm{v}_{\mathrm{i}}\right)\right]}\right.$

$\mathrm{y}=\mathrm{h}_{2}=1.3 \mathrm{~m} \quad \mathrm{v}_{\mathrm{i}}=5.19 \mathrm{~m} / \mathrm{s}$

Therefore, it requires a little more velocity 5.19>5.05 to get the height $\mathrm{h}_{2}$.

If the velocity is $\mathrm{v}_{\mathrm{i}}=5.05 \mathrm{~m} / \mathrm{s}$, it is obtained a maximum height of $\mathrm{h}=1.24 \mathrm{~m}$.

$\mathbf{t}_{\max }=\sqrt{\frac{\boldsymbol{m}}{\boldsymbol{k g}}} \arctan \left(\sqrt{\frac{\boldsymbol{k}}{\boldsymbol{m g}}} \boldsymbol{v}_{\boldsymbol{i}}\right) \quad \mathrm{v}_{\mathrm{i}}=5.19 \mathrm{~m} / \mathrm{s}$

$\mathrm{t} \approx 0.516 \mathrm{~s}$

Neglecting the time the ball makes contact with the ground, the total time spent from the point where the ball was dropped to the point where it was hit with the head is: $t_{t}=t_{1}+t_{2}$ where $t_{1}$ is the fall time and $t_{2}$ is the rise time.

$\mathrm{t}_{\mathrm{t}}=0.6+0.516=1.116 \mathrm{~s}$

It is possible to conclude that the air resistance almost does not affect very much to obtain the results and it can be neglected for small heights. If the height is higher, the effects of air resistance begin to appear and thus, it cannot be neglected. Nevertheless, the difference of the results of the free fall without air resistance are higher with the model of friction force $\mathrm{F}_{\mathrm{f}}=-\mathrm{kv}^{2}$ than with the model of $\mathrm{F}_{\mathrm{f}}=-\mathrm{kv}$. For example, the impact velocity for the downward movement after traveling the height $h_{1}=1.7 \mathrm{~m}$ is $5.65 \mathrm{~m} / \mathrm{s}<5.77 \mathrm{~m} / \mathrm{s}$ and for the upward movement, the initial velocity necessary to get the height of $h_{2}=1.3 \mathrm{~m}$ is $5.19 \mathrm{~m} / \mathrm{s}>5.05 \mathrm{~m} / \mathrm{s}$ due the air resistance.

Parabolic movement with air resistance: $F_{f}=-k v$

It is considered a friction force of the air with the ball proportional to the instantaneous velocity of the object: $F_{f} \propto$ $\mathrm{v} \mathrm{F}_{\mathrm{f}}=-\mathrm{kv}$ where $\mathrm{k}$ is a positive proportional constant. The minus sign is because the friction force is opposite to the velocity or to the movement of the object.

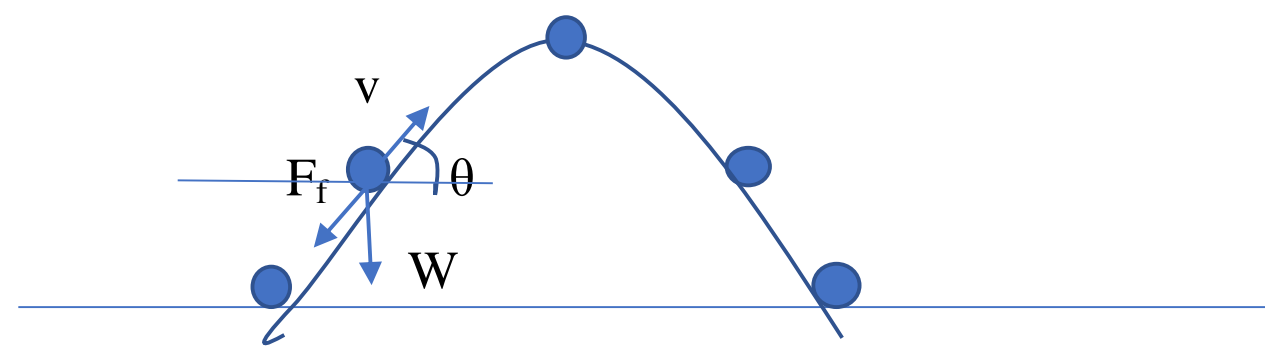

Fig.18. Parabolic movement with air resistance

$\mathrm{m} \frac{\mathrm{dv} \mathrm{x}_{\mathrm{x}}}{\mathrm{dt}}=-\mathrm{kv} \cos \theta \quad \cos \theta=\mathrm{v}_{\mathrm{x}} / \mathrm{v}$ where $\mathrm{F}_{\mathrm{f}}=-\mathrm{kv}$ 
For the horizontal part, it is obtained:

$\mathrm{m} \frac{\mathrm{dv} \mathrm{x}_{\mathrm{x}}}{\mathrm{dt}}=-\mathrm{kv}_{\mathrm{x}} \quad \frac{d v_{x}}{v_{x}}=-\frac{k}{m} d t \quad \mathrm{t}=0 \quad \mathrm{v}=\mathrm{v}_{\mathrm{ix}}$

$\ln \mathrm{v}_{\mathrm{x}}=-\frac{k}{m} t+C \quad \mathrm{C}=\ln \mathrm{v}_{\mathrm{ix}}$

$\mathbf{v}_{\mathrm{x}}=\mathbf{v}_{\mathrm{ix}} \mathbf{e}^{-\mathrm{kt} / \mathrm{m}}$

If the resistance coefficient of the medium is very small, then the exponential function can be approximate in power series up to third order:

$\mathrm{v}_{\mathrm{x}}=\mathrm{v}_{\mathrm{ix}}\left(1-\frac{k}{m} t+\frac{k^{2}}{2 m^{2}} t^{2}-\frac{k^{3}}{6 m^{3}} t^{3}\right)$ other terms are neglected

It is possible to observe at the formula that for resistance coefficient much smaller, then it is obtained the formula of the horizontal velocity for the parabolic movement without air resistance: $\mathrm{v}_{\mathrm{x}}=\mathrm{v}_{\mathrm{ix}}$ (constant velocity).

$\frac{d x}{d t}=v_{i x} e^{-\frac{k t}{m}}$

$\mathrm{x}=-\frac{\mathrm{mv} \mathrm{v}_{\mathrm{ix}}}{\mathrm{k}} \mathrm{e}^{-\frac{\mathrm{kt}}{\mathrm{m}}}+\mathrm{C} \quad \mathrm{t}=0 \quad \mathrm{x}=0 \quad \mathrm{C}=\frac{m v_{i x}}{k}$

$\mathbf{X}=\frac{\mathbf{m v} \text { ix }}{\mathbf{k}}\left(1-\mathbf{e}^{-\frac{\mathrm{kt}}{\mathrm{m}}}\right)$

If the resistance coefficient of the medium is very small, then the exponential function can be approximate in power series up to third order:

$x=\frac{m v_{i x}}{k}\left(1-1+\frac{k}{m} t-\frac{k^{2}}{2 m^{2}} t^{2}+\frac{k^{3}}{6 m^{3}} t^{3}\right) \quad$ other terms are neglected

$x=v_{i x} t-\frac{k}{2 m} v_{i x} t^{2}+\frac{k^{2}}{6 m^{2}} v_{i x} t^{3}$

It is possible to observe at the formula that for resistance coefficient much smaller, then it is obtained the formula of the horizontal distance for the parabolic movement without air resistance: $x=v_{i x} t$

For the vertical part, it is obtained:

$\mathrm{m} \frac{\mathrm{d} v_{y}}{\mathrm{dt}}=-\mathrm{mg}-\mathrm{kvsen} \theta \quad \operatorname{sen} \theta=\mathrm{v}_{\mathrm{y}} / \mathrm{v}$ where $\mathrm{F}_{\mathrm{f}}=-\mathrm{kv}$

$\mathrm{m} \frac{\mathrm{dv}_{\mathrm{y}}}{\mathrm{dt}}=-\mathrm{mg}-\mathrm{kv}_{\mathrm{y}} \quad$ (upward vectors are considered positive)

It is the same differential equation of the vertical launch up. The solutions for the velocity $\mathrm{v}_{\mathrm{y}}$ and the vertical position or height y are:

$v_{y}=\left(\frac{m g}{k}+v_{i y}\right) \mathrm{e}^{-\frac{k t}{m}}-\frac{m g}{k} \quad \mathrm{t}=0 \quad \mathrm{v}_{\mathrm{y}}=\mathrm{v}_{\mathrm{iy}}$

$y=\frac{m}{k}\left(\frac{m g}{k}+\mathrm{v}_{\mathrm{iy}}\right)\left(1-\mathrm{e}^{-\frac{\mathrm{kt}}{\mathrm{m}}}\right)-\frac{m g}{k} t \quad \mathrm{t}=0 \quad \mathrm{y}=0$ 
The time for the maximum height is:

$t_{\text {max }}=\frac{m}{k} \ln \left(\frac{m g+k v_{i y}}{m g}\right) \quad$ time of the maximum height

If the resistance coefficient of the medium is very small, then the logarithmic function can be approximate in power series up to third order:

$t=\frac{v_{i y}}{g}-\frac{k}{2 m}\left(\frac{v_{i y}}{g}\right)^{2}+\frac{1}{3}\left(\frac{k}{m}\right)^{2}\left(\frac{v_{i y}}{g}\right)^{3}$

The maximum height $\mathrm{h}$ is:

$\mathrm{h}=\frac{\mathrm{mv}}{\mathrm{i}} \mathrm{k}-\mathrm{g} \frac{\mathrm{m}^{2}}{\mathrm{k}^{2}} \ln \left(1+\frac{k v_{i y}}{m g}\right) \quad$ maximum height

If the resistance coefficient of the medium is very small, then the logarithmic function can be approximate in power series up to third order:

$\mathrm{h}=\frac{1}{2} \frac{v_{i y^{2}}}{g}-\frac{1}{3} \frac{k v_{i y}{ }^{3}}{m g^{2}}$

Parabolic movement with air resistance: $F_{f x}=-k v^{2} F_{f y}=-k v^{2}$

At this model, it is considered friction forces independent for the horizontal and vertical part proportional to the square of the velocity. Thus, it is obtained: $F_{f x}=-k v_{x}{ }^{2}$ and $F_{f y}=-k v_{y}{ }^{2}$

$\mathrm{m} \frac{\mathrm{dv} \mathrm{v}_{\mathrm{x}}}{\mathrm{dt}}=-\mathrm{k} v_{x}^{2} \quad \mathrm{t}=0 \quad \mathrm{v}=\mathrm{v}_{\mathrm{ix}}$

$\frac{d v_{x}}{v_{x}{ }^{2}}=-\frac{k}{m} d t \quad-\frac{1}{v_{x}}=-\frac{k}{m} \mathrm{t}+\mathrm{C} \quad \mathrm{C}=-\frac{1}{v_{i x}}$

$\frac{1}{v_{x}}=\frac{k}{m} t+\frac{1}{v_{i x}}$

$\mathbf{v}_{\mathbf{x}}=\frac{\mathbf{m v}_{\text {ix }}}{\mathbf{k v}_{\text {ix }} \mathbf{t}+\mathbf{m}} \quad \mathrm{t}=0 \quad \mathrm{v}=\mathrm{v}_{\mathrm{ix}}$

If the resistance coefficient of the medium is very small, then the formula can be approximate and the term $\mathrm{kv}_{\mathrm{ix}} \mathrm{t}$ is neglected. It is possible to observe at the formula that for resistance coefficient much smaller, then it is obtained the formula of the horizontal velocity for the parabolic movement without air resistance: $v_{x}=v_{i x}$ (constant velocity).

$\frac{d x}{d t}=\frac{\mathrm{mv}_{\text {ix }}}{\mathrm{kv}_{\text {ix }} \mathrm{t}+\mathrm{m}} \quad \mathrm{u}=\mathrm{kv}_{\mathrm{ix}} \mathrm{t}+\mathrm{m} \quad \mathrm{du}=\mathrm{kv}_{\mathrm{ix}} \mathrm{dt} \quad \mathrm{dt}=\mathrm{du} / \mathrm{kv}_{\mathrm{ix}}$

$x=\frac{m}{k} \ln \left(\mathrm{kv}_{\mathrm{ix}} \mathrm{t}+\mathrm{m}\right)+C \quad \mathrm{t}=0 \quad \mathrm{x}=0 \quad \mathrm{C}=-\frac{m}{k} \ln (m)$

$x=\frac{m}{k} \ln \left(1+\frac{k v_{i x} t}{m}\right)$

If the resistance coefficient of the medium is very small, then the logarithmic function can be approximate in power series up to third order: 
$x=\frac{m}{k}\left(\frac{\mathrm{kv}_{\mathrm{ix}} \mathrm{t}}{\mathrm{m}}-\frac{1}{2}\left(\frac{\mathrm{kv}_{\mathrm{ix}} \mathrm{t}}{\mathrm{m}}\right)^{2}+\frac{1}{3}\left(\frac{\mathrm{kv}_{\mathrm{ix}} \mathrm{t}}{\mathrm{m}}\right)^{3}\right)$ other terms are neglected.

$x=\mathrm{v}_{\mathrm{ix}} \mathrm{t}-\frac{1}{2} \frac{k v_{i x}{ }^{2}}{m} t^{2}+\frac{1}{3} \frac{k^{2} v_{i x^{3}}}{m^{2}} t^{3}$

It is possible to observe at the formula that for resistance coefficient much smaller, then it is obtained the formula for the horizontal distance $\mathrm{x}$ for the parabolic movement without air resistance: $\mathrm{x}=\mathrm{v}_{\mathrm{ix}} \mathrm{t}$

For the vertical part, it is obtained:

$\mathrm{m} \frac{\mathrm{d} v_{y}}{\mathrm{dt}}=-\mathrm{mg}-\mathrm{k} v_{y}{ }^{2} \quad$ (upward vectors are considered positive)

It is the same differential equation of the vertical launch up. The solutions for the velocity $\mathrm{v}_{\mathrm{y}}$ and the vertical position or height y are:

$v_{y}=\sqrt{\frac{m g}{k}} \tan \left[\arctan \left(\sqrt{\frac{k}{m g}} v_{i y}\right)-\sqrt{\frac{k g}{m}} t\right] \quad \mathrm{t}=0 \quad v_{y}=\mathrm{v}_{\mathrm{iy}}$

$v_{y}=\sqrt{\frac{m g}{k}}\left(\frac{\sqrt{\frac{k}{m g}} v_{i y}-\tan \sqrt{\frac{k g}{m}} t}{1+\sqrt{\frac{k}{m g}} v_{i y} \tan \sqrt{\frac{k g}{m}} t}\right)$

$y=\frac{m}{k} \ln \frac{\cos \left[\arctan \left(\sqrt{\frac{k}{m g}} v_{i y}\right)-\sqrt{\frac{k g}{m}} t\right]}{\cos \left[\arctan \left(\sqrt{\frac{k}{m g}} v_{i y}\right)\right]}$

The time for the maximum height is:

$\mathbf{t}_{\max }=\sqrt{\frac{m}{k g}} \arctan \left(\sqrt{\frac{k}{m g}} v_{i y}\right)$

The maximum height $\mathrm{h}$ is:

$\mathrm{h}=\frac{\mathrm{m}}{\mathrm{k}} \ln \left(\frac{1}{\cos \left[\arctan \left(\sqrt{\frac{\mathrm{k}}{\mathrm{mg}}} \mathrm{v}_{\mathrm{iy}}\right)\right]}\right)$

Parabolic movement with air resistance: $F_{f}=-k v^{2}$

It is considered a friction force of the air with the ball proportional to the square of the of the object velocity: $\mathrm{F}_{\mathrm{f}} \propto$ $\mathrm{v}^{2} \quad \mathrm{~F}_{\mathrm{f}}=-\mathrm{kv}^{2}$ where $\mathrm{k}$ is a positive proportional constant. The minus sign is because the friction force is opposite to the velocity or to the movement of the object.

For the horizontal part, it is obtained:

$\mathrm{m} \frac{\mathrm{d} v_{\mathrm{x}}}{\mathrm{dt}}=-k v^{2} \cos \theta \quad \mathrm{m} \frac{\mathrm{d} v_{\mathrm{x}}}{\mathrm{dt}}=-\mathrm{k} v v_{x} \quad \cos \theta=\mathrm{v}_{\mathrm{x}} / \mathrm{v} \quad \mathrm{F}_{\mathrm{f}}=-k v^{2}$

$\mathrm{m} \frac{\mathrm{d} v_{y}}{\mathrm{dt}}=-\mathrm{mg}-\mathrm{k} v^{2} \operatorname{sen} \theta \quad \mathrm{m} \frac{\mathrm{d} v_{y}}{\mathrm{dt}}=-\mathrm{mg}-\mathrm{k} v v_{y} \quad \operatorname{sen} \theta=\mathrm{v}_{\mathrm{y}} / \mathrm{v} \quad \mathrm{F}_{\mathrm{f}}=-\mathrm{kv} v^{2}$

These differential equations can be solved by numerical methods. Nevertheless, it is possible to change the 
coordinates $\mathrm{x}, \mathrm{y}(\mathrm{axis} \mathrm{x}, \mathrm{y})$ by $\mathrm{r}, \theta$ (axis radial and tangential):

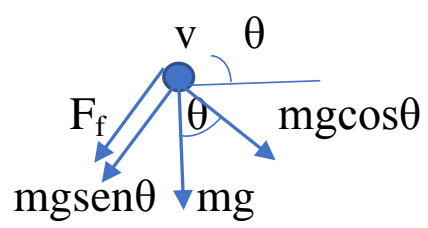

Fig.19. Radial and tangential components for the

parabolic movement

$\mathrm{m} \frac{\mathrm{dv}}{\mathrm{dt}}=-\mathrm{kv}^{2}-\operatorname{mgsen} \theta \quad \mathrm{t}=0 \quad \mathrm{v}=\mathrm{v}_{\mathrm{i}} \quad \theta=\theta_{\mathrm{i}}$

$\mathrm{m} \frac{v^{2}}{\mathrm{r}}=\operatorname{mg} \cos \theta \quad \frac{\mathrm{v}}{\mathrm{r}}=\frac{\mathrm{g} \cos \theta}{v}$

$\frac{\mathrm{dv}}{\mathrm{dt}}=\frac{\mathrm{dv}}{\mathrm{ds}} \frac{\mathrm{ds}}{\mathrm{dt}}=v \frac{\mathrm{dv}}{\mathrm{ds}}=\frac{v}{r} \frac{\mathrm{dv}}{\mathrm{d} \theta} \quad \mathrm{s}=\mathrm{r} \theta$

$\frac{\mathrm{dv}}{\mathrm{dt}}=-\frac{v}{r} \frac{\mathrm{dv}}{\mathrm{d} \theta}$ (the minus sign is due the negative curvature of the parabolic movement and the rate $\mathrm{dv} / \mathrm{dt}$ has opposite sign to the rate $d v / d \theta)$

$\frac{v}{r} \frac{\mathrm{dv}}{\mathrm{d} \theta}=\frac{k}{m} \mathrm{v}^{2}+\operatorname{gsen} \theta \quad \frac{\mathrm{v}}{\mathrm{r}}=\frac{\mathrm{g} \cos \theta}{v}$

$\frac{\mathrm{g} \cos \theta}{v} \frac{\mathrm{dv}}{\mathrm{d} \theta}=\frac{k}{m} \mathrm{v}^{2}+\mathrm{g} \operatorname{sen} \theta \quad \frac{1}{v^{3}} \frac{d v}{d \theta}=\frac{k}{m g \cos \theta}+\frac{\tan \theta}{v^{2}}$

$\frac{d u}{d \theta}+(2 \tan \theta) u=-\frac{2 k}{m g \cos \theta} \quad u=\frac{1}{v^{2}} \quad \frac{d u}{d \theta}=-\frac{2}{v^{3}} \frac{d v}{d \theta}$

The integrating factor is: $\mathrm{w}=\mathrm{e}^{\int 2 \tan \theta \mathrm{d} \theta}=\mathrm{e}^{2 \ln |\sec \theta|}=\sec ^{2} \theta$

$\sec ^{2} \theta \frac{d u}{d \theta}+2\left(\sec ^{2} \theta\right)(\tan \theta) \mathrm{u}=-\frac{2 k \sec ^{3} \theta}{m g}$

$\frac{\mathrm{d}\left(\operatorname{usec}^{2} \theta\right)}{\mathrm{d} \theta}=-\frac{2 \mathrm{ksec}^{3} \theta}{\mathrm{mg}}$

$\frac{\sec ^{2} \theta}{\mathrm{v}^{2}}=-\frac{2 \mathrm{k}}{\mathrm{mg}}\left[\frac{1}{2} \sec \theta \tan \theta+\frac{1}{2} \ln (\sec \theta+\tan \theta)\right]+\mathrm{C}$

$\mathrm{C}=\frac{\sec ^{2} \theta_{\mathrm{i}}}{\mathrm{v}_{\mathrm{i}}{ }^{2}}+\frac{\mathrm{k}}{\mathrm{mg}}\left[\sec \theta_{\mathrm{i}} \tan \theta_{\mathrm{i}}+\ln \left(\sec \theta_{\mathrm{i}}+\tan \theta_{\mathrm{i}}\right)\right]$

$\frac{1}{v^{2}}=\frac{\mathrm{Cmg}-\mathrm{k}[\sec \theta \tan \theta+\ln (\sec \theta+\tan \theta)]}{\operatorname{mgsec}^{2} \theta}$

$\mathrm{v}^{2}=\frac{\mathrm{mgsec}^{2} \theta}{\operatorname{Cmg}-\mathrm{k}[\sec \theta \tan \theta+\ln (\sec \theta+\tan \theta)]} \quad \mathrm{t}=0 \quad \mathrm{v}=\mathrm{v}_{\mathrm{i}} \quad \theta=\theta_{\mathrm{i}}$

$\mathrm{dx}=\mathrm{ds} \cos \theta=\mathrm{r} \cos \theta \mathrm{d} \theta \quad \mathrm{r}=\frac{\mathrm{v}^{2}}{\mathrm{~g} \cos \theta}$

$d x=-\frac{v^{2}}{g} d \theta$ (the minus sign is due that $\mathrm{dx}$ increases when $\mathrm{d} \theta$ decreases) 
$x=-\int \frac{v^{2}}{g} d \theta$

$d y=d \operatorname{sen} \theta=r \operatorname{sen} \theta d \theta \quad r=\frac{v^{2}}{g \cos \theta}$

$d y=-\frac{v^{2} \tan \theta}{g} d \theta \quad$ (the minus sign is due that dy increases when $d \theta$ decreases).

$y=-\int \frac{v^{2} \tan \theta}{g} d \theta$

The flight time is obtained as follows:

$\mathrm{ds}=\mathrm{vdt} \quad \mathrm{rd} \theta=\mathrm{vdt} \quad \mathrm{r}=\frac{\mathrm{v}^{2}}{\mathrm{~g} \cos \theta}$

$\mathrm{dt}=-\frac{\mathrm{v}}{\mathrm{g} \cos \theta} \mathrm{d} \theta$ (the minus sign is due that $\mathrm{dt}$ increases when $\mathrm{d} \theta$ decreases).

$\mathrm{t}=-\int \frac{\mathrm{v}}{\mathrm{g} \cos \theta} \mathrm{d} \theta$

The angle $\theta_{\mathrm{xm}}$ of the maximum horizontal distance $(\mathrm{y}=0)$ is:

$-\int_{\theta_{i}}^{\theta_{x m}} \frac{\mathrm{v}^{2} \tan \theta}{\mathrm{g}} \mathrm{d} \theta=0 \quad \mathrm{y}=0$

The maximum horizontal distance is obtained with this angle $\theta_{\mathrm{xm}}$ :

$\mathrm{x}=-\int_{\theta_{i}}^{\theta_{x m}} \frac{\mathrm{v}^{2}}{\mathrm{~g}} \mathrm{~d} \theta$

The total flight time is obtained with this angle $\theta_{\mathrm{xm}}$ :

$\mathrm{t}=-\int_{\theta_{i}}^{\theta_{x m}} \frac{\mathrm{v}}{\mathrm{g} \cos \theta} \mathrm{d} \theta$

The angle $\theta_{\mathrm{ym}}$ maximum height $\left(\mathrm{v}_{\mathrm{y}}=0\right)$ is: $\theta_{\mathrm{ym}}=0^{\circ}$.

The velocity $\mathrm{v}=\mathrm{v}_{\mathrm{x}}$ is:

$\mathrm{v}^{2}=\frac{1}{\mathrm{C}} \quad \mathrm{C}=\frac{\sec ^{2} \theta_{\mathrm{i}}}{\mathrm{v}_{\mathrm{i}}{ }^{2}}+\frac{\mathrm{k}}{\mathrm{mg}}\left[\sec \theta_{\mathrm{i}} \tan \theta_{\mathrm{i}}+\ln \left(\sec \theta_{\mathrm{i}}+\tan \theta_{\mathrm{i}}\right)\right]$

The maximum height is:

$\mathrm{y}=-\int_{\theta_{i}}^{0} \frac{\mathrm{v}^{2} \tan \theta}{\mathrm{g}} \mathrm{d} \theta$

The horizontal distance at the maximum height is:

$\mathrm{x}=-\int_{\theta_{i}}^{0} \frac{\mathrm{v}^{2}}{\mathrm{~g}} \mathrm{~d} \theta$

The time flight at the maximum height is:

$\mathrm{t}=-\int_{\theta_{i}}^{0} \frac{\mathrm{v}}{\mathrm{g} \cos \theta} \mathrm{d} \theta$ 


\section{Thought Experiment IV (Gedanken experiment IV)}

\section{Parabolic movement without air resistance}

In a Direct free kick, defenders can form a barrier with the desired number of players and as directed by the goalkeeper and move forward once the ball is touched ${ }^{6}$. During a free kick, the defending team must stand 10 yards or $9.14 \mathrm{~m}$ from the ball before the ball is kicked ${ }^{6}$. The average height of the players in the barrier of the free kick is $1.70 \mathrm{~m}$. For example, a Football ball is kicked at an angle $\theta_{\mathrm{i}}=60^{\circ}$ with the horizontal in a Direct free kick. If the ball just passes the barrier made by the players: $\mathrm{x}=9.14 \mathrm{~m} \mathrm{y}=1.70 \mathrm{~m}$, then, the initial velocity of the ball is:

$\Delta \mathrm{y}=\Delta \mathrm{x} \tan \theta_{\mathrm{i}}-\frac{1}{2} \mathrm{~g}\left[\frac{\Delta \mathrm{x}}{\mathrm{v}_{\mathrm{i}} \cos \theta_{\mathrm{i}}}\right]^{2}$

By replacing the values: $\theta_{i}=60^{\circ} \quad x=9.14 \mathrm{~m} \quad \mathrm{y}=1.70 \mathrm{~m}$, it is possible to obtain the initial velocity $\mathrm{v}_{\mathrm{i}}$ of the Football ball: $\mathrm{v}_{\mathrm{i}}=10.76 \mathrm{~m} / \mathrm{s}$.

The time it remains in the air is:

$\Delta \mathrm{y}=0 \quad \Delta \mathrm{y}=\mathrm{v}_{\mathrm{iy}} \mathrm{t}-\frac{1}{2} \mathrm{gt}^{2} \quad \mathrm{v}_{\mathrm{iy}}=\mathrm{v}_{\mathrm{i}} \operatorname{sen} \theta_{\mathrm{i}}$

$t_{t}=\frac{2 v_{i} \operatorname{sen} \theta_{i}}{g}$

By replacing the values of initial velocity, initial angle and the gravity acceleration, it is obtained: $t_{t}=1.9 \mathrm{~s}$.

The ball reaches the next maximum height $h$ :

$\mathrm{v}_{\mathrm{fy}}=0 \mathrm{~m} / \mathrm{s} \quad \mathrm{v}_{\mathrm{fy}}^{2}=\mathrm{v}_{\mathrm{iy}}^{2}-2 \mathrm{~g} \Delta \mathrm{y} \quad \Delta \mathrm{y}=\mathrm{h}=\frac{\left(\mathrm{v}_{\mathrm{i}} \operatorname{sen} \theta_{\mathrm{i}}\right)^{2}}{2 \mathrm{~g}}$

The maximum height is of $\mathrm{y}=4.43 \mathrm{~m}$.

The time for the maximum height $\mathrm{h}$ is:

$\mathrm{v}_{\mathrm{fy}}=\mathrm{v}_{\mathrm{iy}}-\mathrm{gt} \quad \mathrm{v}_{\mathrm{fy}}=0$

$t=\frac{v_{i} \operatorname{sen} \theta_{i}}{g}$. Therefore, $t_{t}=t_{r}+t_{f}=2 t_{r}$ where $t_{r}$ is the rise time and $t_{f}$ is the fall time. Then, it is obtained: $t_{r}=t_{f}$.

$\mathrm{t}=\mathrm{t}_{\mathrm{r}}=0.95 \mathrm{~s}$

The distance $\mathrm{x}$ when the ball reaches the maximum height is:

$\mathrm{x}=\left(\mathrm{v}_{\mathrm{i}} \cos \theta_{\mathrm{i}}\right) \mathrm{t}_{\mathrm{r}}$

$\mathrm{x}=5.12 \mathrm{~m}$ where $\mathrm{y}=4.43 \mathrm{~m}$

Then, the ball passes just above the barrier $(x=9.14 \mathrm{~m} \mathrm{y}=1.7 \mathrm{~m})$ in the downward part of the parabolic movement. By replacing the total time the ball remains in the air, and the initial velocity and the initial angle, the maximum distance reached by the ball is:

$\mathrm{x}=\mathrm{v}_{\mathrm{i}} \cos \theta_{\mathrm{i}}\left(2 \frac{\mathrm{v}_{\mathrm{i}} \operatorname{sen} \theta_{\mathrm{i}}}{\mathrm{g}}\right) \quad \mathrm{x}=\frac{v_{i}^{2} \operatorname{sen} 2 \theta_{i}}{g}$ 
$\mathrm{x}=\left(\mathrm{v}_{\mathrm{i}} \cos \theta_{\mathrm{i}}\right) \mathrm{t}_{\mathrm{t}} \quad \mathrm{x}=10.23 \mathrm{~m}$

This maximum distance is also the double of the horizontal distance for the maximum height. If the Direct free kick is done just on the borderline of the penalty $(16.5 \mathrm{~m}) \mathrm{x}=16.5 \mathrm{~m}$ of distance to the goal line ${ }^{6,7,8}$, then the next scenario is obtained: the barrier done by the players is located at the distance $\mathrm{x}=9.14 \mathrm{~m}$ from the point of the Direct free kick, the maximum horizontal distance reached by the ball is $10.23 \mathrm{~m}$ from the point of the Direct free kick, then the ball reaches the grass at a the distance $1.09 \mathrm{~m}$ after the barrier (10.23-9.14) and at the distance of $6.27 \mathrm{~m}$ before the Goal line (16.5-10.23).

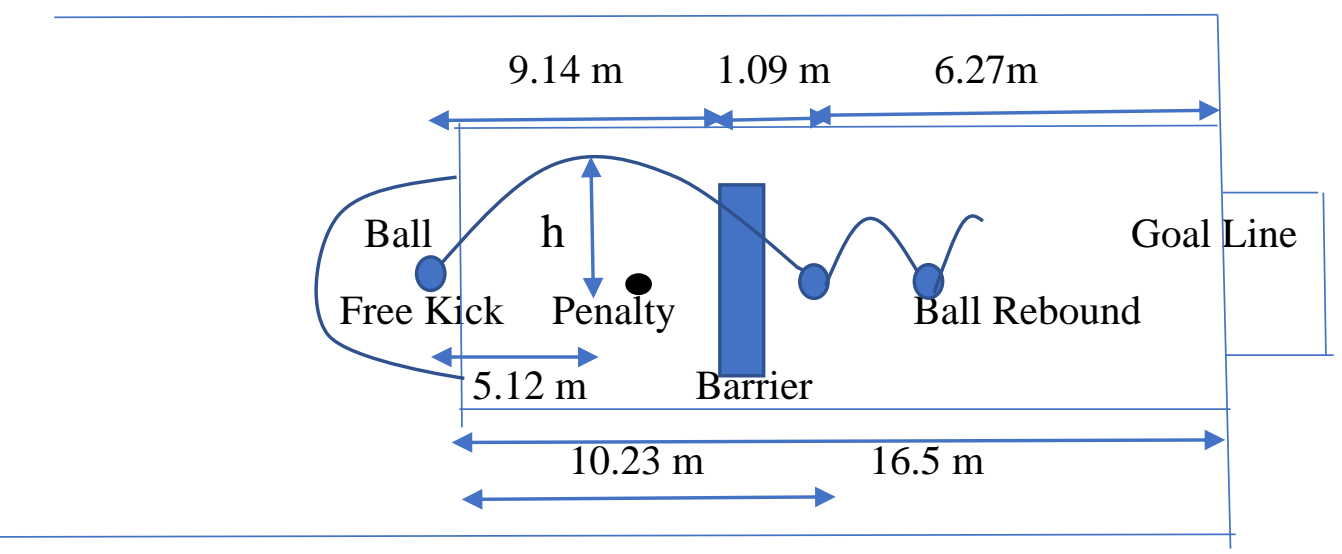

Fig.20. Thought Experiment IV (Gedanken experiment IV)

Then, the next result is possible: the ball does some rebounds and can finishes in a Goal or the ball can be caught by the Goalkeeper.

The results for the parabolic movement without air resistance are:

\section{Parabolic movement without air resistance}

$\mathrm{v}_{\mathrm{i}}=10.76 \mathrm{~m} / \mathrm{s} \quad \theta_{\mathrm{i}}=60^{\circ}$

$\Delta \mathrm{y}=\Delta \mathrm{x} \tan \theta_{\mathrm{i}}-\frac{1}{2} \mathrm{~g}\left[\frac{\Delta \mathrm{x}}{\mathrm{v}_{\mathrm{i}} \cos \theta_{\mathrm{i}}}\right]^{2} \quad$ parabolic equation

$\mathrm{y}=1.7321 \mathrm{x}-0.1693 x^{2}$

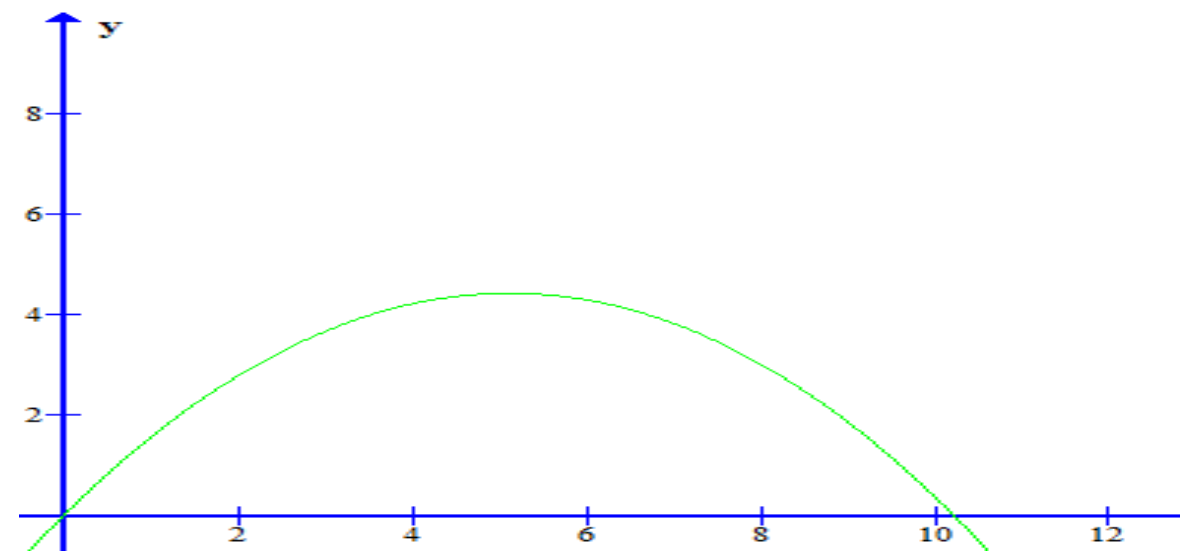

Fig.21. Parabolic movement without air resistance 
Therefore, the important points of the parabolic graph y versus $\mathrm{x}$ axes:

$\mathrm{x}=5.12 \mathrm{~m} \quad \mathrm{y}_{\max }=4.43 \mathrm{~m} \quad \mathrm{t}_{\max }=0.95 \mathrm{~s}$

$\mathrm{x}_{\max }=10.23 \mathrm{~m} \quad \mathrm{y}=0 \quad \mathrm{t}_{\mathrm{t}}=1.9 \mathrm{~s}$

$\mathrm{x}=9.14 \mathrm{~m} \quad \mathrm{y}=1.7 \mathrm{~m} \quad \mathrm{t}=1.69 \mathrm{~s}$

Parabolic movement with friction force $F_{f}=-k v$

$\mathrm{v}_{\mathrm{i}}=10.76 \mathrm{~m} / \mathrm{s} \quad \theta_{\mathrm{i}}=60^{\circ} \mathrm{m}=0.450 \mathrm{~kg} \mathrm{k}=0.0126$

$\mathrm{v}_{\mathrm{x}}=\mathrm{v}_{\mathrm{ix}} \mathrm{e}^{-\mathrm{kt} t \mathrm{~m}} \quad \mathrm{t}=0 \quad \mathrm{v}_{\mathrm{x}}=\mathrm{v}_{\mathrm{ix}} \quad \mathrm{v}_{\mathrm{ix}}=\mathrm{v}_{\mathrm{i}} \cos \theta_{\mathrm{i}} \quad \mathrm{v}_{\mathrm{iy}}=\mathrm{v}_{\mathrm{i}} \operatorname{sen} \theta_{\mathrm{i}}$

$\mathrm{x}=\frac{\mathrm{mv}_{\mathrm{ix}}}{\mathrm{k}}\left(1-\mathrm{e}^{-\frac{\mathrm{kt}}{\mathrm{m}}}\right) \quad \mathrm{t}=0 \quad \mathrm{x}=0$

$v_{y}=\left(\frac{m g}{k}+v_{i y}\right) e^{-\frac{k t}{m}}-\frac{m g}{k} \quad t=0 \quad v_{y}=v_{i y}$

$\mathrm{y}=\frac{\mathrm{m}}{\mathrm{k}}\left(\frac{\mathrm{mg}}{\mathrm{k}}+\mathrm{v}_{\mathrm{iy}}\right)\left(1-\mathrm{e}^{-\frac{\mathrm{kt}}{\mathrm{m}}}\right)-\frac{\mathrm{mg}}{\mathrm{k}} \mathrm{t}$

The time for the maximum height is: $t_{\max }=\frac{\mathrm{m}}{\mathrm{k}} \ln \left(\frac{\mathrm{mg}+\mathrm{kv}_{\mathrm{iy}}}{\mathrm{mg}}\right)$

$\mathrm{t}_{\max }=0.938 \mathrm{~s}$. The total flight time is: $\mathrm{t}_{\mathrm{t}}=1.88 \mathrm{~s}$.

The maximum height $\mathrm{h}$ is: $\mathrm{h}=\frac{\mathrm{mv}_{\mathrm{iy}}}{\mathrm{k}}-\mathrm{g} \frac{\mathrm{m}^{2}}{\mathrm{k}^{2}} \ln \left(1+\frac{k v_{i y}}{m g}\right)$

$\mathrm{h}=4.35 \mathrm{~m}$

$\mathrm{x}=192.1420\left(1-\mathrm{e}^{-0.028 \mathrm{t}}\right) \quad$ For $\mathrm{t}_{\max }=0.938 \mathrm{~s} \quad \mathrm{x}=4.93 \mathrm{~m}$

$\mathrm{y}=12832.802\left(1-\mathrm{e}^{-0.028 \mathrm{t}}\right)-350$. For $\mathrm{t}_{\max }=0.938 \mathrm{~s} \quad \mathrm{y}=\mathrm{h}=4.35 \mathrm{~m}$

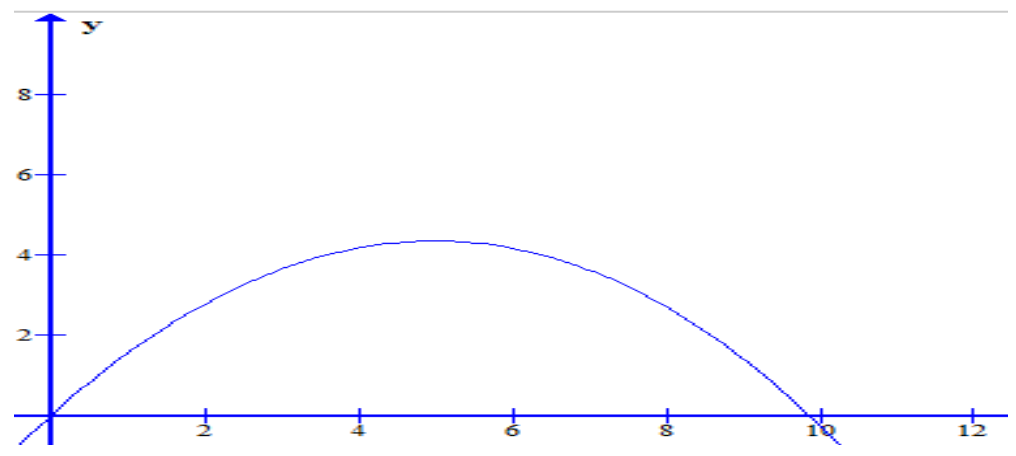

Fig.22. Parabolic movement with friction force $\mathrm{F}_{\mathrm{f}}=-\mathrm{kv}$

Therefore, the important points of the parabolic graph y versus $\mathrm{x}$ axes:

$\mathrm{x}=4.93 \mathrm{~m} \quad \mathrm{y}_{\max }=\mathrm{h}=4.35 \mathrm{~m} \quad \mathrm{t}_{\max }=0.93 \mathrm{~s}$

$\mathrm{x}_{\max }=9.85 \mathrm{~m} \quad \mathrm{y}=0 \quad \mathrm{t}_{\mathrm{t}}=1.88 \mathrm{~s}$

$\mathrm{x}=9.14 \mathrm{~m} \quad \mathrm{y}=1.22 \mathrm{~m} \quad \mathrm{t}=1.741 \mathrm{~s}$ 
Therefore the ball is stopped by the barrier because the height of the player is the $y=1.70 \mathrm{~m}$ which is located at a distance $\mathrm{x}=9.14 \mathrm{~m}$. Besides, if the ball is not stopped by the barrier, the maximum distance reached by the ball is $\mathrm{x}_{\max }=9.85 \mathrm{~m}$ which is smaller than the maximum distance by the ball without air resistance $\mathrm{x}=10.23 \mathrm{~m}(\Delta \mathrm{x} \approx 0.4 \mathrm{~m})$. Also, the maximum height reached by the ball is $y_{\max }=4.35 \mathrm{~m}$ which is smaller than the maximum height by the ball without air resistance $y=4.43 \mathrm{~m}(\Delta y \approx 0.1 \mathrm{~m})$. These results demonstrate the effects of air resistance in Football.

Parabolic movement with friction force $F_{f x}=-k v^{2} \quad F_{f y}=-k v^{2}$

$\mathrm{v}_{\mathrm{i}}=10.76 \mathrm{~m} / \mathrm{s} \quad \theta_{\mathrm{i}}=60^{\circ} \mathrm{m}=0.450 \mathrm{~kg} \mathrm{k}=0.0126$

$\mathrm{v}_{\mathrm{x}}=\frac{\mathrm{mv}_{\mathrm{ix}}}{\mathrm{kv}_{\mathrm{ix}} \mathrm{t}+\mathrm{m}} \quad \mathrm{t}=0 \quad \mathrm{v}=\mathrm{v}_{\mathrm{ix}} \quad \mathrm{v}_{\mathrm{ix}}=\mathrm{v}_{\mathrm{i}} \cos \theta_{\mathrm{i}} \quad \mathrm{v}_{\mathrm{iy}}=\mathrm{v}_{\mathrm{i}} \operatorname{sen} \theta_{\mathrm{i}}$

$\mathrm{x}=\frac{\mathrm{m}}{\mathrm{k}} \ln \left(1+\frac{\mathrm{kv}_{\text {ix }} \mathrm{t}}{\mathrm{m}}\right) \quad \mathrm{t}=0 \quad \mathrm{x}=0$

$\mathrm{v}_{\mathrm{y}}=\sqrt{\frac{\mathrm{mg}}{\mathrm{k}}} \tan \left[\arctan \left(\sqrt{\frac{\mathrm{k}}{\mathrm{mg}}} \mathrm{v}_{\mathrm{iy}}\right)-\sqrt{\frac{\mathrm{kg}}{\mathrm{m}}} \mathrm{t}\right] \quad \mathrm{t}=0 \quad v_{y}=\mathrm{v}_{\mathrm{iy}}$

$v_{y}=\sqrt{\frac{m g}{k}}\left(\frac{\sqrt{\frac{k}{m g}} v_{i y}-\tan \sqrt{\frac{k g}{m}} t}{1+\sqrt{\frac{k}{m g}} v_{i y} \tan \sqrt{\frac{k g}{m}} t}\right)$

$y=\frac{m}{k} \ln \frac{\cos \left[\arctan \left(\sqrt{\frac{k}{m g}} v_{i y}\right)-\sqrt{\frac{k g}{m}} t\right]}{\cos \left[\arctan \left(\sqrt{\frac{k}{m g}} v_{i y}\right)\right]} \quad \mathrm{t}=0 \quad \mathrm{y}=0$

The time for the maximum height is: $\mathrm{t}_{\max }=\sqrt{\frac{m}{k g}} \arctan \left(\sqrt{\frac{k}{m g}} v_{i y}\right)$

$\mathrm{t}_{\max }=0.882 \mathrm{~s}$. The total flight time is: $\mathrm{t}_{\mathrm{t}}=1.764 \mathrm{~s}$.

The maximum height $\mathrm{h}$ is: $\mathrm{h}=\frac{\mathrm{m}}{\mathrm{k}} \ln \left(\frac{1}{\cos \left[\arctan \left(\sqrt{\frac{\mathrm{k}}{\mathrm{mg}}} \mathrm{v}_{\mathrm{iy}}\right)\right]}\right)$

$\mathrm{h}=3.957 \mathrm{~m}$

$\mathrm{x}=35,714 \ln (1+0.151 \mathrm{t})$ For $\mathrm{t}_{\max }=0.882 \mathrm{~s} x=4.465 \mathrm{~m}$

$y=35.714 \ln \left(\frac{\cos (0.462-0.524 t)}{0.895}\right)$ For $\mathrm{t}_{\max }=0.882 \mathrm{~s} \mathrm{y}=\mathrm{h}=3.957 \mathrm{~m}$

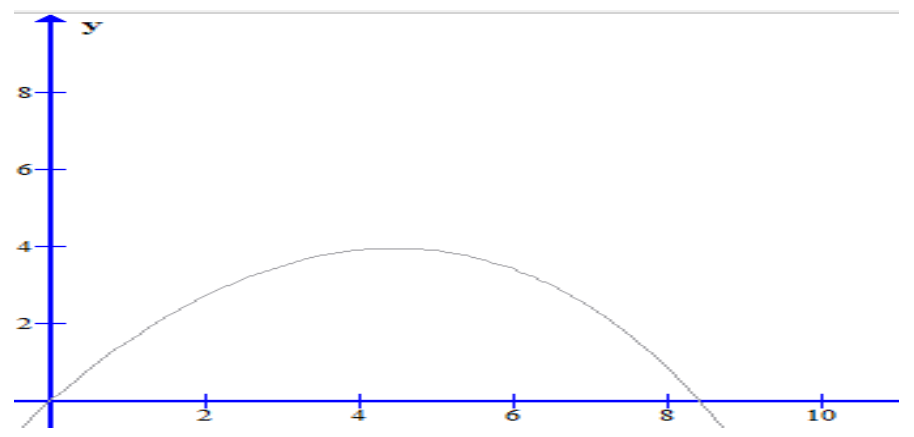

Fig.23. Parabolic movement with friction force $F_{f x}=-k v^{2} F_{f y}=-k v^{2}$ 
Therefore, the important points of the parabolic graph y versus $\mathrm{x}$ axes:

$\mathrm{x}=4.465 \mathrm{~m} \quad \mathrm{y}_{\max }=\mathrm{h}=3.96 \mathrm{~m} \quad \mathrm{t}_{\max }=0.882 \mathrm{~s}$

$\mathrm{x}_{\max }=8.43 \mathrm{~m} \quad \mathrm{y}=0 \quad \mathrm{t}_{\mathrm{t}}=1.764 \mathrm{~s}$

Therefore the ball bounces off the grass before the barrier which is located at a distance of $x=9.14 \mathrm{~m}$. Besides, the maximum distance reached by the ball is $\mathrm{x}_{\max }=8.43 \mathrm{~m}$ which is smaller than the maximum distance by the ball without air resistance $\mathrm{x}=10.23 \mathrm{~m}(\Delta \mathrm{x} \approx 2 \mathrm{~m})$. Also, the maximum height reached by the ball is $\mathrm{y}_{\max }=3.96 \mathrm{~m}$ which is smaller than the maximum height by the ball without air resistance $y=4.43 \mathrm{~m}(\Delta y \approx 0.4 \mathrm{~m})$. These results demonstrate the effects of the air resistance in Football.

Besides, the difference of the results of the parabolic movement without air resistance are higher with the model of friction force $\mathrm{F}_{\mathrm{fx}}=-\mathrm{kv}^{2} \mathrm{~F}_{\mathrm{fy}}=-\mathrm{kv} v^{2}(\Delta \mathrm{x} \approx 2 \mathrm{~m} \Delta \mathrm{y} \approx 0.4 \mathrm{~m})$ than with the model of $\mathrm{F}_{\mathrm{f}}=-\mathrm{kv}(\Delta \mathrm{x} \approx 0.4 \mathrm{~m} \Delta \mathrm{y} \approx 0.1 \mathrm{~m})$.

The comparison of the model with friction $\mathrm{F}_{\mathrm{fx}}=-\mathrm{kv}^{2} \mathrm{~F}_{\mathrm{fy}}=-\mathrm{kv}^{2}$ (gray) and the model with friction $\mathrm{F}_{\mathrm{f}}=-\mathrm{kv}$ (blue) with the model of parabolic movement without air resistance (green) is shown in the next graph:

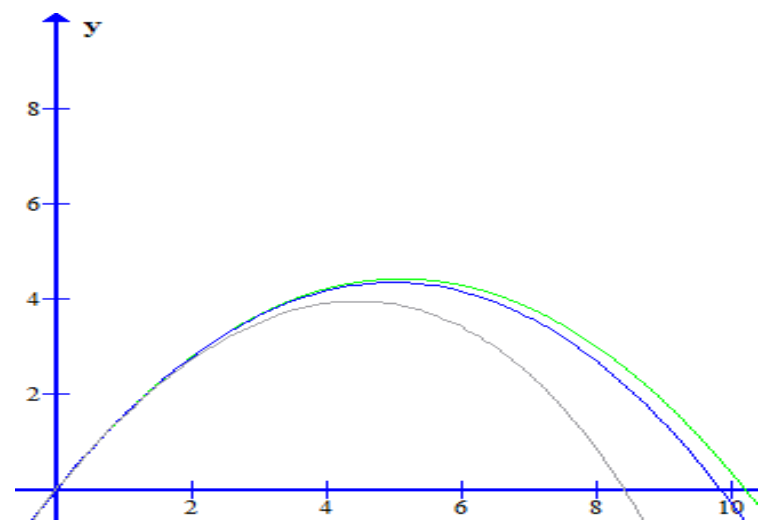

Fig.24. Parabolic movement without air resistance (green), with air resistance and friction force $\mathrm{F}_{\mathrm{f}}=-\mathrm{kv}$ (blue) and with air resistance and friction force $\mathrm{F}_{\mathrm{fx}}=-\mathrm{kv}^{2} \mathrm{~F}_{\mathrm{fy}}=-\mathrm{kv}^{2}$ (gray)

It is possible to appreciate the difference in maximum height and maximum horizontal distance for the friction models with the parabolic movement without air resistance (green). The difference is higher for the model with friction force $\mathrm{F}_{\mathrm{fx}}=-\mathrm{kv}^{2} \mathrm{~F}_{\mathrm{fy}}=-\mathrm{kv}^{2}$ (gray).

Parabolic movement with friction force: $F_{f}=-k v^{2}$

$\mathrm{v}_{\mathrm{i}}=10.76 \mathrm{~m} / \mathrm{s} \quad \theta_{\mathrm{i}}=60^{\circ}=1.0472 \operatorname{Rad} \mathrm{m}=0.450 \mathrm{~kg} \mathrm{k}=0.0126$

$\mathrm{v}^{2}=\frac{\mathrm{mgsec}^{2} \theta}{\operatorname{Cmg}-\mathrm{k}[\sec \theta \tan \theta+\ln (\sec \theta+\tan \theta)]} \quad \mathrm{t}=0 \quad \mathrm{v}=\mathrm{v}_{\mathrm{i}} \quad \theta=\theta_{\mathrm{i}}$

$\mathrm{C}=\frac{\sec ^{2} \theta_{\mathrm{i}}}{\mathrm{v}_{\mathrm{i}}{ }^{2}}+\frac{\mathrm{k}}{\mathrm{mg}}\left[\sec \theta_{\mathrm{i}} \tan \theta_{\mathrm{i}}+\ln \left(\sec \theta_{\mathrm{i}}+\tan \theta_{\mathrm{i}}\right)\right]$

$\mathrm{C}=0.04821$

$\mathrm{V}^{2}=\frac{4.41 \sec ^{2} \theta}{0.2126-0.0126[\sec \theta \tan \theta+\ln (\sec \theta+\tan \theta)]}$ 
$\mathrm{v}=\left(\frac{4.41 \sec ^{2} \theta}{0.2126-0.0126[\sec \theta \tan \theta+\ln (\sec \theta+\tan \theta)]}\right)^{0.5} \quad \theta_{\mathrm{i}}=1.0472 \mathrm{Rad} \quad \mathrm{v}_{\mathrm{i}}=10.76 \mathrm{~m} / \mathrm{s}$

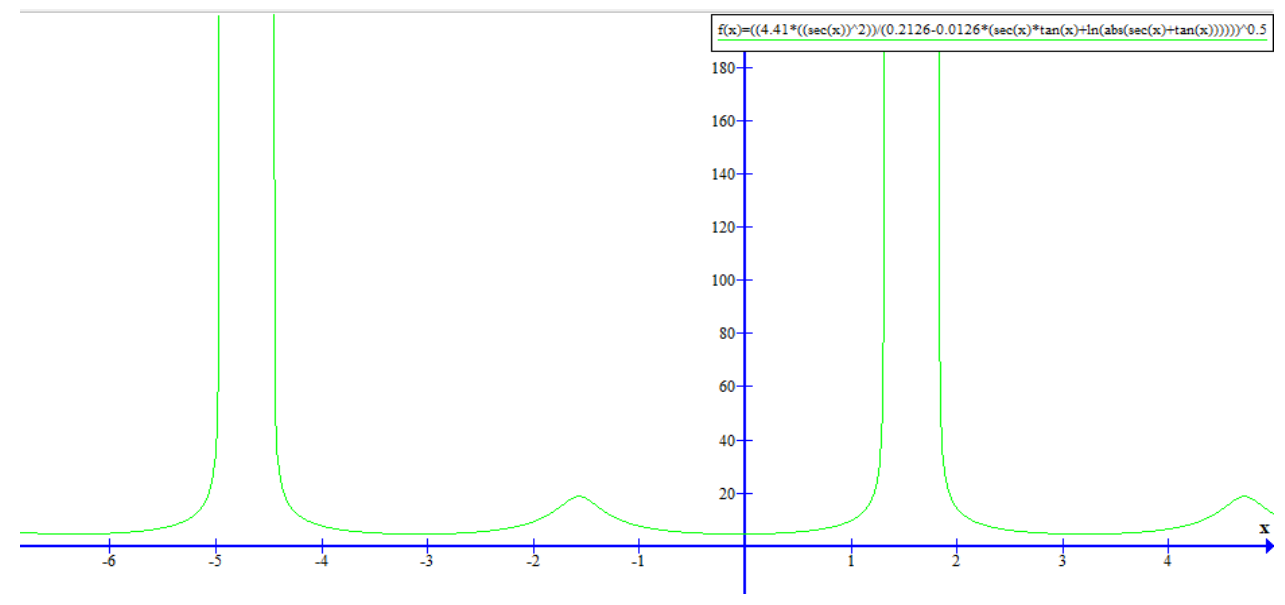

Fig.25. Graph of the velocity v versus the angle $\theta$

$-\int_{\theta_{i}}^{\theta_{x m}} \frac{\mathrm{v}^{2} \tan \theta}{\mathrm{g}} \mathrm{d} \theta=0 \quad \mathrm{y}=0$ : angle $\theta_{\mathrm{xm}}$ of the maximum horizontal distance

$\theta_{\mathrm{i}}=1.0472 \operatorname{Rad} \theta_{\mathrm{xm}}=-1.1268 \operatorname{Rad} \mathrm{v}_{\mathrm{f}}=9.031 \mathrm{~m} / \mathrm{s}$ (impact velocity)

$\mathrm{x}=-\int_{\theta_{i}}^{\theta_{x m}} \frac{\mathrm{v}^{2}}{\mathrm{~g}} \mathrm{~d} \theta:$ maximum horizontal distance

$\mathrm{x}=8.08 \mathrm{~m}$

$\mathrm{t}=-\int_{\theta_{i}}^{\theta_{x m}} \frac{\mathrm{v}}{\mathrm{g} \cos \theta} \mathrm{d} \theta:$ total flight time

$\mathrm{t}_{\mathrm{t}}=1.77 \mathrm{~s}$

$\theta_{\mathrm{ym}}=0^{\circ}:$ angle $\theta_{\mathrm{ym}}$ maximum height $\left(\mathrm{v}_{\mathrm{y}}=0\right)$

$\mathrm{v}^{2}=\frac{1}{\mathrm{C}}:$ velocity $\mathrm{v}=\mathrm{v}_{\mathrm{x}}$ at the maximum height

$\mathrm{v}^{2}=20.74 \quad \mathrm{v}=\mathrm{v}_{\mathrm{x}}=4.55 \mathrm{~m} / \mathrm{s} \quad \theta_{\mathrm{ym}}=0^{\circ}$

$\mathrm{y}=-\int_{\theta_{i}}^{0} \frac{\mathrm{v}^{2} \tan \theta}{\mathrm{g}} \mathrm{d} \theta:$ maximum height

$\mathrm{y}_{\max }=3.85 \mathrm{~m}$

$\mathrm{x}=-\int_{\theta_{i}}^{0} \frac{\mathrm{v}^{2}}{\mathrm{~g}} \mathrm{~d} \theta:$ horizontal distance at the maximum height

$\mathrm{x}=4.22 \mathrm{~m} \quad \mathrm{y}_{\max }=3.85 \mathrm{~m}$

$\mathrm{t}=-\int_{\theta_{i}}^{0} \frac{\mathrm{v}}{\operatorname{gcos} \theta} \mathrm{d} \theta:$ time flight at the maximum height

$\mathrm{t}_{\mathrm{ym}}=0.86 \mathrm{~s}$

Therefore the ball bounces off the grass before the barrier which is located at a distance of $x=9.14 \mathrm{~m}$. Besides, the 
maximum distance reached by the ball is $\mathrm{x}_{\max }=8.08 \mathrm{~m}$ which is smaller than the maximum distance by the ball without air resistance $\mathrm{x}=10.23 \mathrm{~m}(\Delta \mathrm{x} \approx 2.2 \mathrm{~m})$. Also, the maximum height reached by the ball is $\mathrm{y}_{\max }=3.85 \mathrm{~m}$ which is smaller than the maximum height by the ball without air resistance $y=4.43 \mathrm{~m}(\Delta y \approx 0.5 \mathrm{~m})$. These results demonstrate the effects of the air resistance in Football.

It is possible to conclude that the air resistance affects to obtain the results and it cannot be neglected for high air resistance. If the flight time of the ball increases, the effects of air resistance begin to appear and thus, it cannot be neglected. Besides, the difference of the results of the parabolic movement without air resistance are higher with the model of friction force $\mathrm{F}_{\mathrm{f}}=-\mathrm{kv} v^{2}(\Delta \mathrm{x} \approx 2.2 \mathrm{~m} \Delta \mathrm{y} \approx 0.5 \mathrm{~m})$ than with the other models.

\section{Thought Experiment V (Gedanken experiment V)}

If a ball is kicking with an initial angle $\theta_{\mathrm{i}}$ and the barrier done by the players is at the horizontal distance $\mathrm{x}=\mathrm{d}=9.14$ $\mathrm{m}$ with a height $\mathrm{y}=\mathrm{h}=1.70 \mathrm{~m}$ and the ball passes the barrier just at the maximum height of the parabolic motion $\left(\mathrm{v}_{\mathrm{fy}}=0\right) \mathrm{x}=\mathrm{d}=9.14 \mathrm{~m} \mathrm{y}_{\max }=\mathrm{h}=1.70 \mathrm{~m}$, then it is obtained:

$v_{\text {fy }}=v_{\text {iy }}-$ gt $\quad v_{\text {fy }}=0$

$\mathrm{v}_{\mathrm{i}} \operatorname{sen} \theta_{\mathrm{i}}=\mathrm{gt}$

$\mathrm{d}=\left(\mathrm{v}_{\mathrm{i}} \cos \theta_{\mathrm{i}}\right) \mathrm{t} \quad(* *) \quad \Delta \mathrm{x}=\mathrm{d}$

Dividing $(*)$ for $(* *)$, it is obtained:

$\frac{\mathrm{v}_{\mathrm{i}} \operatorname{sen} \theta_{\mathrm{i}}}{\mathrm{d}}=\frac{\mathrm{g}}{\mathrm{v}_{\mathrm{i}} \cos \theta_{\mathrm{i}}}$

$\mathrm{dg}=\mathrm{v}_{\mathrm{i}}^{2} \operatorname{sen} \theta_{\mathrm{i}} \cos \theta_{\mathrm{i}} \quad(* * *)$

$v_{\text {fy }}^{2}=v_{i y}^{2}-2 g \Delta y \quad v_{f y}=0 \quad \Delta y=h$

$2 \mathrm{gh}=\mathrm{v}_{\mathrm{i}}^{2} \operatorname{sen}^{2} \theta_{\mathrm{i}}(* * * *)$

Dividing $(* * * *)$ for $(* * *)$, the initial angle is:

$\tan \theta_{\mathrm{i}}=\frac{2 \mathrm{~h}}{\mathrm{~d}} \quad \tan \theta_{\mathrm{i}}=0,37 \quad \theta_{\mathrm{i}}=20.4^{\circ}$

$\Delta \mathrm{y}=\Delta \mathrm{x} \tan \theta_{\mathrm{i}}-\frac{1}{2} \mathrm{~g}\left[\frac{\Delta \mathrm{x}}{\mathrm{v}_{\mathrm{i}} \cos \theta_{\mathrm{i}}}\right]^{2} \quad$ (parabolic equation)

$\mathrm{h}=\mathrm{d} \frac{2 \mathrm{~h}}{\mathrm{~d}}-\frac{1}{2} \mathrm{gt}^{2} \quad \mathrm{t}=\Delta \mathrm{x} /\left(\mathrm{v}_{\mathrm{i}} \cos \theta_{\mathrm{i}}\right)$

$\mathrm{t}=\sqrt{\frac{2 \mathrm{~h}}{\mathrm{~g}}}:$ time of the maximum height

Thus, the rise time is: $t=\sqrt{\frac{2 h}{g}} \quad t=t_{r}=0.58 \mathrm{~s}$

The total time is the double of the rise time: $\mathrm{t}_{\mathrm{t}}=2 \mathrm{t}_{\mathrm{r}}=2\left(\sqrt{\frac{2 h}{g}}\right)$ 
$\mathrm{t}_{\mathrm{t}}=1.17 \mathrm{~s}$

The vertical initial velocity is:

$\mathrm{v}_{\mathrm{fy}}=\mathrm{v}_{\mathrm{iy}}{ }^{-} \mathrm{gt}$

$\mathrm{v}_{\mathrm{fy}}=0 \quad \mathrm{v}_{\mathrm{iy}}=\mathrm{gt}_{\mathrm{r}} \quad \mathrm{t}_{\mathrm{r}}=\sqrt{\frac{2 \mathrm{~h}}{\mathrm{~g}}} \quad \mathrm{v}_{\mathrm{iy}}=\sqrt{2 \mathrm{gh}}$

$\mathrm{v}_{\mathrm{fy}}^{2}=\mathrm{v}_{\mathrm{iy}}^{2}-2 \mathrm{~g} \Delta \mathrm{y} \quad \Delta \mathrm{y}=\mathrm{h} \quad \mathrm{v}_{\mathrm{fy}}=0 \quad \mathrm{v}_{\mathrm{iy}}=\sqrt{2 g h}$

$\mathrm{v}_{\mathrm{iy}}=5.77 \mathrm{~m} / \mathrm{s}$

The horizontal initial velocity is:

$\mathrm{v}_{\mathrm{ix}}=\frac{d}{t} \quad \mathrm{t}=\mathrm{t}_{\mathrm{r}} \quad \mathrm{v}_{\mathrm{ix}}=\sqrt{\frac{\mathrm{d}^{2} \mathrm{~g}}{2 \mathrm{~h}}}$

$\mathrm{v}_{\mathrm{ix}}=\frac{d}{t} \quad \mathrm{v}_{\mathrm{ix}}=15.52 \mathrm{~m} / \mathrm{s}$

The initial velocity is:

$\mathrm{v}_{\mathrm{i}}^{2}=\mathrm{v}_{\mathrm{ix}}^{2}+\mathrm{v}_{\mathrm{iy}}^{2} \quad \mathrm{v}_{\mathrm{i}}=\sqrt{\frac{\mathrm{d}^{2} \mathrm{~g}}{2 \mathrm{~h}}+2 \mathrm{gh}}$

$\mathrm{v}_{\mathrm{i}}=16.6 \mathrm{~m} / \mathrm{s}$

The maximum distance reached by the ball is:

$\mathrm{x}=\mathrm{v}_{\mathrm{ix}} \mathrm{t}_{\mathrm{t}}$ or $\mathrm{x}=2(9.14)$

$\mathrm{x}=18.3 \mathrm{~m}$

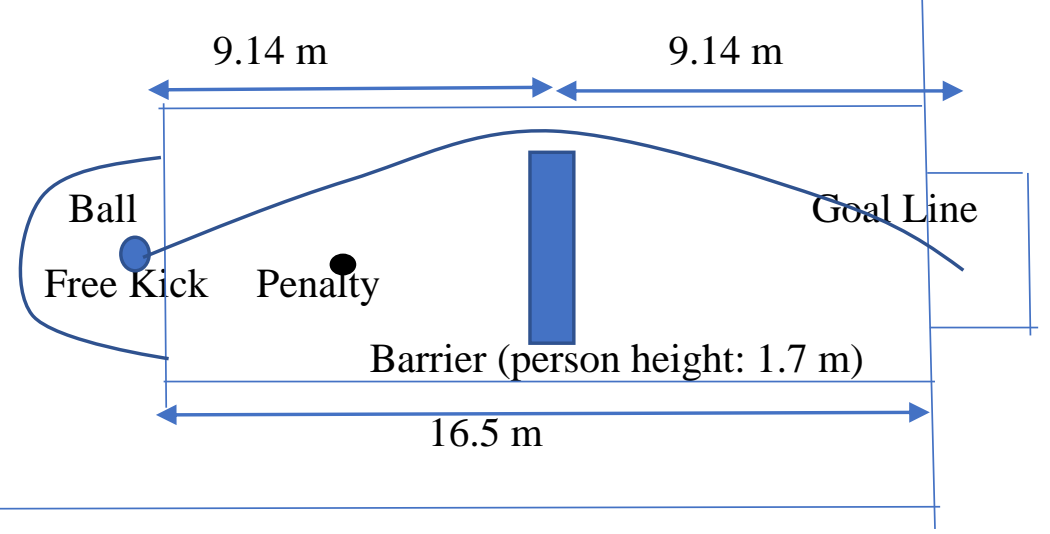

Fig.26. Thought Experiment V (Gedanken experiment V)

If the Direct free kick is performed just on the borderline of the penalty at the distance $x=16.5 \mathrm{~m}$ from the Goal line, the barrier done by the players is located at the distance $\mathrm{x}=9.14 \mathrm{~m}$ from the point of the Direct free kick, then the ball reaches the grass at a the distance $9.14 \mathrm{~m}$ after the barrier which passes the goal line. Thus, the ball does not rebound before the goal line. Then, the next result is possible: the direct free kick can finishes in a Goal or the ball 
can be caught by the Goalkeeper.

The results for the parabolic movement without air resistance are:

\section{Parabolic movement without air resistance}

$\mathrm{v}_{\mathrm{i}}=16.6 \mathrm{~m} / \mathrm{s} \quad \theta_{\mathrm{i}}=20.4^{\circ}$

$\Delta \mathrm{y}=\Delta \mathrm{x} \tan \theta_{\mathrm{i}}-\frac{1}{2} \mathrm{~g}\left[\frac{\Delta \mathrm{x}}{\mathrm{v}_{\mathrm{i}} \cos \theta_{\mathrm{i}}}\right]^{2} \quad$ parabolic equation

$y=0.371 x-0.020 x^{2}$

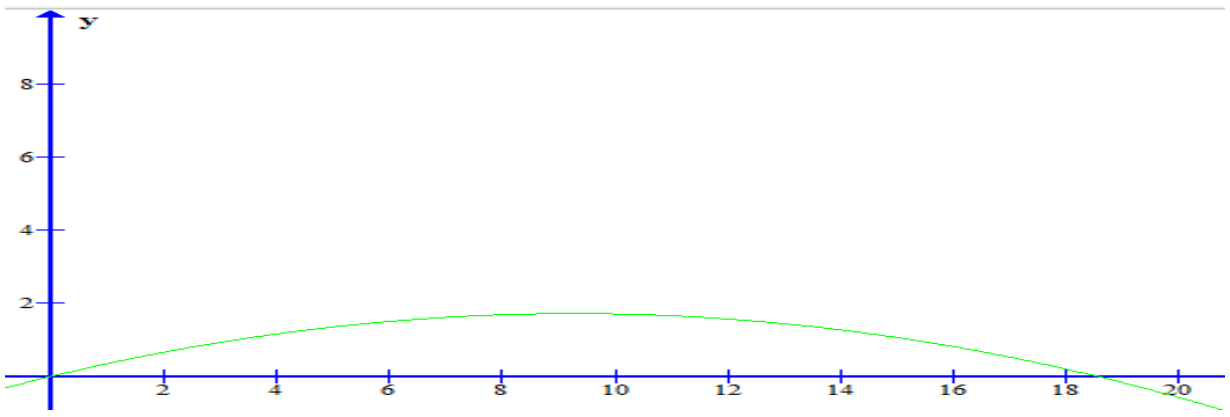

Fig.27. Parabolic movement without air resistance

Therefore, the important points of the parabolic graph $\mathrm{y}$ versus $\mathrm{x}$ axes:

$\mathrm{x}=9.14 \mathrm{~m} \quad \mathrm{y}_{\max }=1.7 \mathrm{~m} \quad \mathrm{t}=0.58 \mathrm{~s}$

$\mathrm{x}_{\max }=18.3 \mathrm{~m} \quad \mathrm{y}=0 \quad \mathrm{t}=1.17 \mathrm{~s}$

\section{Parabolic movement with friction force $F_{f}=-k v$}

$\mathrm{v}_{\mathrm{i}}=16.6 \mathrm{~m} / \mathrm{s} \quad \theta_{\mathrm{i}}=20.4^{\circ} \quad \mathrm{m}=0.450 \mathrm{~kg} \quad \mathrm{k}=0.0126$

$\mathrm{v}_{\mathrm{x}}=\mathrm{v}_{\mathrm{ix}} \mathrm{e}^{-\mathrm{kt} / \mathrm{m}} \quad \mathrm{t}=0 \quad \mathrm{v}_{\mathrm{x}}=\mathrm{v}_{\mathrm{ix}} \quad \mathrm{v}_{\mathrm{ix}}=\mathrm{v}_{\mathrm{i}} \cos \theta_{\mathrm{i}} \quad \mathrm{v}_{\mathrm{iy}}=\mathrm{v}_{\mathrm{i}} \operatorname{sen} \theta_{\mathrm{i}}$

$x=\frac{m v_{i x}}{k}\left(1-e^{-\frac{k t}{m}}\right) \quad \mathrm{t}=0 \quad \mathrm{x}=0$

$v_{y}=\left(\frac{m g}{k}+\mathrm{v}_{\mathrm{iy}}\right) \mathrm{e}^{-\frac{\mathrm{kt}}{\mathrm{m}}}-\frac{\mathrm{mg}}{\mathrm{k}} \quad \mathrm{t}=0 \quad \mathrm{v}_{\mathrm{y}}=\mathrm{v}_{\text {iy }}$

$y=\frac{m}{k}\left(\frac{m g}{k}+\mathrm{v}_{\mathrm{iy}}\right)\left(1-\mathrm{e}^{-\frac{\mathrm{kt}}{\mathrm{m}}}\right)-\frac{m g}{k} t$

The time for the maximum height is: $t_{\max }=\frac{m}{k} \ln \left(\frac{m g+k v_{i y}}{m g}\right)$

$\mathrm{t}_{\max }=0.586 \mathrm{~s} . \quad$ The total flight time is: $\mathrm{t}_{\mathrm{t}}=1.174 \mathrm{~s}$.

The maximum height $\mathrm{h}$ is: $\mathrm{h}=\frac{\mathrm{mv}_{\mathrm{iy}}}{\mathrm{k}}-\mathrm{g} \frac{\mathrm{m}^{2}}{\mathrm{k}^{2}} \ln \left(1+\frac{k v_{i y}}{m g}\right)$

$\mathrm{h}=1.69 \mathrm{~m}$

$x=555.674\left(1-e^{-0.028 t}\right)$ For $\mathrm{t}_{\max }=0.586 \mathrm{~s} \mathrm{x}=9.02 \mathrm{~m}$ 
$y=12706.654\left(1-\mathrm{e}^{-0.028 \mathrm{t}}\right)-350 t$ For $\mathrm{t}_{\max }=0.586 \mathrm{~s} \mathrm{y}=\mathrm{h}=1.69 \mathrm{~m}$

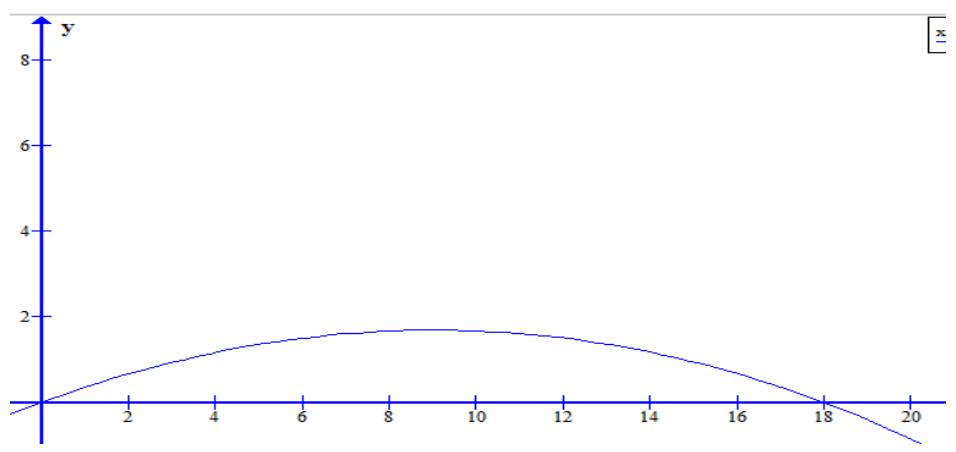

Fig.28. Parabolic movement with friction force $\mathrm{F}_{\mathrm{f}}=-\mathrm{kv}$

Therefore, the important points of the parabolic graph $\mathrm{y}$ versus $\mathrm{x}$ ares:

$$
\begin{array}{lll}
\mathrm{x}=9.02 \mathrm{~m} & \mathrm{y}_{\max }=\mathrm{h}=1.69 \mathrm{~m} & \mathrm{t}_{\max }=0.586 \mathrm{~s} \\
\mathrm{x}_{\max }=17.91 \mathrm{~m} & \mathrm{y}=0 & \mathrm{t}_{\mathrm{t}}=1.174 \mathrm{~s} \\
\mathrm{x}=9.14 \mathrm{~m} & \mathrm{y}=1.68 \mathrm{~m} & \mathrm{t}=0.592 \mathrm{~s}
\end{array}
$$

Therefore the ball is stopped by the barrier because the height of the player is the $y=1.70 \mathrm{~m}$ which is located at a distance $\mathrm{x}=9.14 \mathrm{~m}$. Besides, if the ball is not stopped by the barrier, the maximum distance reached by the ball is $\mathrm{x}_{\max }=17.91 \mathrm{~m}$ which is smaller than the maximum distance by the ball without air resistance $\mathrm{x}=18.3 \mathrm{~m}(\Delta \mathrm{x} \approx 0.4 \mathrm{~m})$. Also, the maximum height reached by the ball is $\mathrm{y}_{\max }=1.69 \mathrm{~m}$ which is a little less than the maximum height by the ball without air resistance $y=1.7 \mathrm{~m}(\Delta \mathrm{y} \approx 0,01)$. These demonstrate the effects of air resistance in Football.

Parabolic movement with friction force $F_{f x}=-k v^{2} \quad F_{f y}=-k v^{2}$

$\mathrm{v}_{\mathrm{i}}=16.6 \mathrm{~m} / \mathrm{s} \quad \theta_{\mathrm{i}}=20.4^{\circ} \mathrm{m}=0.450 \mathrm{~kg} \mathrm{k}=0.0126$

$\mathrm{v}_{\mathrm{x}}=\frac{\mathrm{mv}_{\mathrm{ix}}}{\mathrm{kv}_{\mathrm{ix}} \mathrm{t}+\mathrm{m}} \quad \mathrm{t}=0 \quad \mathrm{v}=\mathrm{v}_{\mathrm{ix}} \quad \mathrm{v}_{\mathrm{ix}}=\mathrm{v}_{\mathrm{i}} \cos \theta_{\mathrm{i}} \quad \mathrm{v}_{\mathrm{iy}}=\mathrm{v}_{\mathrm{i}} \operatorname{sen} \theta_{\mathrm{i}}$

$x=\frac{m}{k} \ln \left(1+\frac{k v_{i x} t}{m}\right) \quad t=0 \quad x=0$

$v_{y}=\sqrt{\frac{m g}{k}} \tan \left[\arctan \left(\sqrt{\frac{k}{m g}} v_{i y}\right)-\sqrt{\frac{k g}{m}} t\right] \quad \mathrm{t}=0 \quad v_{y}=\mathrm{v}_{\mathrm{iy}}$

$v_{y}=\sqrt{\frac{m g}{k}}\left(\frac{\sqrt{\frac{k}{m g}} v_{i y}-\tan \sqrt{\frac{k g}{m}} t}{1+\sqrt{\frac{k}{m g}} v_{i y} \tan \sqrt{\frac{k g}{m}} t}\right)$

$y=\frac{m}{k} \ln \frac{\cos \left[\arctan \left(\sqrt{\frac{k}{m g}} v_{i y}\right)-\sqrt{\frac{k g}{m}} t\right]}{\cos \left[\arctan \left(\sqrt{\frac{k}{m g}} v_{i y}\right)\right]} \quad \mathrm{t}=0 \quad \mathrm{y}=0$

The time for the maximum height is: $\mathrm{t}_{\max }=\sqrt{\frac{m}{k g}} \arctan \left(\sqrt{\frac{k}{m g}} v_{i y}\right)$ $\mathrm{t}_{\max }=0.573 \mathrm{~s}$. The total flight time is: $\mathrm{t}_{\mathrm{t}}=1.14 \mathrm{~s}$. 
The maximum height $\mathrm{h}$ is: $\mathrm{h}=\frac{\mathrm{m}}{\mathrm{k}} \ln \left(\frac{1}{\cos \left[\arctan \left(\sqrt{\frac{\mathrm{k}}{\mathrm{mg}}} \mathrm{v}_{\mathrm{iy}}\right)\right]}\right)$

$\mathrm{h}=1.63 \mathrm{~m}$

$x=35,714 \ln (1+0.436 t)$ For $\mathrm{t}_{\max }=0.573 \mathrm{~s} \quad \mathrm{x}=7.96 \mathrm{~m}$

$y=35.714 \ln \left(\frac{\cos (0.299-0.524 t)}{0.955}\right) \quad$ For $\mathrm{t}_{\max }=0.573 \mathrm{~s} \quad \mathrm{y}=\mathrm{h}=1.63 \mathrm{~m}$

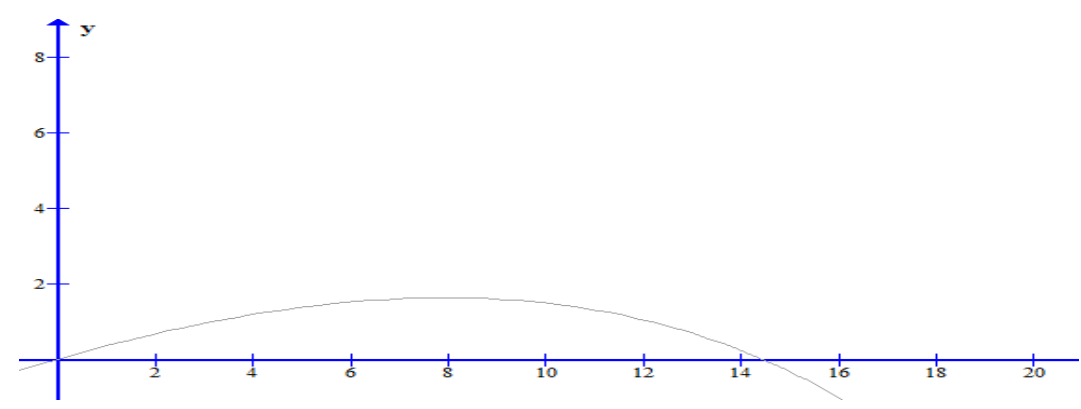

Fig.29. Parabolic movement with friction force $F_{f x}=-k v^{2} F_{f y}=-k v^{2}$

Therefore, the important points of the parabolic graph y versus $\mathrm{x}$ axes:

$$
\begin{array}{lll}
\mathrm{x}=7.96 \mathrm{~m} & \mathrm{y}_{\max }=\mathrm{h}=1.63 \mathrm{~m} & \mathrm{t}_{\max }=0.573 \mathrm{~s} \\
\mathrm{x}_{\max }=14.46 \mathrm{~m} & \mathrm{y}=0 & \mathrm{t}_{\mathrm{t}}=1.14 \mathrm{~s} \\
\mathrm{x}=9.14 \mathrm{~m} & \mathrm{y}=1.59 \mathrm{~m} & \mathrm{t}=0.669 \mathrm{~s}
\end{array}
$$

Therefore the ball is stopped by the barrier because the height of the player is $y=1.70 \mathrm{~m}$ which is located at a distance $\mathrm{x}=9.14 \mathrm{~m}$. Besides, if the ball is not stopped by the barrier, the maximum distance reached by the ball is $\mathrm{x}_{\max }=14.46 \mathrm{~m}$ which is smaller than the maximum distance by the ball without air resistance $\mathrm{x}=18.3 \mathrm{~m}(\Delta \mathrm{x} \approx 3.8 \mathrm{~m})$. Also, the maximum height reached by the ball is $\mathrm{y}_{\max }=1.63 \mathrm{~m}$ which is smaller than the maximum height by the ball without air resistance $y=1.7 \mathrm{~m}(\Delta y \approx 0.07 \mathrm{~m})$. These results demonstrate the effects of the air resistance in Football. Besides, the difference of the results of the parabolic movement without air resistance are higher with the model of friction force $\mathrm{F}_{\mathrm{fx}}=-\mathrm{kv}^{2} \quad \mathrm{~F}_{\mathrm{fy}}=-\mathrm{kv}^{2}(\Delta \mathrm{x} \approx 3.8 \mathrm{~m} \Delta \mathrm{y} \approx 0.07 \mathrm{~m})$ than with the model of $\mathrm{F}_{\mathrm{f}}=-\mathrm{kv}(\Delta \mathrm{x} \approx 0.4 \mathrm{~m}$ $\Delta y \approx 0.01 \mathrm{~m}$ ). The comparison of the model with friction $\mathrm{F}_{\mathrm{fx}}=-\mathrm{kv}^{2} \mathrm{~F}_{\mathrm{fy}}=-\mathrm{kv}^{2}$ (gray) and the model with friction $\mathrm{F}_{\mathrm{f}}=-\mathrm{kv}$ (blue) with the model of parabolic movement without air resistance (green) is shown in the next graph:

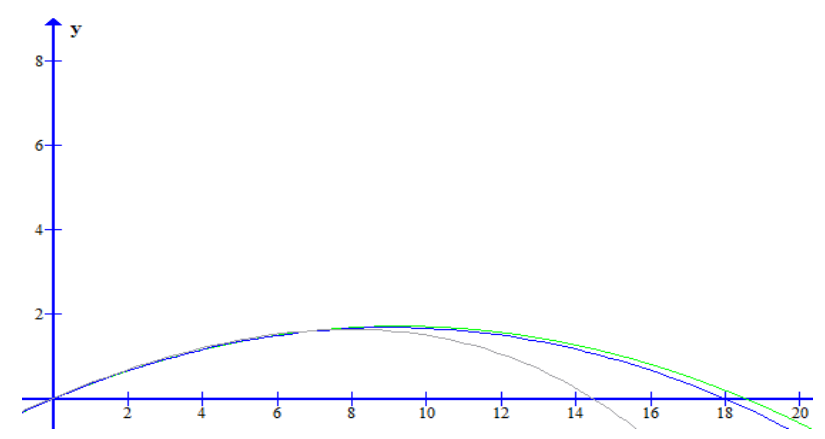

Fig.30. Parabolic movement without air resistance (green), with air resistance and friction force $F_{f}=-k v(b l u e)$ and with air resistance and friction force $\mathrm{F}_{\mathrm{fx}}=-\mathrm{kv}^{2} \mathrm{~F}_{\mathrm{fy}}=-\mathrm{kv}^{2}$ (gray) 
It is possible to appreciate the difference in maximum height and maximum horizontal distance for the friction models with the parabolic movement without air resistance (green). The difference is higher for the model with friction force $\mathrm{F}_{\mathrm{fx}}=-\mathrm{kv} v^{2} \mathrm{~F}_{\mathrm{fy}}=-\mathrm{kv} v^{2}$ (gray).

Parabolic movement with friction force: $F_{f}=-k v^{2}$

$\mathrm{v}_{\mathrm{i}}=16.6 \mathrm{~m} / \mathrm{s} \quad \theta_{\mathrm{i}}=20.4^{\circ}=0.356 \mathrm{Rad} \mathrm{m}=0.450 \mathrm{~kg} \mathrm{k}=0.0126$

$\mathrm{v}^{2}=\frac{\mathrm{mgsec}^{2} \theta}{\operatorname{Cmg}-\mathrm{k}[\sec \theta \tan \theta+\ln (\sec \theta+\tan \theta)]} \quad \mathrm{t}=0 \quad \mathrm{v}=\mathrm{v}_{\mathrm{i}} \quad \theta=\theta_{\mathrm{i}}$

$\mathrm{C}=\frac{\sec ^{2} \theta_{\mathrm{i}}}{\mathrm{v}_{\mathrm{i}}{ }^{2}}+\frac{\mathrm{k}}{\mathrm{mg}}\left[\sec \theta_{\mathrm{i}} \tan \theta_{\mathrm{i}}+\ln \left(\sec \theta_{\mathrm{i}}+\tan \theta_{\mathrm{i}}\right)\right]$

$\mathrm{C}=0.006304$

$\mathrm{v}^{2}=\frac{4.41 \sec ^{2} \theta}{0.0278-0.0126[\sec \theta \tan \theta+\ln (\sec \theta+\tan \theta)]}$

$\mathrm{v}=\left(\frac{4.41 \sec ^{2} \theta}{0.0278-0.0126[\sec \theta \tan \theta+\ln (\sec \theta+\tan \theta)]}\right)^{0.5} \quad \theta_{\mathrm{i}}=0.356 \operatorname{Rad} \quad \mathrm{v}_{\mathrm{i}}=16.6 \mathrm{~m} / \mathrm{s}$

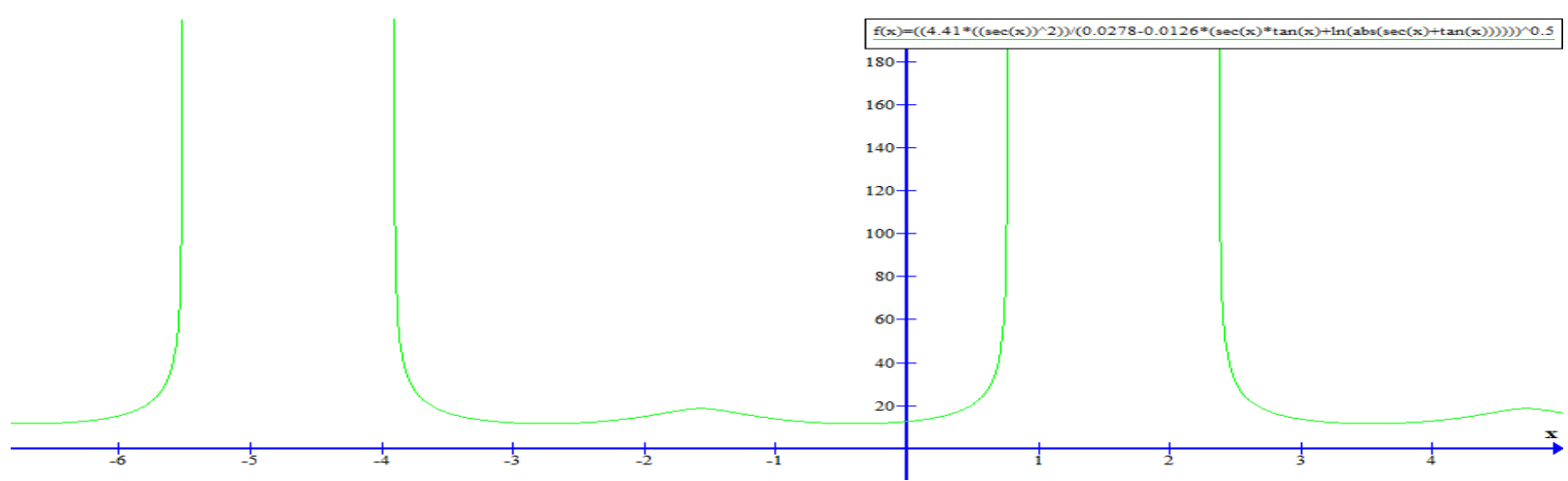

Fig.31. Graph of the velocity v versus the angle $\theta$

$-\int_{\theta_{i}}^{\theta_{x m}} \frac{\mathrm{v}^{2} \tan \theta}{\mathrm{g}} \mathrm{d} \theta=0 \quad \mathrm{y}=0$ : angle $\theta_{\mathrm{xm}}$ of the maximum horizontal distance

$\theta_{\mathrm{i}}=0.356 \operatorname{Rad} \theta_{\mathrm{xm}}=-0.45 \operatorname{Rad} \mathrm{v}_{\mathrm{f}}=11.59 \mathrm{~m} / \mathrm{s}$ (impact velocity)

$\mathrm{x}=-\int_{\theta_{i}}^{\theta_{x m}} \frac{\mathrm{v}^{2}}{\mathrm{~g}} \mathrm{~d} \theta:$ maximum horizontal distance

$\mathrm{x}=13.83 \mathrm{~m}$

$\mathrm{t}=-\int_{\theta_{i}}^{\theta_{x m}} \frac{\mathrm{v}}{\mathrm{g} \cos \theta} \mathrm{d} \theta:$ total flight time

$\mathrm{t}_{\mathrm{t}}=1.09 \mathrm{~s}$

$\theta_{\mathrm{ym}}=0^{\circ}$ : angle $\theta_{\mathrm{ym}}$ maximum height $\left(\mathrm{v}_{\mathrm{y}}=0\right)$

$\mathrm{v}^{2}=\frac{1}{\mathrm{C}}:$ velocity $\mathrm{v}=\mathrm{v}_{\mathrm{x}}$ at the maximum height

$\mathrm{v}^{2}=158.63 \quad \mathrm{v}=\mathrm{v}_{\mathrm{x}}=12.59 \mathrm{~m} / \mathrm{s} \quad \theta_{\mathrm{ym}}=0^{\circ}$ 
$\mathrm{y}=-\int_{\theta_{i}}^{0} \frac{\mathrm{v}^{2} \tan \theta}{\mathrm{g}} \mathrm{d} \theta:$ maximum height

$\mathrm{y}_{\max }=1.46 \mathrm{~m}$

$\mathrm{x}=-\int_{\theta_{i}}^{0} \frac{\mathrm{v}^{2}}{\mathrm{~g}} \mathrm{~d} \theta:$ horizontal distance at the maximum height

$\mathrm{x}=7.36 \mathrm{~m} \quad \mathrm{y}_{\max }=1.46 \mathrm{~m}$

$\mathrm{t}=-\int_{\theta_{i}}^{0} \frac{\mathrm{v}}{\operatorname{gcos} \theta} \mathrm{d} \theta:$ time flight at the maximum height

$\mathrm{t}_{\mathrm{ym}}=0.53 \mathrm{~s}$

Therefore the ball bounces off the grass before the barrier which is located at a distance of $x=9.14 \mathrm{~m}$. Besides, the maximum distance reached by the ball is $\mathrm{x}_{\max }=13.83 \mathrm{~m}$ which is smaller than the maximum distance by the ball without air resistance $\mathrm{x}=18.3 \mathrm{~m}(\Delta \mathrm{x} \approx 4.4 \mathrm{~m})$. Also, the maximum height reached by the ball is $\mathrm{y}_{\max }=1.46 \mathrm{~m}$ which is smaller than the maximum height by the ball without air resistance $y=1.7 \mathrm{~m}(\Delta y \approx 0.2 \mathrm{~m})$. These results demonstrate the effects of the air resistance in Football.

It is possible to conclude that the air resistance affects to obtain the results and it cannot be neglected for high air resistance. If the flight time of the ball increases, the effects of air resistance begin to appear and thus, it cannot be neglected. Besides, the difference of the results of the parabolic movement without air resistance are higher with the model of friction force $\mathrm{F}_{\mathrm{f}}=-\mathrm{kv} \mathrm{v}^{2}(\Delta \mathrm{x} \approx 4.4 \mathrm{~m} \Delta \mathrm{y} \approx 0.2 \mathrm{~m})$ than with the other models.

The effect of the air resistance increases as the horizontal distance is higher or for a higher flight time. The air resistance force applied for a longer time causes a more significant braking. The air resistance has a determining effect on the maximum horizontal distance and the maximum height reached by the object.

In conclusion, if there is less air resistance which occurs when there is less atmospheric pressure or for place with a high altitude above sea level, then there is less air friction of the ball with the air and the ball gets a larger maximum horizontal distance and a higher maximum height than the horizontal distance and height at sea level. This analysis is for the air resistance which depends of the atmospheric conditions of the place where the match is played. Other factor to consider is the wind in a Football match. If there is a strong wind against a team in the Football match, then, it is complicate to performance air pass and to advance to the field of the other team.

Therefore, it is possible to apply Physics in Football as the thought experiments (Gedanken experiment) have been done. Of course, Football players do not apply Physics directly, but it can be said, that this is something intrinsic and intuitive in the Football player ${ }^{6,7,8}$ and Physics can corroborate or verify the skills that the player has done with the Football ball.

\section{Effects of the gravitation in astronauts and on the Football ball and the players due the altitude of the city} above sea level where the match takes place: "The ball doesn't bend"

The gravity acceleration is not the same in different places or cities on the Earth since the gravity depends on the position of the place or city respect to the center of the Earth. Cities further away from the center of the Earth or at 
higher altitudes have less gravity and thus the ball has less gravitational force or weight which is a vector directed towards the center of the Earth $^{2,3,6}$. In practice, the height of the city is measured relative to the sea level. The gravitational force at distance $r$ of the Earth Center or at a distance $h$ of the Earth Surface or at the altitude $h$ above sea level $r=R_{e}+h$ is ${ }^{2,3,6}: \quad F_{g}=W=m g^{\prime}=G \frac{M_{e} m}{r^{2}}=G \frac{M_{e} m}{\left(R_{e}+h\right)^{2}}$

$g^{\prime}=G \frac{M_{e}}{r^{2}}=G \frac{M_{e}}{\left(R_{e}+h\right)^{2}} \quad g^{\prime}=G \frac{M_{e}}{\left(R_{e}+h\right)^{2}}$

$\mathrm{h}=0 \quad \mathrm{r}=\mathrm{R}_{\mathrm{e}} \quad \mathrm{g}^{\prime}=\mathrm{g}=\mathrm{G} \frac{\mathrm{M}_{\mathrm{e}}}{\mathrm{R}_{\mathrm{e}}{ }^{2}} \quad \mathrm{~g}^{\prime}=\mathrm{g}=9.82 \mathrm{~m} / \mathrm{s}^{2}:$ gravity near the Earth surface

$\mathrm{h}->\infty$ or $\mathrm{r}->\infty \quad \mathrm{g}^{\prime}=0 \quad \mathrm{~F}_{\mathrm{g}}=\mathrm{W}=\mathrm{mg}^{\prime}->0$

$\mathrm{G}=6.67 * 10^{-11} \mathrm{~N} \mathrm{~m}^{2} / \mathrm{kg}^{2}, \mathrm{M}_{\mathrm{e}}=5.98 * 10^{24} \mathrm{~kg}, \mathrm{R}_{\mathrm{e}}=6.37 * 10^{6} \mathrm{~m}$ where $\mathrm{G}$ is the gravitational constant, $\mathrm{M}_{\mathrm{e}}$ is the Earth mass and $\mathrm{R}_{\mathrm{e}}$ is the Earth radius. The value of the gravity changes depending of the altitude $\mathrm{h}$ of the place or city above sea level ${ }^{2,3}$ The value of the gravity near the Earth Surface $(\mathrm{h}=0)$ is $\mathrm{g}=9.82 \mathrm{~m} / \mathrm{s}^{2}$. The value of the gravity in an altitude of $\mathrm{h}=3650 \mathrm{~m}$ (La Paz, Bolivia) is: $9.81 \mathrm{~m} / \mathrm{s}^{2}$ where La Paz is the highest city in the world. If the altitude is $\mathrm{h}=500 \mathrm{~km}$, the gravity acceleration is: $\mathrm{g}^{\prime}=8.45 \mathrm{~m} / \mathrm{s}^{2}$. Therefore, when $\mathrm{h}$ increases, $\mathrm{g}^{\prime}$ decreases and the weight because the weight is proportional to the gravity $\mathrm{F}_{\mathrm{g}}{ }^{\prime}=\mathrm{W}^{\prime}=\mathrm{mg}^{\prime}$. Then, there is a lower gravitational pull, weight or gravitational force when the altitude increases.

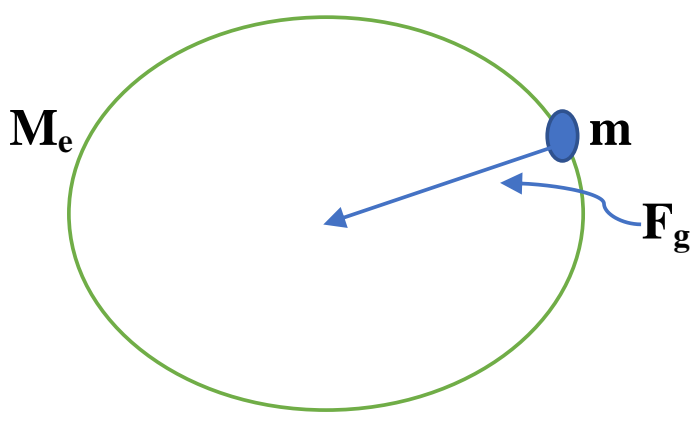

Fig.32. A particle on the Earth Surface with the gravitational attraction to the center of the Earth due the gravitational force

Besides, the gravity changes depending of the depth of the particle $m$ inside of the Earth Planet ${ }^{2,3}$. If it could be possible to enter to the depth inside of the Earth Planet, the gravity decreases until the gravity is zero at the center of the Earth ${ }^{2,3}$. It is evident that there is no more gravitational force at the center of the Earth and there is no more gravitational attraction due the particle is already at the center of the Earth. Then, the value of the gravity is zero: $\mathrm{g}=0 \mathrm{~m} / \mathrm{s}^{2}$ at the center of the Earth ${ }^{2,3,6}$.

The next formula is obtained for $\mathrm{h}<<\mathrm{R}_{\mathrm{e}}$ :

$g^{\prime}=G \frac{M_{e}}{\left(R_{e}+h\right)^{2}} \quad g^{\prime}=G \frac{M_{e}}{R_{e}^{2}\left(1+\frac{h}{R_{e}}\right)^{2}}$

If $\mathrm{h}<<\mathrm{R}_{\mathrm{e}}$ and by applying binomial expansion, then the formula of the gravity is: $\mathrm{g}^{\prime}=\mathrm{G} \frac{\mathrm{M}_{\mathrm{e}}}{\mathrm{R}_{\mathrm{e}}{ }^{2}}\left(1-2 \frac{\mathrm{h}}{\mathrm{R}_{\mathrm{e}}}\right)$ where the other terms are neglected. 
$g^{\prime}=g\left(1-2 \frac{h}{R_{e}}\right)$ for $h<<R_{e}$ and $g=G \frac{M_{e}}{\left(R_{e}\right)^{2}}$

The graph of the gravity $g^{\prime}$ versus the altitude $\mathrm{h}$ is as follows:

$g^{\prime}=G \frac{M_{e}}{\left(R_{e}+h\right)^{2}} \quad g^{\prime}=\frac{3.9 * 10^{14}}{\left(6.38 * 10^{6}+h\right)^{2}}$

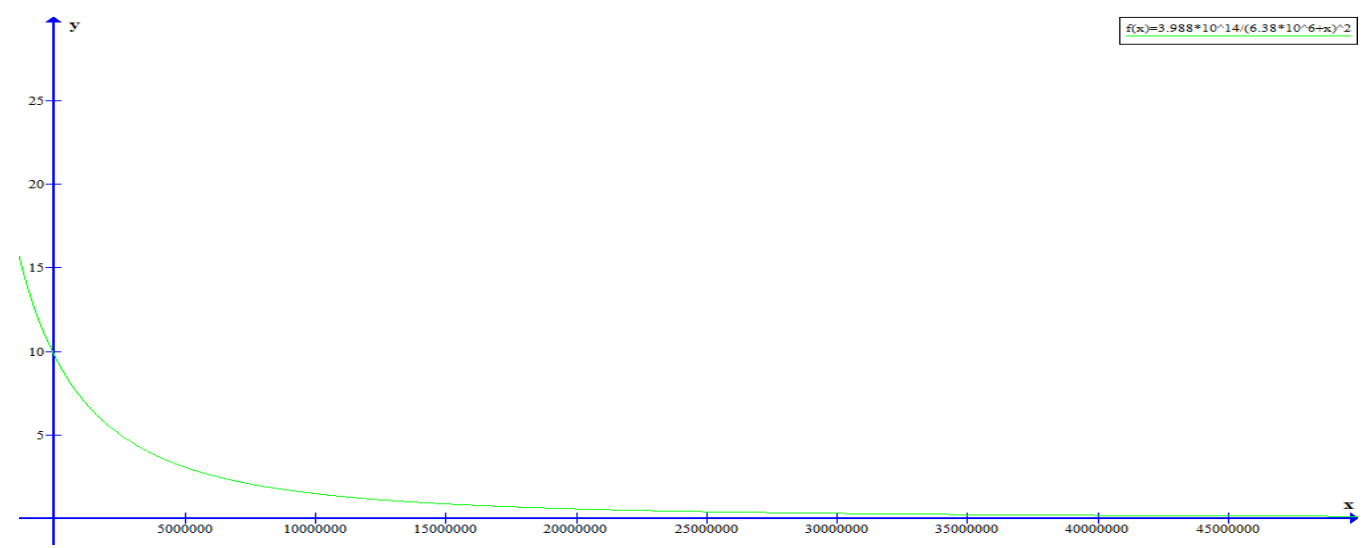

Fig.33. The gravity g' versus the altitude $h$ above sea level

Regarding Football, the trajectory of the ball in an air pass, Goalkeeper kick and direct free kick is parabolic. Furthermore, the ball will go farther, more forward with less rotation and with more velocity at a city with an altitude above sea level than at sea level. It is due the lower gravitational pull to attract the ball to the ground in the city with high altitude above sea level ${ }^{6,7,8}$. Moreover, in a direct free kick, the ball does not take the desired spin and the ball moves more sideways or lateral and with less rotation: "the ball does not bend". This can be a problem for goalkeepers when trying to catch the ball and at the same time an advantage for the home team that is already used to these effects of gravitational variations ${ }^{6,7,8}$.

For other hand, the decrease of the gravity respect to the altitude above sea level is advantageous for moving, lifting and throwing objects. The combined effect of the decrease in the force of gravity and the decrease in the density of the air in a place or city with high altitude, allows to improve the performance in the height, length and pole jumps by several centimeters and the discus and javelin throws by several decimeters but as long as the respective acclimatization has been done and the hypoxia does not affect the organism.

\section{Effect of the Gravity in Football players and astronauts}

The gravity acceleration $g$ and the gravitational force or weight decrease when the altitude increases ${ }^{2,3,6}$ as it was mentioned before. For example, when $\mathrm{h}=3650 \mathrm{~m}$ (La Paz, Bolivia), the gravity acceleration is: $\mathrm{g}^{\prime}=9.81 \mathrm{~m} / \mathrm{s}^{2}$.

$\mathrm{F}_{\mathrm{g}}=\mathrm{W}=\mathrm{mg}$ at the sea level and $\mathrm{F}_{\mathrm{g}}{ }^{\prime}=\mathrm{W}^{\prime}=\mathrm{mg}^{\prime}$ at the altitude $\mathrm{h}$ above sea level

$\frac{\Delta \mathrm{W}}{\mathrm{W}^{\prime}}=\frac{\mathrm{m}\left(\mathrm{g}-\mathrm{g}^{\prime}\right)}{\mathrm{mg}}=\frac{0.01}{9.82}=0.0010$

Therefore, the weight of the ball, person or object is reduced a percent of $0.1 \%$ at an altitude of $3650 \mathrm{~m}$ above sea level.

Other example is when $\mathrm{h}=500 \mathrm{~km}$, the gravity acceleration is: $\mathrm{g}^{\prime}=8.45 \mathrm{~m} / \mathrm{s}^{2}$. 
$\frac{\Delta \mathrm{W}}{\mathrm{W}^{\prime}}=\frac{\mathrm{m}\left(\mathrm{g}-\mathrm{g}^{\prime}\right)}{\mathrm{mg}}=\frac{1.34}{9.82}=0.14$

Therefore, the weight of the ball, person or object is reduced a percent of $14 \%$ at an altitude of $500 \mathrm{~km}$ above sea level.

On our planet Earth, the gravity provides the force that makes our muscles and bones develop the resistance necessary to function properly on the planet ${ }^{2,3}$. Thus, the muscles and bones must be strong enough to allow walking, running, lifting objects for example, where nutrition, food and exercising the muscles help in the ability for the muscles and bones to function properly under the action of the gravity ${ }^{2,3}$. If gravity decreases too much, then the muscles and bones atrophy because the body doesn't feel they are needed. Thus, the muscles lose a little mass if gravity decreases enough. For example, if gravity is zero, muscle mass could decrease by as much as $5 \%$ each week and bones could lose bone at the rate of $1 \%$ per month. The total bone loss could go up to $40-60 \%^{2,3}$. In addition, if gravity decreases, the circulatory system is also affected. In the Earth, gravity causes blood to stagnate at our feet. When the human being is standing, the blood pressure in our feet which is about $20 \mathrm{~cm} \mathrm{Hg}$, is much higher than in the head which is about 6-8 $\mathrm{cm} \mathrm{Hg}$. This difference of the blood pressure is due the gradient or difference in gravity between both parts of the body ${ }^{2,3}$.

If gravity is zero, there is no difference in gravity or gradient and blood pressure balances throughout the body around $10 \mathrm{~cm} \mathrm{Hg}$. Thus, fluid flows from the legs to the head, the face looks flushed, and the legs become thin due to zero gravity for example. The result of this is that the abnormally high blood pressure in the head $(10 \mathrm{~cm} \mathrm{Hg})$ makes the brain believes that there is too much blood in the body and thus, a decrease in the respective blood production is ordered ${ }^{2,3}$. This is possible to lose about $22 \%$ of the blood due the uniform blood pressure in zero gravity. For other hand, when blood pressure is balanced, the heart does not work as much and the heart muscles could atrophy ${ }^{2,3}$.

This is what astronauts experience in space. Astronauts spend weeks and months in spacecraft and space stations orbiting the Earth. Although the gravitational force of the Earth acts on the spacecraft, astronauts experience long periods of zero gravity due the centripetal motion: the spacecraft and the astronaut experience the same gravitational force of the Earth and thus the astronaut inside the spacecraft would experience a weight of zero. It is similar to the situation of the person who falls into an elevator under the action of the Earth's gravity ${ }^{2,3}$ : if there is a scale under the person in free fall with the elevator, the scale does not feel the weight and pressure of the person and this will mark a weight of $\mathrm{W}=0 \mathrm{~N}$.

Besides, when a spacecraft takes off, astronauts experience an acceleration of various gravities (3g) higher than the Earth's gravity ${ }^{2,3}$. When the person is subjected to various gravities vertically, the blood can pool in the lower extremities and this can cause the blood vessels to distend or the capillaries to burst. In these conditions, the heart has trouble pumping blood throughout the body. With a force of about $4 \mathrm{~g}$, the pool of blood in the lower body deprives the head of enough oxygen. Lack of blood circulation to the eyes can cause temporary blindness, and if oxygen is lacking in the brain, the person feels disoriented and eventually loses consciousness. An ordinary person 
can only withstand various gravities for a short period. However, astronauts wear $\mathrm{g}$ suits designed to prevent blood stagnation. This is also experienced on a roller coaster when climbing after a steep descent ${ }^{2,3}$.

Because of all this, astronauts undergo rigorous physical conditioning programs before traveling into space. When they return to planet Earth, the astronauts' bodies (muscles, bones and circulatory system) have to adjust and adapt again to the environment of Earth's gravity. Body recovery takes a different time depending on the respective atrophied system. For example, blood volume is restored within a few days if astronauts drink a lot of fluids. Muscles regenerate for about a month, depending on the astronaut's duration in space in zero gravity. Bone recovery usually takes longer than muscle recovery. For example, if an astronaut spends between three and six months in space, it could take two to three years to recover the lost bone. In addition, nutrition, food and exercise are essential for the recovery process ${ }^{2,3}$. Moreover, there are various devices that simulate approximately zero gravity (artificial gravity) so that astronauts can exercise and experiment the conditions in space. For example, there is the application of negative pressure to the lower part of the body to restore a gradient or difference in pressure in the body similar to that of space. In addition, there are devices with centrifuges to create an environment of gravity similar to that of space $^{2,3}$.

Space probes and unmanned spacecraft have visited Mars to one day send astronauts there. This implies a trip of around six months in zero gravity and later a stay on Mars where gravity is around 38\% of Earth's gravity ${ }^{2,3}$.

The value of gravity on Mars is $3.71 \mathrm{~m} / \mathrm{s}^{2}$ :

$\mathrm{g}^{\prime}=(3.71 / 9.8) * 100=38 \%$.

Then, the Martian gravity is $38 \%$ of the terrestrial gravity approximately.

Therefore, the weight of the ball, person or object is decreased because the weight is proportional to the gravity $\mathrm{F}_{\mathrm{g}}{ }^{\prime}=\mathrm{W}^{\prime}=\mathrm{mg}^{\prime}$.

$\mathrm{F}_{\mathrm{g}}=\mathrm{W}=\mathrm{mg}$ in the Earth $\quad \mathrm{F}_{\mathrm{g}}{ }^{\prime}=\mathrm{W}^{\prime}=\mathrm{mg}^{\prime}$ in Mars

$\frac{\Delta \mathrm{W}}{\mathrm{W}^{\prime}}=\frac{\mathrm{m}\left(\mathrm{g}-\mathrm{g}^{\prime}\right)}{\mathrm{mg}}=0.62$

The weight of the ball, person or object in Mars is reduced a percent of $62 \%$ respect to the weight of the person in the Earth. Obviously, this would have effects in the astronaut's body as it was mentioned before and hence the need to train astronauts in extreme conditions and in reduced gravity ${ }^{2,3}$.

5. Effects of the atmospheric pressure on the Football ball and players due the altitude of the city above sea level where the match takes place: "The ball doesn't bend"

The atmospheric pressure also affects the movement of a Football ball ${ }^{6,7,8}$. Therefore, it is important to consider the atmospheric pressures around the ball. The change in the atmospheric pressure have effect in the friction of the ball with the air which has effect in the spin of the ball. Therefore, the effects of the friction of the ball with the air (air resistance to the ball) and the ball spin depends of the value of the atmospheric pressure which depends of the 
altitude of the city above sea level. For example, these effects occur in "high altitude" cities, such as La Paz, Bolivia. Due to these effects on the ball, it is said for example that "the ball does not bend" $6,7,8$.

From the view point of Physics, the atmospheric pressure is not the same for a city at sea level that in a city at a high altitude above sea level ${ }^{2,3}$. The air mass at sea level can be located in a more compact volume or zone with less volume $\mathrm{V}_{\mathrm{o}}<\mathrm{V}$ where $\mathrm{V}_{\mathrm{o}}$ is the air volume at sea level and $\mathrm{V}$ is the air volume in a city with high attitude above sea level ${ }^{2,3}$. The formula of density is: $\rho=\frac{\mathrm{m}}{\mathrm{V}}, \mathrm{V}_{\mathrm{o}}<\mathrm{V}, \rho<\rho_{\mathrm{o}}$ where $\rho_{\mathrm{o}}$ is the air density at sea level and $\rho$ is the air density in a city with high altitude above sea level. In conclusion, the air is less dense in a place or city with high altitude above sea level than in a place at sea level ${ }^{2,3}$

Besides, the air mass at sea level can be located in a more compact cross section area with less area $A_{o}<A$ where $A_{o}$ is the air cross section area at sea level and $\mathrm{A}$ is the air cross section area in a city with high attitude above sea level. The formula of pressure is $\mathrm{P}=\frac{\mathrm{F}}{\mathrm{A}}, \mathrm{A}_{\mathrm{o}}<\mathrm{A}, \quad \mathrm{P}<\mathrm{P}_{\mathrm{o}}$ where $\mathrm{P}_{\mathrm{o}}$ is the atmospheric pressure at sea level and $\mathrm{P}$ is the atmospheric pressure in a city with high altitude above sea level ${ }^{2,3}$. Therefore, the air pressure is lower in cities that are higher above sea level ${ }^{2,3}$.

It is possible to obtain a relation between the density and the pressure:

$\rho=\frac{\mathrm{m}}{\mathrm{V}}=\frac{\mathrm{mg}}{\text { Ahg }}=\frac{\mathrm{F}_{\mathrm{g}}}{\text { Ahg }}=\frac{\mathrm{P}}{\mathrm{hg}}=\mathrm{kP}$ where $\mathrm{F}_{\mathrm{g}}$ is the gravitational force or weight $\mathrm{W}$ of the air, $\mathrm{P}=\frac{\mathrm{F}_{\mathrm{g}}}{\mathrm{A}}$ the atmospheric pressure and $\frac{1}{\mathrm{hg}}$ is a constant, g: gravity and $\mathrm{h}$ : height of the mass air which is in a air volume $\mathrm{V}$.

Then, $\rho=\mathrm{kP}$ where $\mathrm{k}$ is a proportionality constant.

Therefore, the density $\rho$ is proportional to the atmospheric pressure $\mathrm{P}$ :

$\rho \propto \mathrm{P} \rho=\mathrm{kP}$. Then, the lower the air density: $\rho<\rho_{0}$, the lower the atmospheric pressure: $\mathrm{P}<\mathrm{P}_{\mathrm{o}}$. Thus, when the altitude increases respect to the sea level, then the air density decreases (the air is less dense) and also the atmospheric pressure decreases because they are reciprocally proportional ${ }^{2,3}$.

For example, at sea level $(\mathrm{y}=0 \mathrm{~m})$ the air pressure is about $101.3 \mathrm{kPa}(1 \mathrm{~atm}$ or $76 \mathrm{~cm} \mathrm{Hg}$ ) and at an altitude of 8848 $\mathrm{m}(\mathrm{y}=8848 \mathrm{~m})$ which is the altitude of the Mount Everest, it decreases to $34 \mathrm{kPa}$. The formula that relates the atmospheric pressure and the altitude is obtained as follows. It is considered a cubic volume of air of height h:

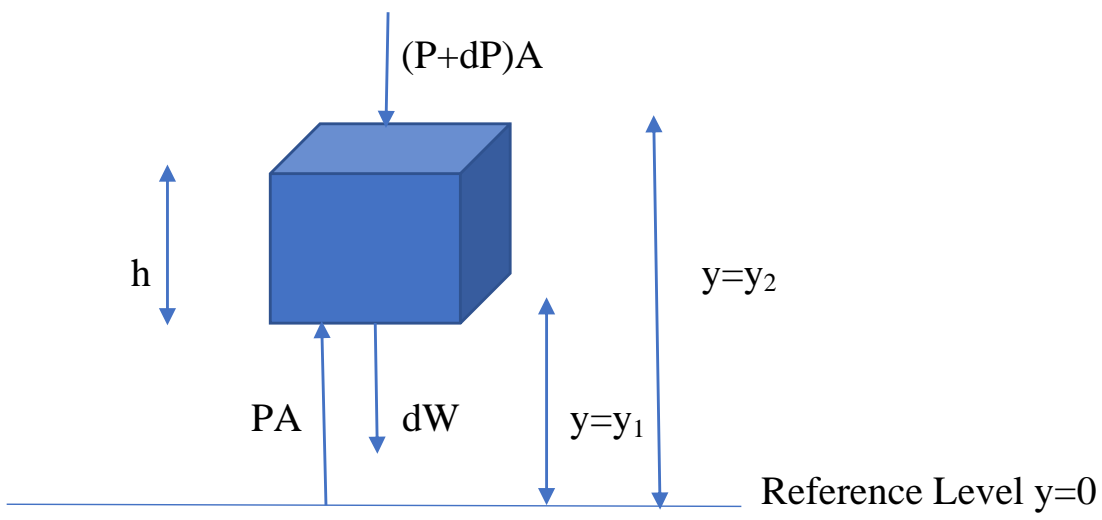

Fig.34. Cubic volume of air of height $h$ 
A: cross-sectional area of the air cube, $\mathrm{PA}$ : force on the bottom surface of the cube, $(\mathrm{P}+\mathrm{dP}) \mathrm{A}$ : force on the top surface of the cube, $d W$ : weight of the air cube: $d W=g d m=g \rho d V=g \rho A d y, d y$ : differential height of the air cube

$\mathrm{PA}-(\mathrm{P}+\mathrm{dP}) \mathrm{A}-\rho \mathrm{g} A d y=0 \quad \mathrm{P}-\mathrm{P}-\mathrm{dP}-\rho g d y=0$

$\mathrm{dP}=-$ ggdy $\quad \rho=\mathrm{kP} \quad \mathrm{dP}=-\mathrm{kPgdy}$

$\int_{\mathrm{P}_{\mathrm{o}}}^{\mathrm{P}} \frac{\mathrm{dP}}{\mathrm{P}}=\int_{0}^{\mathrm{y}}-\mathrm{kgdy} \quad \ln \left(\frac{\mathrm{P}}{\mathrm{P}_{\mathrm{o}}}\right)=-\mathrm{kgy}$

$\mathrm{P}=\mathrm{P}_{\mathrm{o}} \mathrm{e}^{-\mathrm{kgy}} \quad \mathrm{y}=0 \quad \mathrm{P}=\mathrm{P}_{\mathrm{o}} \quad \rho=\rho_{\mathrm{o}} \quad \rho=\mathrm{kP} \quad \mathrm{k}=\frac{\rho_{\mathrm{o}}}{\mathrm{P}_{\mathrm{o}}}$

$\mathrm{P}=\mathrm{P}_{\mathrm{o}} \mathrm{e}^{-\frac{\rho_{\mathrm{og}} \mathrm{g}}{\mathrm{P}_{\mathrm{o}}}}$ which is the formula of the relation between the atmospheric pressure $\mathrm{P}$ versus the altitude $\mathrm{y}$ where $\mathrm{P}_{\mathrm{o}}$ is the atmospheric pressure at sea level, $\rho_{\mathrm{o}}$ is the density at sea level and $\mathrm{g}$ is the gravity.

When $y=0 \quad P=P_{0} \rho=\rho_{0}$, and when y increases respect to the sea level, then the atmospheric pressure and the air density $(\rho=k P)$ decrease. Besides, it is obtained: $\quad \mathrm{y}->\infty \quad P->0$

The value of the constant $\mathrm{k}: \mathrm{P}=\mathrm{P}_{\mathrm{o}} \mathrm{e}^{-\mathrm{kgy}}$ is possible to obtain with reference values for the altitude and the atmospheric pressure.

$\mathrm{y}=0$ sea level $\mathrm{P}=101.3 \mathrm{kPa} \quad \mathrm{P}=\mathrm{P}_{\mathrm{o}}=101.3 \mathrm{kPa}(1 \mathrm{~atm}$ or $76 \mathrm{~cm} \mathrm{Hg})$

$\mathrm{y}=8848 \mathrm{~m}$ (Mount Everest altitude) $\mathrm{P}=34 \mathrm{kPa}$

$\mathrm{P}=\mathrm{P}_{\mathrm{o}} \mathrm{e}^{-\mathrm{kgy}} \quad \ln \left(\frac{\mathrm{P}}{\mathrm{P}_{\mathrm{o}}}\right)=-\mathrm{kgy}$

$k=-\frac{\ln \left(\frac{34}{101.3}\right)}{(9.8)(8848)}$

$\mathrm{k}=1.259 * 10^{-5} \mathrm{~kg} \quad \mathrm{gk}=0.000123387$

$\mathrm{P}=(101.3) \mathrm{e}^{-0.000123387 \mathrm{y}}(\mathrm{kPa})$

The graph of the atmospheric pressure versus the altitude is as follows:

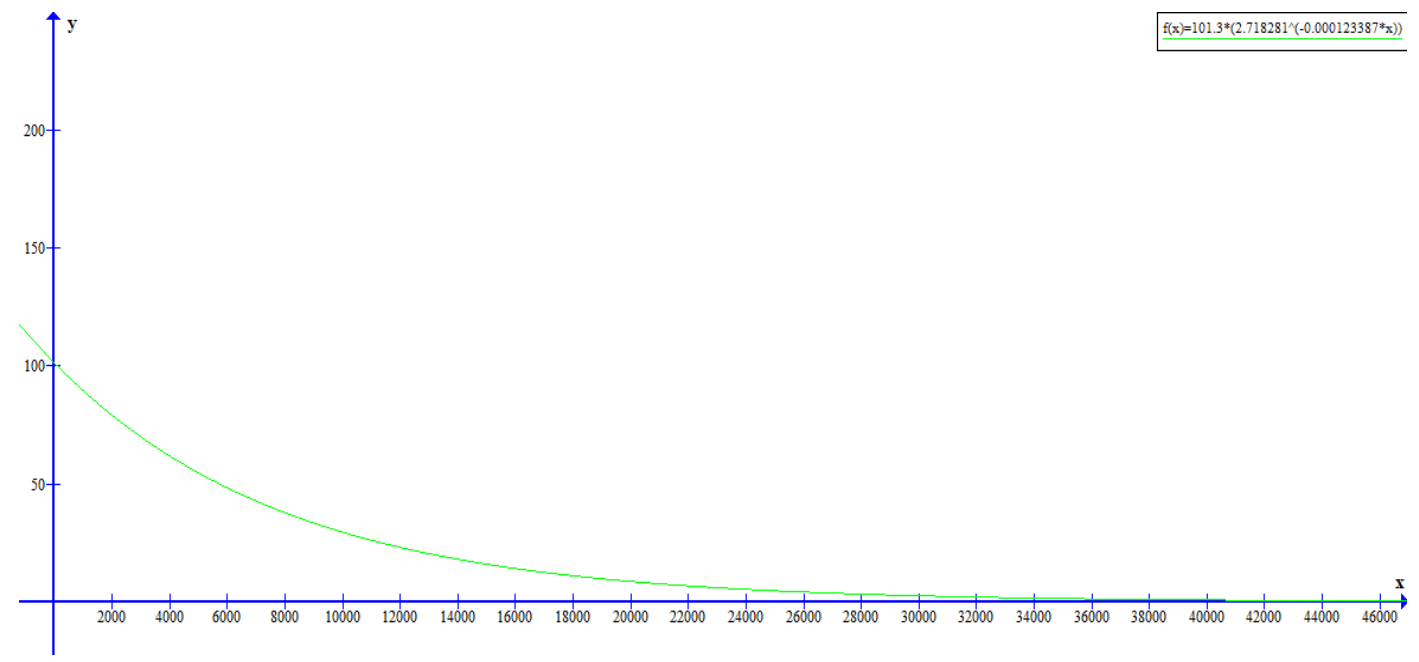

Fig.35. Graph of the atmospheric pressure versus the altitude 
The formula of the relation between the density versus the altitude y above sea level is: $\rho=k P \quad k=\frac{\rho_{0}}{P_{o}} \quad \rho=\frac{\rho_{0}}{P_{o}} P$ $\mathrm{P}=\mathrm{P}_{\mathrm{o}} \mathrm{e}^{-\frac{\rho_{\mathrm{ogy}}}{\mathrm{P}_{\mathrm{o}}}}$

$\rho=\rho_{\mathrm{o}} \mathrm{e}^{-\frac{\rho_{\mathrm{ogy}}}{\mathrm{P}_{\mathrm{o}}}} \quad \rho=\rho_{\mathrm{o}} \mathrm{e}^{-\mathrm{kgy}}$

Where, $\rho_{\mathrm{o}}$ is the density at sea level, $\mathrm{P}_{\mathrm{o}}$ is the atmospheric pressure at sea level and $\mathrm{g}$ is the gravity.

The value of the constant $\mathrm{k}$ is the same constant $\mathrm{k}$ obtained for the atmospheric pressure. It is also possible to obtain with reference values for the altitude and the density.

$\mathrm{y}=0$ sea level $\quad \rho=\rho_{\mathrm{o}}=1.29 \mathrm{~kg} / \mathrm{m}^{3}$

$\mathrm{y}=8848 \mathrm{~m}$ (Mount Everest altitude) $\rho=0.426 \mathrm{~kg} / \mathrm{m}^{3}$

$\rho=\rho_{\mathrm{o}} \mathrm{e}^{-\mathrm{kgy}} \quad \ln \left(\frac{\rho}{\rho_{\mathrm{o}}}\right)=-\mathrm{kgy}$

$\mathrm{k}=-\frac{\ln \left(\frac{0.426}{1.29}\right)}{(9.8)(8848)}$

$\mathrm{k}=1.277 * 10^{-5} \mathrm{~kg} \quad \mathrm{gk}=0.000125$

$\rho=(1.29) \mathrm{e}^{-0.000125 \mathrm{y}}$

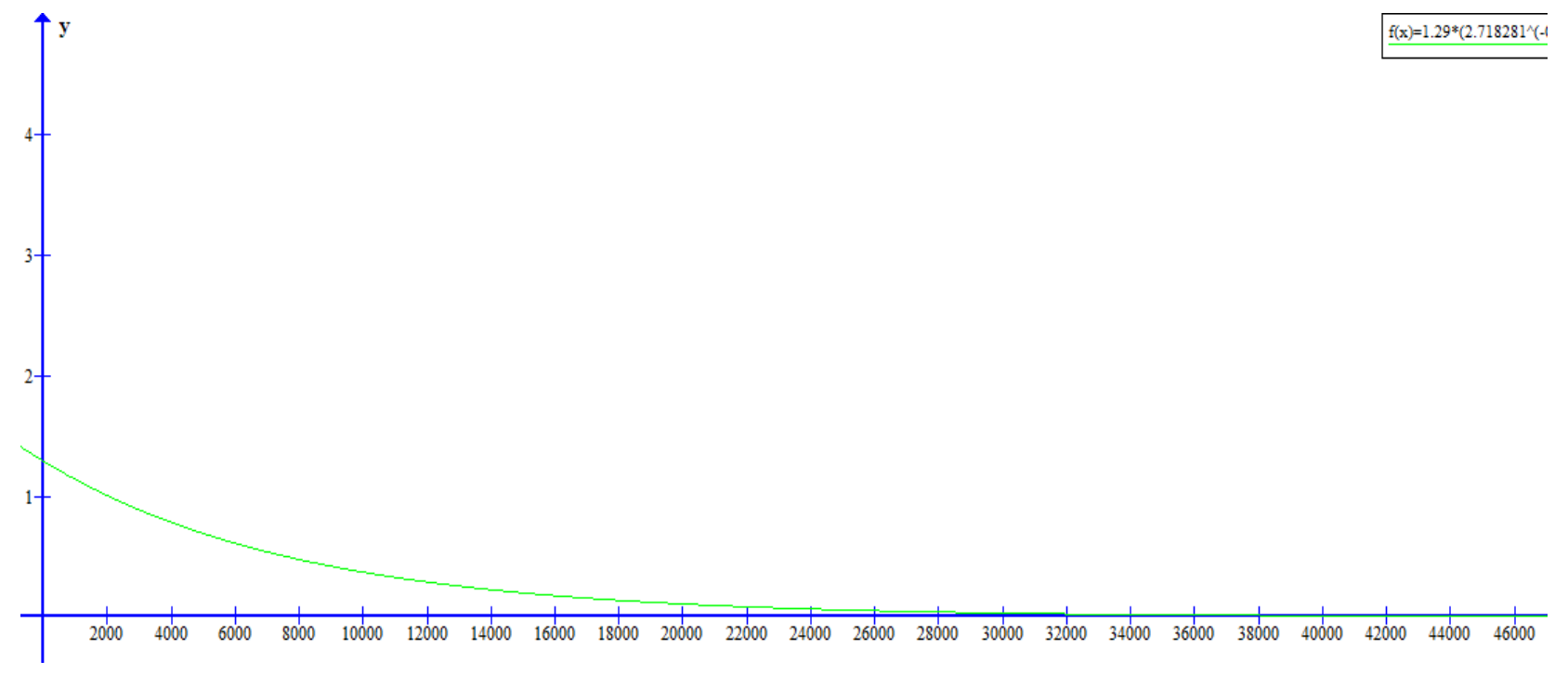

Fig.36. Graph of the density versus the altitude

Some values of the atmospheric pressure and density are:

$\mathrm{P}=(101.3) \mathrm{e}^{-0.000123387 \mathrm{y}}(\mathrm{kPa}) \quad \rho=(1.29) \mathrm{e}^{-0.000125 \mathrm{y}}$

$\mathrm{y}=0$ (sea level): $\quad \mathrm{P}=101.3 \mathrm{kPa} \quad \rho=1.29 \mathrm{~kg} / \mathrm{m}^{3}$

$\mathrm{y}=3650 \mathrm{~m}$ (La Paz, Bolivia): $\quad \mathrm{P}=64.57 \mathrm{kPa} \quad \rho=0.817 \mathrm{~kg} / \mathrm{m}^{3}$

$\mathrm{y}=4000 \mathrm{~m}: \quad \mathrm{P}=61.84 \mathrm{kPa} \quad \rho=0.782 \mathrm{~kg} / \mathrm{m}^{3}$

$y=8848 \mathrm{~m}$ (Mount Everest altitude): $\mathrm{P}=34 \mathrm{kPa} \quad \rho=0.426 \mathrm{~kg} / \mathrm{m}^{3}$ 
The values corroborate that when y increases respect to the sea level, then the atmospheric pressure and the density decrease. The atmospheric pressure decreases proportionally to height at a rate of $1 \mathrm{mmHg}$ or $0,1 \mathrm{kPa}$ for every 10 meters of ascent approximately, but the chemical composition of the air remains the same as at sea level. The atmospheric pressure is the pressure exerted on our heads by the column of air that we have on the planet. The atmospheric pressure decreases with the altitude and, consequently, the pressure of all gases (nitrogen, oxygen, etc.). In the first 100 kilometers of atmosphere, the oxygen concentration (in percentage relative to the other gases: $21 \%$ oxygen, along with $78 \%$ nitrogen and $1 \%$ other gases) does not decreases and remains stable but, the number of oxygen molecules in the air that is breathed decreases with the altitude. Thus, the oxygen concentration in the air is also $21 \%$ in the mount Everest which has $8.8 \mathrm{Km}$ of altitude. After $100 \mathrm{~km}$, the oxygen concentration starts to vary with the altitude.

Therefore, the atmospheric pressure decreases as we gain height: the higher the height, the lower the atmospheric pressure, the lower the number of air particles (less weight of the air column) and lower number of oxygen molecules in the air that is breathed but the oxygen concentration in the air remains stable up to $100 \mathrm{~km}$ approximately.

For example, if it is filled a box with air in the beach at sea level where the atmospheric pressure is $101.3 \mathrm{kPa} \approx 100$ $\mathrm{kPa}$, it will contain $21 \%$ oxygen, with a maximum atmospheric pressure $(101,3 \mathrm{kPa})$ and $100 \%$ of air molecules (oxygen included). If it is filled the same box with air at the top of Everest $(8848 \mathrm{~m}$ ) where the atmospheric pressure is $34 \mathrm{kPa}$, it will still have the same concentration of $21 \%$ oxygen compared to other gases in a relative or partial way. However, the amount of air molecules and oxygen molecules will be reduced to $34 \%$ approximately at the top of the Everest with respect to the $100 \%$ of air molecules at sea level due to the lower atmospheric pressure. The reason is that by decreasing the atmospheric pressure in the altitude, the air molecules separate and escape from the box, having a smaller quantity of molecules for the same volume.

In resume, there is the same $21 \%$ concentration of oxygen in the air relative to the other gases at sea level and the mount Everest but, the number of oxygen molecules decreases in $34 \%$ in the mount Everest. The result of reducing the number of oxygen molecules by $34 \%$ in the mount Everest $(\mathrm{P}=34 \mathrm{kPa})$ produces a partial pressure of oxygen $\left(\mathrm{pO}_{2}\right)$ in the lungs of: $21 \% * 34 \mathrm{kPa} / 100=7,1 \mathrm{kPa}$ or $5,36 \mathrm{~cm} \mathrm{Hg}$. At sea level, the partial pressure of oxygen in the lungs is: $21 \% * 101,3 \mathrm{kPa} / 100=21,3 \mathrm{kPa}$ or $15,96 \mathrm{~cm}$. Hg.

Regarding Football, there is less atmospheric pressure and the air is less dense when the match is played in a city with high altitude. Thus, there is less air resistance on the ball, the friction of the air on the ball is lower and the ball does not spin as much: "the ball does not bend" ${ }^{6,7,8}$.

Other situation that occur is for example in an Goalkeeper kick, Free kick or air pass: the ball in a city with high altitude above sea level would go further than in the plain or at sea level, because the ball does not spin as much due the less friction of the air with the ball which is due the lower air resistance, lower air density and lower atmospheric pressure ${ }^{6,7,8}$. In a Direct free kick, the ball does not take the desired spin (rotation) and the ball moves more sideways or lateral or with less rotation: "the ball does not bend". Due it, the ball acquires more velocity 
because it moves more forward with less rotation. This can be a problem for goalkeepers when trying to catch the ball and at the same time an advantage for the home team that is already used to these effects ${ }^{6,7,8}$.

\section{Effect of the Atmospheric pressure in Football players}

Because air is compressible, the density and atmospheric pressure are higher on the earth's surface or at sea level and decrease with altitude as it was mentioned before. The external pressure of the atmosphere is very important for the normal functioning of the organism. Thus, the pressurized suits astronauts wear in space or on the moon are needed to supply oxygen and create an external pressure similar to that found on the Earth's surface ${ }^{2,3}$. The variations in the atmospheric pressure can cause pressure changes in the ears as altitude changes, which can lead to possible earache. For example, the ears are covered and uncovered when ascending or descending in mountains or when traveling by plane when the plane increases or decreases in altitude ${ }^{2,3}$.

When climbing a mountain, the air pressure outside the ear may be lower than in the middle ear. The pressure difference pushes the eardrum out. If this pressure is not relieved, it is possible to feel a severe earache ${ }^{2,3}$. Therefore, the pressure is relieved by pushing air through the Eustachian tube into the throat which is when the ears are felt to pop. Therefore, the pressure can be relieved by yawning or swallowing ${ }^{2,3}$. In the opposite case, when descending a mountain, the external pressure increases and the lower pressure in the middle ear must equalize it to avoid earache $e^{2,3}$.

Regarding Football, the lower atmospheric pressure in cities that are higher above sea level also affects players such as decrease in the physical performance, extreme tiredness, dizziness, headache, nausea, earache, changes of the blood pressure, possible tachycardia, possible pulmonary edema in the most severe cases, and no normal breathing or hypoxia which is a decrease in the oxygen content of air that is breathed ${ }^{2,3}$.

Furthermore, the human body is made up largely of fluids, which exert an outward pressure ${ }^{2,3}$. Because the external atmospheric pressure decreases when the height of the city or place increases, the blood pressure of the organism (which depends of this external atmospheric pressure) can change with the atmospheric conditions and height of the city or place. Therefore, in Football, it is important to measure the blood pressure of the players when they plays a match in a high altitude city or place ${ }^{6,7,8}$.

For other hand, the decrease of the air density respect to the altitude above sea level facilitates respiratory mechanics because it reduces the work of the respiratory muscles to overcome the resistance of the airways. It also favors the movement, lifting and launching of objects but as long as the respective acclimatization has been done and the hypoxia does not affect the organism.

In the hypoxia, the chemical composition of the air that is breathed remains the same as at sea level (21\% of oxygen in the air) and thus, the percentage of oxygen in the inspired air does not decrease, but the partial pressure of the gases that comprise the air decreases and this results in a reduction in the number of oxygen molecules in the air that is breathed, the oxygen saturation in the blood decreases, affecting the gas exchange between the environment and the lungs, between the lungs and the blood, and between the blood and the cells, providing a smaller supply of oxygen molecules to the tissues, and in particular skeletal muscle. Then, the decrease in pressure 
produces that there is less oxygen in the air that is breathed. This effect is known as "percent effective oxygen". At sea level, the partial pressure of oxygen in the lungs is $21,3 \mathrm{kPa}$ or 15,96 $\mathrm{cm}$. $\mathrm{Hg}$. At the Everest Mountain where the atmospheric pressure is $\mathrm{P}=34 \mathrm{kPa}$, the partial pressure of oxygen in the lungs is $7,1 \mathrm{kPa}$ or $5,36 \mathrm{~cm} \mathrm{Hg}$. At the top of Everest, it is breathed the same concentration of air as at sea level, but the amount of oxygen molecules is lower due the reduction in atmospheric pressure. Consequently, although the same volume of air penetrates the lungs as at sea level, when the partial pressure of the air is reduced, the oxygen saturation in the blood decreases, so the supply of oxygen to the tissues is compromised affecting the gas exchange between the environment and the lungs. Then, the Football players begin to feel the dreaded symptoms of altitude sickness. Fortunately, the human body has an oxygen-transporting protein, hemoglobin $(\mathrm{Hb})$, that despite such large differences in oxygen pressure in the lungs, $\mathrm{Hb}$ saturation barely decreases by $10 \%$. For saturation of $\mathrm{Hb}$ to be $100 \%$, it is required to breathe pure oxygen or air in a hyperbaric chamber at approximately 2 atmospheres of pressure.

Besides, the atmospheric and physics conditions of the high altitude affects performance in exercises lasting more than 4 or 5 minutes. In the first hours of staying in the altitude, the body starts up mechanisms that seek to compensate for the adverse effects of hypoxia, which are known as the accommodation process. The organic and functional changes observed during the stay of a few weeks are called acclimatization. Both conditions are reversible when descending from altitude and settling back in the lowlands. Thus, there are players who get very tired faster within the 90 minutes of a Football game. There are teams that do not like to play in cities at high altitude and have even made the request not to play under these conditions, although this has not been accepted ${ }^{6,7,8}$. Then, some teams do a process of accommodation or acclimatization before the match.

Therefore, since performance is reduced for an athlete at height, training at height has been massively disseminated in order to improve the performance capacity of athletes.

\section{Effects of the velocity, air viscosity (Bernoulli Effect) and turbulence (Magnus Effect) on the Football ball}

The Bernoulli effect occurs when the roofs of buildings are detached by strong winds, hurricanes or tornadoes due to the reduction of atmospheric pressure in the upper part due. The internal air pressure can be significantly higher than the external air pressure which can produce a large net force which causes that the roof of the building is detached. This is similar when there is a sheet of paper on a table and blow over the top of the surface and the paper is lifted. The reason is that air moving rapidly over the upper surface causes a decrease in pressure above the paper and thus, a net upward force is produced ${ }^{2,3}$. It is possible to explain by applying the Bernoulli's equation ${ }^{2,3}$. The Bernoulli's equation is as follows:

$\mathrm{P}_{1}+\frac{1}{2} \rho \mathrm{v}_{1}^{2}+\rho g \mathrm{y}_{1}=\mathrm{P}_{2}+\frac{1}{2} \rho \mathrm{v}_{2}^{2}+\rho g \mathrm{y}_{2}$ where $\mathrm{P}+\frac{1}{2} \rho \mathrm{v}^{2}+\rho g \mathrm{y}=$ constant

If the fluid is at rest, $\left(\mathrm{v}_{1}=\mathrm{v}_{2}=0\right)$, the Bernoulli equation is the pressure-depth equation: $\mathrm{P}_{1}=\mathrm{P}_{2}+\rho g\left(\mathrm{y}_{2}-\mathrm{y}_{1}\right)$ where $\mathrm{P}_{2}$ can be the atmospheric pressure $\mathrm{P}_{2}=\mathrm{P}_{\mathrm{a}} \quad \mathrm{P}_{1}=\mathrm{P}$ and $\mathrm{y}_{2}-\mathrm{y}_{1}=h \quad \mathrm{P}=\mathrm{P}_{\mathrm{a}}+\rho g h$

If the flow is horizontal $\left(\mathrm{y}_{1}=\mathrm{y}_{2}\right)$, then $\mathrm{P}+\frac{1}{2} \rho \mathrm{v}^{2}$ is constant, and so, if velocity increases, then the pressure decreases and, if the velocity decreases, then the pressure increases ${ }^{2,3}$. In the Football ball, the low-velocity side of the ball is 
under higher pressure than the high-velocity side. This causes a net force to act on the ball towards the low pressure side and deflect the ball and thus, its trajectory is curved ${ }^{2,3}$.

Besides, if there are no fluid losses within the Venturi tube, the mass of fluid entering a tube in a given time must equal the mass leaving the tube at the same time due to the conservation of mass. The resulting equation is known as the continuity or flow rate equation for an incompressible fluid (constant density): $\quad \Delta \mathrm{m}_{1}=\Delta \mathrm{m}_{2} \quad$ (mass conservation)

$\rho_{1} \Delta \mathrm{V}_{1}=\rho_{2} \Delta \mathrm{V}_{2} \quad \rho_{1} \mathrm{~A}_{1} \Delta \mathrm{x}_{1}=\rho_{2} \mathrm{~A}_{2} \Delta \mathrm{x}_{2}$

$\rho_{1} A_{1} v_{1} \Delta t=\rho_{2} A_{2} v_{2} \Delta t \quad \rho_{1} A_{1} v_{1}=\rho_{2} A_{2} v_{2} \quad$ or $\rho A v$ is constant

For incompressible fluid, the density is constant: $\rho_{1}=\rho_{2}=\rho$

$\mathrm{A}_{1} \mathrm{v}_{1}=\mathrm{A}_{2} \mathrm{v}_{2} \quad$ or $\quad \mathrm{Av}$ is constant

Therefore, in a region with a smaller cross-sectional area, the flow velocity is higher and by Bernoulli's equation, the pressure in that region is lower than in other regions. In the opposite case, if the region has larger cross-sectional area, the flow velocity is lower and by Bernoulli's equation, the pressure is higher than in other regions ${ }^{2,3}$.

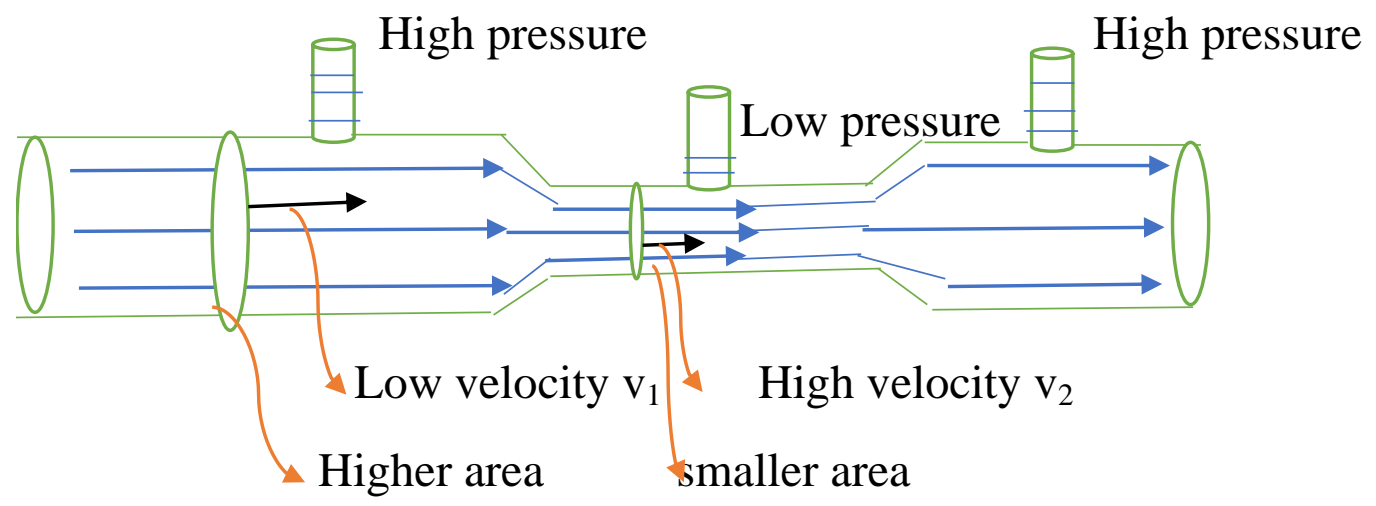

Fig.37. Venturi Tube with a liquid flow showing high and low pressure regions

and high and low velocity regions

Regarding Football, it occurs in some Direct free kicks performed by professional Football players ${ }^{9}$ (as for example Roberto Carlos of the Brasil's selection) when they kick the free kick with a lot of effect, which affects the movement of the ball. In a free kick, the Football player can curve the ball while the ball heading for the goal by giving it the appropriate effect which affects the ball spin. Therefore, this depends of the velocity and the spin of the ball when the player kicks ${ }^{6,7,8}$. This can be explained by means of the Bernoulli equation and the viscosity properties of $\mathrm{air}^{2,3}$.

If the ball is not spinning, the motion of the air current through the ball is roughly a streamline. If the ball is moving from left to right, then from the point of view of the ball, the air is moving from right to left. Behind the ball, it is formed a symmetrical region of turbulence. The flow lines represent the air flow relative to the ball ${ }^{2,3}$. Therefore, 
if air were an ideal fluid, then there is a zero viscosity and there is the same air fluid on both sides and the spin of a thrown ball would not alter the direction or trajectory of motion of the ball ${ }^{2,3}$.

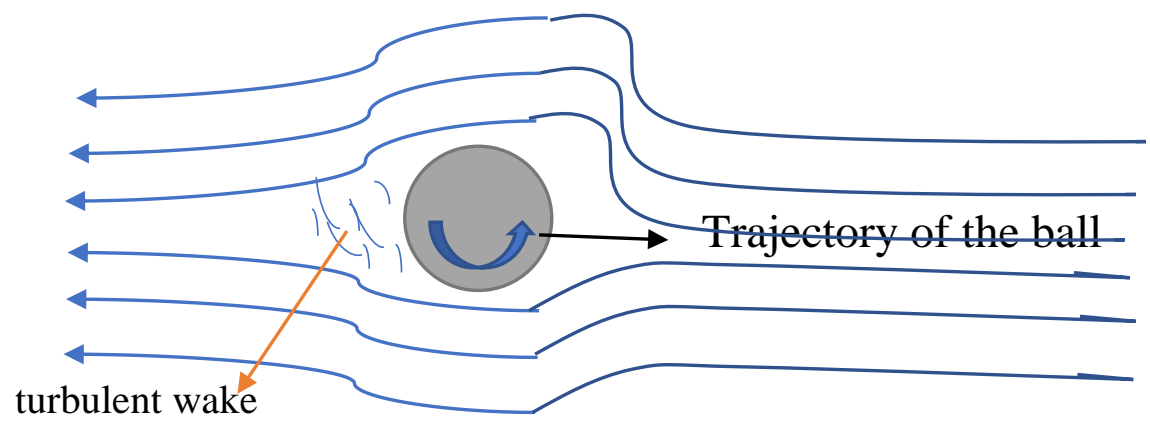

Fig.38. Trajectory of the ball in an ideal air fluid with the air flow through the ball

For other hand, when the ball spins in the counterclockwise direction in a viscous air, the layers of air near the surface of the ball are pulled in the direction of the spin due viscosity. The combined effect of the steady flow with the air entrained by the spinning movement produces the flow lines shown in the figure below and an asymmetric turbulence pattern ${ }^{2,3}$.

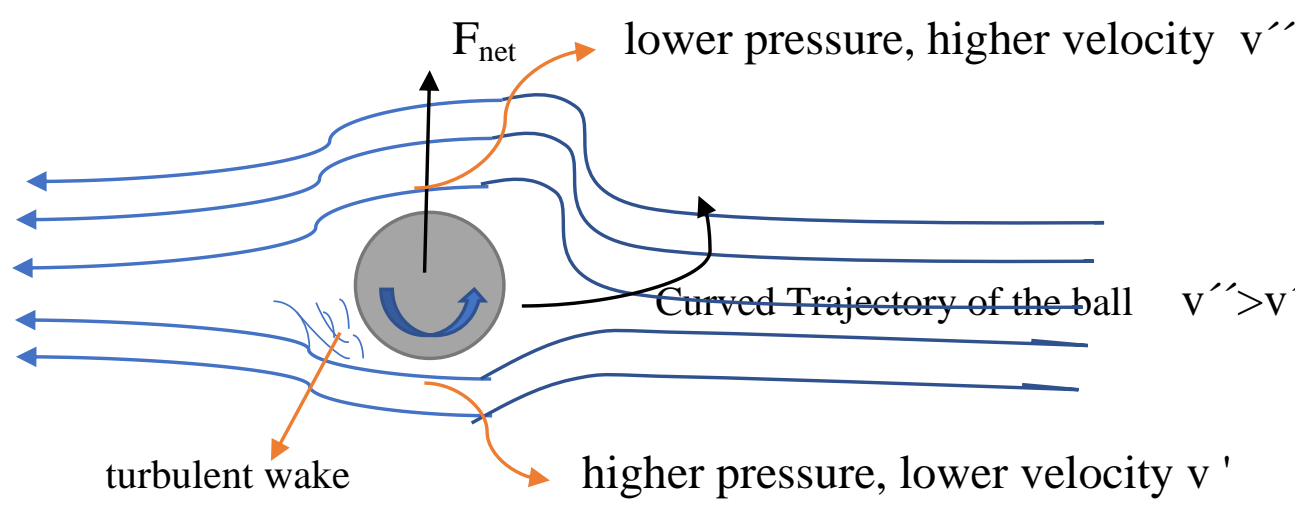

Fig.39. Trajectory of the ball in a viscous air with the air flow through the ball

Because air is viscous, friction between the air and the ball causes the ball to drag a thin boundary layer of air with it as it spins. This makes the velocity of the ball relative to the air much higher on one side than the other because on one side (top of the ball), the velocity of the ball and air have the same direction while on the other side (bottom) they have opposite directions ${ }^{2,3}$. Thus, the velocity of the air at the top of the ball is higher than the velocity at the bottom. Besides, in a viscous air, the faster flow of air on one side of the ball creates a pressure difference. Then, applying Bernoulli's equation, the pressure at the bottom of the ball is higher than that at the top and thus, the pressure difference on the ball produces a lateral deflection force $\mathrm{F}$ toward the region of low pressure which is called lift force ${ }^{2,3}$.

Generally, the curve follows the direction the front of the ball turns. When it is required to kick a ball that curves to one side, the axis of rotation must be vertical (perpendicular to the article page or in the direction of the gravity). If the axis of rotation is vertical and if the ball spins counterclockwise, the ball makes a curve to the left. If the ball rotates clockwise, the ball makes a curve to the right. For other hand, if it is required to kick a ball down, the axis 
of rotation must be horizontal. Thus, if the axis of rotation is in the horizontal plane, the deflecting force could be upwards or downwards, which can be achieved that the ball does not fall as much or that it falls more quickly due to the influence of gravity. Then, the axis of rotation can be oriented in any direction (horizontal or vertical) to produce various effects by the combination of the deflecting force and gravity ${ }^{2,3}$.

Sometimes the Football ball is kicked at high velocity, causing another spin to kick in. The rotation of the ball causes the boundary layer of air to separate at different points on each side of the ball. This separation produces a turbulent wake that deviates in the direction of the spin of the ball. The result is a pressure difference that causes the ball to drift in the opposite direction. This is known as the Magnus effect after Gustavo Magnus who discovered the effect. Therefore, the turbulent wake of a fast-moving ball causes the ball to curve. Applying Newton's third law, the turbulent wake is deflected in one direction and the reaction force deflects the ball in the opposite direction $^{2,3}$.

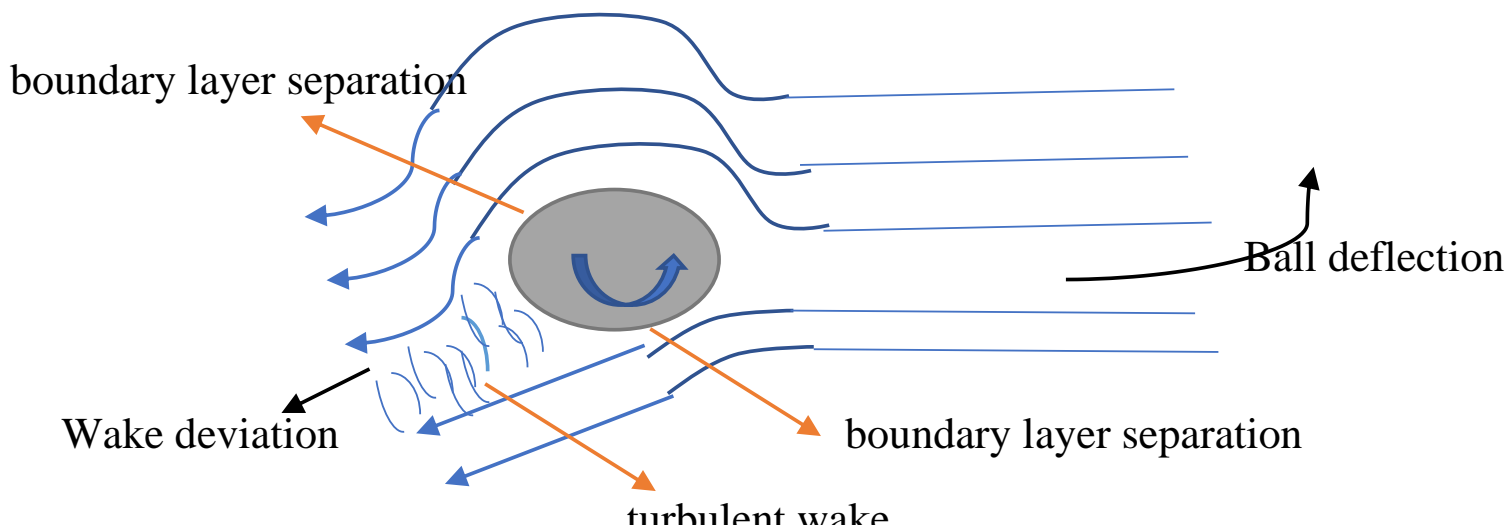

Fig.40. Ball deflection due the Magnus effect with the turbulent wake which causes the ball to curve because of the Newton's third law

There are other balls as tennis, golf and baseball balls that also have this curve effect of their trajectory ${ }^{2,3}$. Golf balls are dimpled to create turbulence. Localized turbulence can reduce air resistance due to the Magnus effect and make balls have a longer range. Swimmers also use it to minimize turbulence and water resistance $e^{2,3}$.

A practical application of the Bernoulli Effect is the shape of the aircraft wings. The shape of aircraft wings is designed such that the upper surface has a smaller radius and area of curvature than the lower surface. Then, the region with the smaller area or upper surface has the flow air faster than the region with the larger area or lower surface. By applying the Bernoulli's principle, the region with higher velocity (upper surface) of air flow has also the lower pressure ${ }^{2,3}$. As result, the pressure difference produces a deflection force $\mathrm{F}$ toward the region of low pressure which is called lift force. The net upward force F depends on different factors such as the velocity of the airplane, the area of the wing, its curvature, and the angle between the wing and the horizontal. As the angle increases, turbulence occurs at the top of the wing reducing the lift predicted by Bernoulli's principle ${ }^{2,3}$. In practice, the wings are tilted upward causing the air mass under the wing to deflect downward. The impact of air against the surface of the underside of the wing contributes an additional upward force. Thus, the air molecules must acquire a downward momentum component and the wing acquires an equal upward momentum ${ }^{2,3}$. 


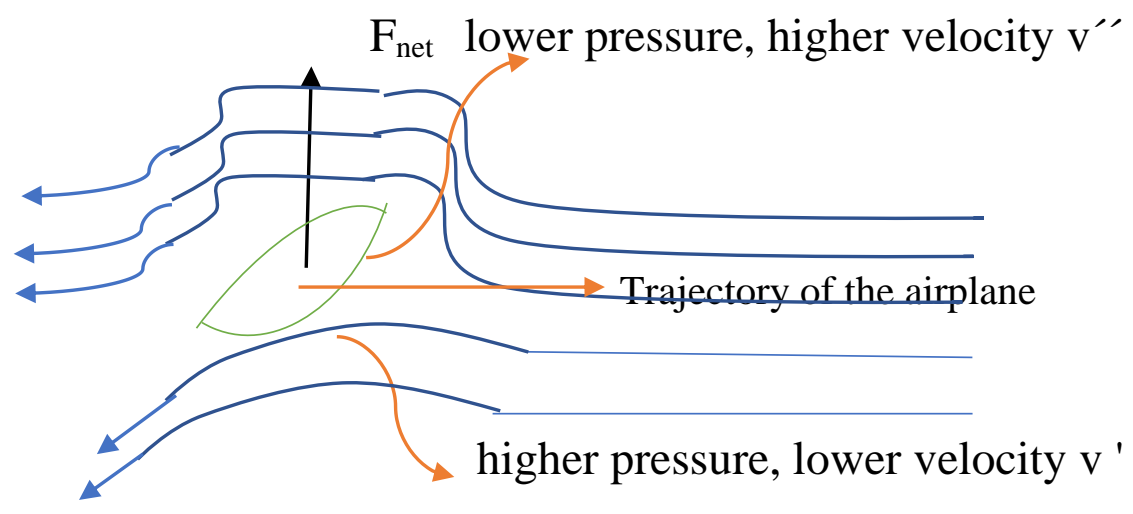

Fig.41. Shape of aircraft wing with the air flow through the wing and the lift force

\section{Devices to measure the Atmospheric Pressure and the blood pressure}

\section{Measurement of the Atmospheric Pressure with mercury (Hg) tube}

The formula that relates the pressure respect with the depth $\mathrm{h}$ in a fluid is as follows. It is considered a cubic volume of fluid of height $\mathrm{h}$ within of a container with the same fluid:

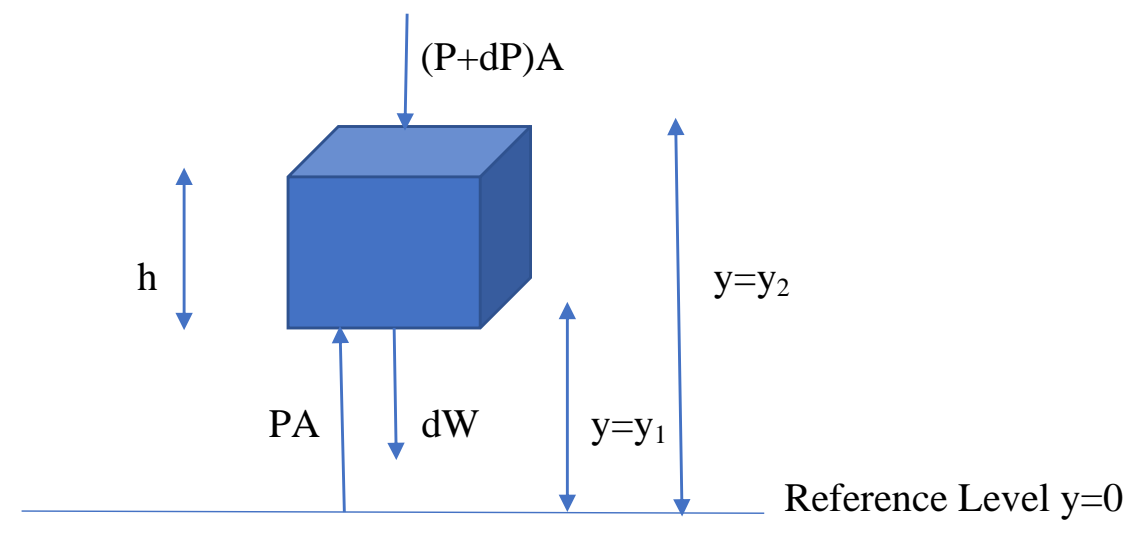

Fig.42. Cubic volume of fluid of height $h$

A: cross-sectional area of the fluid cube

PA: force on the bottom surface of the cube

$(\mathrm{P}+\mathrm{dP}) \mathrm{A}$ : force on the top surface of the cube

$\mathrm{dW}$ : weight of the fluid cube: $\mathrm{dW}=\mathrm{gdm}=\mathrm{g} \rho \mathrm{dV}=\mathrm{g} \rho \mathrm{Ady}$

dy: differential height of the fluid cube

PA-(P+dP)A- $\rho g A d y=0 \quad$ P-P-dP- $\rho g d y=0$

$\mathrm{dP}=-\rho g d y \quad \rho$ is constant within of the fluid

$\mathrm{P}_{2}-\mathrm{P}_{1}=-\rho g\left(\mathrm{y}_{2}-\mathrm{y}_{1}\right) \quad \mathrm{P}_{1}=\mathrm{P}_{2}+\rho g\left(\mathrm{y}_{2}-\mathrm{y}_{1}\right)$

$\mathrm{P}_{1}=\mathrm{P} \quad \mathrm{P}_{2}=\mathrm{P}_{\mathrm{a}} \quad \mathrm{y}_{2}-\mathrm{y}_{1}=\mathrm{h}$

$\mathrm{P}=\mathrm{P}_{\mathrm{a}}+\rho g h \quad \mathrm{P}$ : pressure of the fluid at the depth $\mathrm{h}$. 
Thus, the pressure $\mathrm{P}$ is increased when the depth $\mathrm{h}$ is increased within of the fluid ${ }^{2,3}$.

A device used to measure an unknown pressure $(\mathrm{P})$ is the manometer or pressure gauge ${ }^{2,3}$. An extreme of the tube in form of $U$ contains a liquid which is open to the atmosphere and the other extreme is connected to a system of unknown pressure $\mathrm{P}$.

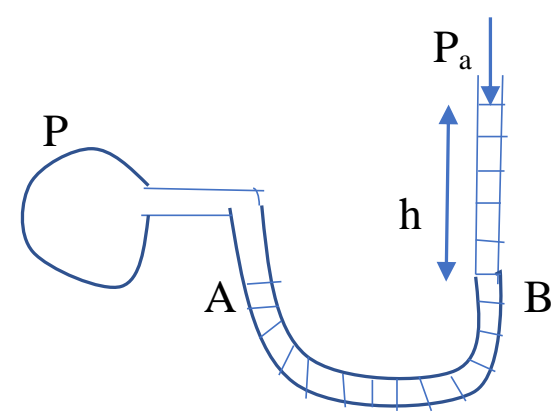

Fig.43. Manometer or Pressure gauge

The pressure at the point $\mathrm{B}$ is:

$\mathrm{P}_{\mathrm{B}}=\mathrm{P}_{\mathrm{a}}+\rho g h$ where $\rho$ is the density of the fluid.

$\mathrm{P}=\mathrm{P}_{\mathrm{a}}+\rho g h \quad$ where $\mathrm{P}_{\mathrm{A}}=\mathrm{P}_{\mathrm{B}}=\mathrm{P}$

The pressure $\mathrm{P}$ is known as the absolute pressure and $\mathrm{P}-\mathrm{P}_{\mathrm{a}}=\rho g h$ is the gauge pressure. If $\mathrm{P}>\mathrm{P}_{\mathrm{a}}$ then $\mathrm{h}>0$ and if $\mathrm{P}<\mathrm{P}_{\mathrm{a}}$ then $\mathrm{h}<0$. If $\mathrm{P}=\mathrm{P}$, then $\mathrm{h}=0$.

A device to measure the atmospheric pressure is the barometer invented by Torricelli ${ }^{2,3}$. A large tube is closed in one of the extremes and filled with mercury $(\mathrm{Hg})$ and then, it is flipped over a mercury container. The closed extreme of the tube is at the vacuum and the value is $\mathrm{P}=0$.

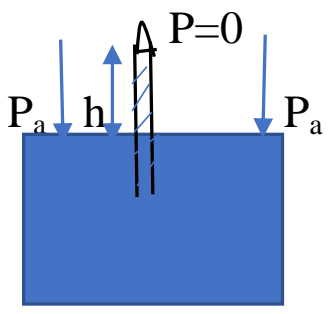

Fig.44. Torricelli Manometer (barometer) of $\mathrm{Hg}$

$\mathrm{P}_{\mathrm{a}}=\rho g h \quad \rho:$ mercury density $\quad \mathrm{h}$ : height of the mercury tube.

The value of 1 atmospheric pressure ${ }^{2,3}$ is equal to $76 \mathrm{~cm}$ of $\mathrm{H}_{\mathrm{g}}$ at $0^{\circ} \mathrm{C}$ and at sea level where the gravity is $\mathrm{g}=9.8$ $\mathrm{m} / \mathrm{s}^{2}$. The density of the mercury with those conditions is $\rho=13600 \mathrm{~kg} / \mathrm{m}^{3}$. By replacing these values at the formula, it is obtained the atmospheric pressure in Pascal $(\mathrm{Pa})^{2,3}: \mathrm{P}_{\mathrm{a}}=1.013^{*} 10^{5} \mathrm{~N} / \mathrm{m}^{2}$ where $1 \mathrm{~N} / \mathrm{m}^{2}=1 \mathrm{~Pa}$.

If the measurement with this device is done in other place or city with different altitude above sea level, then the height of the mercury tube $\mathrm{h}$ is different and thus, the atmospheric pressure $\mathrm{P}_{\mathrm{a}}=\rho \mathrm{gh}$ is also different $\mathrm{t}^{2,3}$. In fact, the height of the mercury tube in a city with an altitude above sea level is lower than $76 \mathrm{~cm} \mathrm{of} \mathrm{Hg}^{2,3}$. Therefore, the 
atmospheric pressure $\mathrm{P}_{\mathrm{a}}$ in a place or city with an altitude above sea level is lower than the atmospheric pressure at sea level: $\mathrm{P}_{\mathrm{a}}<1.013 * 10^{5} \mathrm{~N} / \mathrm{m}^{2}$ or $\mathrm{P}_{\mathrm{a}}<76 \mathrm{~cm} \mathrm{Hg}$.

In resume, the atmospheric pressure decreases according the altitude of the place or city increases. Besides, if there are storms or extreme weather conditions, the height of the mercury tube decreases (compared with the $76 \mathrm{~cm}$ of $\mathrm{Hg}$ at sea level) and thus, it is other form of variation of the atmospheric pressure due climatic conditions ${ }^{2,3}$. For example, if the height of the mercury tube at the Torricelli manometer is $\mathrm{h}=73 \mathrm{~cm}$ of $\mathrm{Hg}$ due storms, then the atmospheric pressure is $\mathrm{P}=0.973 * 10^{5} \mathrm{~N} / \mathrm{m}^{2}$ compared with the $1.013 * 10^{5}$ at sea level.

\section{Measurement of the Blood pressure}

The pump is a machine that transfers mechanical energy to a fluid to increase its pressure and make the fluid flow. The heart is a muscular pump that propels blood through the body's network of arteries, capillaries, and veins. The inner chambers of the heart enlarge and fill with freshly oxygenated blood from the lungs with each pumping cycle $^{2,3}$

When the chambers called the ventricles contract, blood is pushed out through the arteries. The main arteries branch out, forming narrower arteries until they reach the capillaries. In capillaries, nutrients and oxygen carried by the blood are exchanged with the surrounding tissues and waste is collected. Then, the blood flows into the veins to complete the circuit and return to the heart ${ }^{2,3}$.

Arterial blood pressure rises and falls in response to the cardiac cycle. Thus, when the ventricles contract, pushing blood into the arterial system, the pressure in the arteries rises abruptly. The maximum pressure that is reached during ventricular contraction is called the systolic pressure. When the ventricles relax, the arterial pressure drops to its lowest value before the next contraction. This lower pressure is called diastolic ${ }^{2,3}$. Artery walls are quite elastic and expand and contract with each pumping cycle. The alternation between expansions and contractions can be detected as a pulse in the arteries near the surface of the body. Thus, the radial artery near the surface of the wrist is commonly used to measure the pulse of people. This pulse is equal to the rate of contraction of the ventricles which reflects the heart rate ${ }^{2,3}$

Measuring a person's blood pressure involves measuring the pressure of the blood on the walls of the arteries, which is done with a device called a sphygmomanometer which measures the arterial pressure in $\mathrm{mm} \mathrm{Hg}$ or Torr (Torricelli) $1 \mathrm{~atm}=760$ Torr. The sphygmomanometer consists of an inflatable rubber cuff or cover applied on the arm to temporarily cut off blood Flow. The sphygmomanometer is connected to a column of mercury next to a graduated scale, enabling the determination of systolic and diastolic blood pressure by increasing and gradually releasing the pressure in the cuff. Thus, the inflatable cover pressure is slowly reduced while the pressure is heard with a stethoscope. Then, there is a time when blood just begins to flow through the constricted artery. The flow is turbulent and produces a specific sound with each beat of the heart. When this sound is heard, the pressure is read on the gauge (systolic) which has a value close to $120 \mathrm{~mm} \mathrm{Hg}$. When the turbulent heartbeats disappear because the blood is already flowing smoothly, the diastolic reading is read on the pressure gauge, which has a value close to $80 \mathrm{~mm} \mathrm{Hg}$. Blood pressure is reported by giving systolic and diastolic pressures as follows: 120/80. Normal 
systolic blood pressure varies between 100 and 140 and diastolic between 70 and 90 . The arterial pressure is gauge or manometric because it measures the gauge pressure of a fluid which is the arterial blood and measures the pressure of the blood on the walls of the arteries ${ }^{2,3}$.

The blood flows from heart to the aorta and then, it goes around the circulatory system, passing through arteries (small arteries), capillaries and venules (small veins), to return to the heart through the veins. As it moves away from the heart, the diameter of the blood vessels decreases as they branch. Then, the velocity of blood flow is slower in capillaries because the area of the capillaries is much higher than that of the arteries or veins as established by the continuity equation ${ }^{2,3}$. As result, the pressure in capillaries is higher than in the arteries or veins due the Bernoulli's equation. This causes a net force to act in the capillaries towards the low pressure region of arteries and veins which allow the flow of blood in the circulatory system ${ }^{2,3}$. Thus, the pressure in the arteries or veins decrease as their diameter decrease. In small arteries, such as those in the arm, the blood pressure is of the order of $10-20 \mathrm{~mm} \mathrm{Hg}$, and there is no systolic-diastolic variation ${ }^{2,3}$.

The high blood pressure is a common health problem. The elastic walls of the arteries expand under the hydraulic force of the blood pumped from the heart. However, elasticity could decrease with age. A high level of cholesterol in the blood can cause fatty deposits called platelets to form on the walls of the blood vessels. It can narrow and roughen the arterial pathways, hindering the flow of blood and reducing the radius and effective area of the artery or blood vessel and thus, increasing the velocity or rate of the blood flow in the artery plugged because of the continuity equation ${ }^{2,3}$. It can produces a form of arteriosclerosis, or hardening of the arteries.

\section{Thought Experiment VI (Gedanken experiment VI)}

\section{Intravenous infusion (IV) with help of gravity}

A patient receives a gravitational flow IV in a hospital. The gauge pressure of the fluid at the base of the IV should be higher than the pressure in the vein because fluids flows from the higher pressure region to the lower pressure region. If the blood gauge pressure in the vein is $25.0 \mathrm{~mm} \mathrm{Hg}$ (the liquid is incomprehensible), then the IV must be located at the next height:

$\mathrm{P}_{\mathrm{v}}$ : pressure in the vein $\rho$ : liquid density $($ blood $)=1.05^{*} 10^{3} \mathrm{~kg} / \mathrm{m}^{3}$

P: gauge pressure of the fluid at the base of the IV

$\mathrm{P}_{\mathrm{v}}=(25 \mathrm{~mm} \mathrm{Hg})=2.5 \mathrm{~cm} \mathrm{Hg} *\left(1.013 * 10^{5} \mathrm{~Pa} / 76 \mathrm{~cm} \mathrm{Hg}\right)=3.33 * 10^{3} \mathrm{~Pa}$

$\mathrm{P}=\rho g h>\mathrm{P}_{\mathrm{v}} \quad \mathrm{h}>\left(3.33 * 10^{3} \mathrm{~Pa}\right) /\left(1.05 * 10^{3} * 9.8\right)=0.32 \mathrm{~m}=32 \mathrm{~cm}$

IV serum must be at least $32 \mathrm{~cm}$ above the infusion site.

8. Weather conditions: rain, snow, wind, hail, high or low temperature, humidity, water vapor and irradiation at high altitude and use of the technology

The atmospheric conditions in the Earth are suitable for human life and also for playing Football. However, sometimes extreme weather conditions affect the normal development of a Football game. Thus, weather 
conditions are very important for the development of a good Football game. For example, it is very difficult to play Football when there is too much rain, snow, wind, high temperature or humidity. When it rains or snows a lot, the ball does not move easily on the grass and therefore, it is difficult to pass with the ball at grass level or to kick the ball with rebounds. Respect to the wind, it is difficult to perform a large air pass when there is a lot of wind. It is also complicate to play Football when there is high temperature or humidity and the game can be suspended to avoid a sunstroke of the players. Thus, it is forbidden to play at midday in some Football tournaments due a possible sunstroke of the players ${ }^{6,7,8}$.

For other hand, the temperature decreases when the height of the place increases with respect to sea level. The temperature drops at a rate of $1^{\circ} \mathrm{C}$ every $150 \mathrm{~m}$. It is necessary to consider the thermal sensation, which depends on both the ambient temperature and the wind speed. The thermal sensation is the equivalent of the temperature that the body appreciates as a product of these two factors. For example, when the ambient temperature is $5^{\circ} \mathrm{C}$ and the wind speed is $20 \mathrm{~km} / \mathrm{h}$, the thermal sensation that our body registers is as if we were at a temperature of $1^{\circ} \mathrm{C}$.

In addition, the decrease in water vapor in the atmosphere when the altitude increases is more intense than the decrease in the partial pressure of oxygen. At $2000 \mathrm{~m}$ the water vapor decreases by $50 \%$, and at $4000 \mathrm{~m}$, the decrease is $75 \%$. This is one of the most important causes of dehydration at high altitudes, which together with the speed of the wind, and the changes that occur in the endocrine system (antidiuretic hormone, aldosterone, renin) are factors that contribute to both dehydration and cooling. Besides, when the altitude is increased, it is also increased both infrared and ultraviolet radiation, the latter being the one that causes sunburns and inflammation of the cornea. Solar irradiation increases between $2 \%$ and $4 \%$ every 100 meters of ascent, up to 2000 meters above sea level. Then $1 \%$ for every additional 100 meters of ascent. The presence of snow further accentuates the effect of radiation by reflection of sunlight, and radiation can be increased by up to $90 \%$.

Therefore, many times matches are suspended due the extreme weather conditions. This is the decision of the referee and the organizing committee suspend or not the match or to wait a few hours until the weather condition changes.

For other hand, all resources in favor of the Football team should be maximized in a Football game. This consists of not only the strategies or tactical schemes, but also using all the advantages, characteristics and resources of the team at the appropriate time: " Use the best cards of the playing card at the beginning because later the card does not come out ". For example, the physical and sporting characteristics of some players are the best for a given Football game and besides, substitutions should be the most appropriate for the match ${ }^{6,7,8}$.

Even the weather conditions and location can be used to make the result favorable. For example, it is possible to choose which half of the field to start the match (kickoff) or to start at the beginning with the ball. Sometimes teams choose to take their favorite hald field at the beginning according to the weather conditions: respect to the wind or the sun for example, and give the other team the kick-off. This is a smart strategy, especially if the sun will rise higher in the sky and be in the eyes of the goalkeepers or use the wind in favor at the first half or the second ${ }^{6,7,8}$. Besides, there are teams that plays better if the level of the match is fast and then, the grass is watered to have a 
quick game ${ }^{6,7,8}$. In addition, there are teams that play very well in cities with high altitude or for example with warm climates.

Although, sometimes there are extreme weather conditions in some countries that complicate the practice of Football, it has been possible to build stadiums that are suitable for these climates and to wear respective clothing that facilitates the practice of Football ${ }^{6,7}$. For example, there are new stadiums with the possibility of moving roofs and so, the game can be played in any weather condition with or without a roof. Thus, the roof covers the Football field when required. Also, there is the technology to heat the grass by means of heating devices under the grass which is required when there is a lot of $\operatorname{snow}^{6,7,8}$. Therefore, technology can help a lot for the normal development of a Football game.

Moreover, nowadays technology helps a lot for the efficient performance of players and to use all the best physical conditions on the Football field. In this way, it is maximized the important details that can contribute to winning the Football game. It contributes a lot the technical body such as the Coach, Technical assistant, Physical trainer, Doctor, Managers, Scientists, who know very well all the best that the team has and the physical conditions that can be used in a certain Football game. Thus, Teamwork is the key to this beautiful sport: The Football ${ }^{6,78}$.

For example, technologies have been incorporated to know characteristics of the players: control of distance run by the player on the field, velocity, potency. In addition, Medical Technologies have been incorporated: medical control of their performance such as sweating, calories, blood pressure ${ }^{6,7,8}$. This can be obtained by means of sensors on the player and on the Football field and stadium through sensors, cameras and software. Besides, the Football technology has also been incorporated in the trainings that are very helpful to the coach and physical trainer to obtain an efficiency of the player and of the strategies applied in the Football field.

\section{Conclusions}

The Cavendish Experiment demonstrates the real gravitational interaction between objects with mass ${ }^{4}$. Two masses that are subjected to a gravitational field interact through a distance action interaction and indeed, it is emitted gravitational energy between them. The gravitational interaction and the gravitational energy emission which influences the Perihelion Precession of Mercury, the light frequency with the less frequency measured (gravitational redshift) and light deflection when the light passes near the $\mathrm{Sun}^{4}$ are demonstrated at my article with the discovered formulas: "The Fundament of the Mass and Effects of the Gravitation on a Particle and Light" ${ }^{4}$ The results are in agreement with the experiment result and with the Relativity Theory with high accuracy ${ }^{4}$. For other hand, the emission of the electromagnetic radiation (photons) produces a decrease in the mass of the accelerated electron which is given by the formula of the "Variant Mass for an accelerated charged particle"

It is applied Physics in Football as for example: Free fall, Parabolic motion, Newton Law, Work and Energy, Energy conservation, and Impulse and Momentum ${ }^{1,2,3}$. Afterward, it is researched the effects of the air resistance in the maximum horizontal distance and height reached by the ball. The air resistance has a determining effect on the maximum horizontal distance and the maximum height reached by the object. It is concluded that there is more maximum horizontal distance and height of the ball when there is less air resistance, less air friction of the ball with 
the air, less air density or less atmospheric pressure which occur at places with high altitude above sea level. The difference of the results of the parabolic movement without air resistance are higher with the model of air friction force $F_{f}=-k v^{2}$ than with the other models $F_{f}=-k v$ and $F_{f x}=-k v_{x}{ }^{2}$ and $F_{f y}=-k v_{y}^{2}$. The air resistance force applied for a longer time causes a more significant braking.

For other hand, it is very important for the Football practice the gravitational field of the Earth, the specific value of the gravity and the atmospheric conditions of the Earth. Thus, it is researched the effects of the variable physics as the atmospheric pressure and gravity and climatic conditions (heavy rain, wind, snow, hail, high temperature or humidity) that influence in a Football match and the respective applied technology that help for a normal development of a Football game ${ }^{6}$.

There is less atmospheric pressure and the air is less dense when the altitude of the city increases. The formula that relates the atmospheric pressure and the altitude is obtained at this research: $\mathrm{P}=(101.3) \mathrm{e}^{-0.000123387 \mathrm{y}}(\mathrm{kPa})$. It is possible to observe at the formula that when y increases respect to the sea level, then the atmospheric pressure decreases.

The gravity acceleration, the gravitational field and the gravitational force (weight) or pull toward the center of the Earth decrease when the altitude of place or city increases ${ }^{2,3,6}$. The formula that relates the gravity and the altitude is obtained at this research: $g^{\prime}=\frac{3.9 * 10^{14}}{\left(6.38 * 10^{6}+h\right)^{2}}$. It is possible to observe at the formula that when $\mathrm{y}$ increases respect to the sea level, then the gravity decreases and the weight also decreases because $\mathrm{F}_{\mathrm{g}}=\mathrm{W}=\mathrm{mg}^{\prime}$.

The atmospheric pressure and gravity have the next effect on the ball when the match is played in a city with high altitude above sea level: lower weight of the ball, less friction of the ball with the air, less air resistance on the ball, the ball moves further than in the plain or at sea level, the ball acquires more velocity and moves more forward, sideways or lateral, the ball does not take the desired and the ball moves with less rotation or the ball does not spin as much: "the ball does not bend"6,7,8. It is due the lower gravitational pull to attract the ball to the ground and the lower friction of the air with the ball which is due the lower air resistance, lower air density and lower atmospheric pressure in the city with high altitude above sea level ${ }^{6,7,8}$. This occurs for example in a Direct free kick and in cities with high altitude such as La Paz, Bolivia ${ }^{6,7,8}$. This can be a problem for the visiting team and for goalkeepers when trying to catch the ball and at the same time an advantage for the home team that is already used to these effects ${ }^{6,7,8}$.

Furthermore, it is researched the effects of the ball velocity, air viscosity (Bernoulli Effect) and turbulence (Magnus Effect) on the Football ball. In a free kick, the Football player can curve the ball with a lot of effect while the ball heading for the goal by giving it the appropriate velocity and spin when the ball is kicked ${ }^{6,7,8}$. It can be explained by means of the Bernoulli equation and the viscosity properties of air $^{2,3}$. The friction between the air and the ball causes the ball to drag a thin boundary layer of air with it as it spins and as result, the velocity of the ball relative to the air is much higher on one side than the other. The low-velocity side of the ball is under higher pressure than the high-velocity side by applying Bernoulli Principle. Then, the pressure differences in the ball causes a net force to act on the ball towards the low pressure side and deflect it and thus, its trajectory is curved ${ }^{2,3}$. 
Sometimes the Football ball is kicked at high velocity, causing another spin to kick in: the Magnus effect. The separation of the air layers due the ball rotation produces a turbulent wake that deviates in the direction of the spin of the ball. The turbulent wake of a fast-moving ball causes the ball to curve. Applying Newton's third law, the turbulent wake is deflected in one direction and the reaction force deflects the ball in the opposite direction ${ }^{2,3}$. The axis of rotation can be oriented in any direction to produce various effects by the combination of the deflecting force and gravity ${ }^{2,3}$. In addition, it is researched the effects of the gravity variation in the Football players when they plays a match in a high altitude city or place ${ }^{6,7,8}$. On our planet Earth, the gravity provides the force that makes our muscles and bones develop the resistance necessary to function properly on the planet ${ }^{2,3}$. Thus, the muscles and bones must be strong enough to allow walking, running, lifting objects for example, where nutrition, food and exercising the muscles help in the ability for the muscles and bones to function properly under the action of the gravity ${ }^{2,3}$. Thus, the gravity value is very important for the normal functioning of the muscles, bones and the normal functioning of the circulatory system and the heart. If the gravity decreases very much, the next effects appear: the weight of the human being is reduced a percent, the muscles and bones atrophy because the body doesn't feel they are needed, the muscles lose a little mass and the legs become thin, the circulatory system is affected and the blood production is decreased which is due that there is less difference in gravity or gradient between the feet and the head. If the gravity is zero, the blood pressure balances throughout the body around $10 \mathrm{~cm}$ $\mathrm{Hg}$, the fluid flows from the legs to the head, the face looks flushed, the legs become thin, the heart does not work as much and the heart muscles could atrophy ${ }^{2,3}$. Besides, it is researched the effects of the variations of the atmospheric pressure in the Football players when they plays a match in a high altitude city or place $e^{6,7,8}$. The external pressure of the atmosphere is very important for the normal functioning of the organism. Thus, the variations in the atmospheric pressure as altitude changes can affect Football players such as: decrease in the physical performance, extreme tiredness, dizziness, headache, nausea, earache, changes of the blood pressure, possible tachycardia, possible pulmonary edema in the most severe cases, and no normal breathing or hypoxia which is a decrease in the oxygen content of air that is breathed ${ }^{2,3}$.

The concentration of oxygen will only begin to decrease when the altitude is above 100 kilometers. Thus, it is not reduced the concentration of oxygen in the air in the altitude up to $100 \mathrm{~km}$ (the ratio of oxygen to other gases remains constant at 21\%), but the number of air molecules is reduced, including oxygen which produces hypoxia or no normal breathing. Then, as result of the decrease of the oxygen molecules that is breathed which is due the decrease in the atmospheric pressure in high altitude, it is produced hypoxia: the oxygen saturation in the blood decreases, affecting the gas exchange between the environment and the lungs, between the lungs and the blood, and between the blood and the cells, providing a smaller supply of oxygen molecules to the tissues, and in particular skeletal muscle. For example, at the top of Everest, it is breathed the same concentration of air as at sea level, but the amount of oxygen molecules is lower due the reduction in atmospheric pressure. Consequently, although the same volume of air penetrates the lungs as at sea level, when the partial pressure of the air is reduced, the oxygen saturation in the blood decreases, so the supply of oxygen to the tissues is compromised affecting the gas exchange between the environment and the lungs. Fortunately, the human body has an oxygen-transporting 
protein, hemoglobin $(\mathrm{Hb})$, that despite such large differences in oxygen pressure in the lungs, $\mathrm{Hb}$ saturation barely decreases by $10 \%$. Then, the Football players begin to feel the dreaded symptoms of altitude sickness. In fact, there are players who get very tired faster within the 90 minutes of a Football game. There are teams that do not like to play in cities at high altitude and have even made the request not to play under these conditions, although this has not been accepted ${ }^{6,7,8}$. The atmospheric and physics conditions of the high altitude affect performance in exercises lasting more than 4 or 5 minutes. In the first hours of staying in the altitude, the body starts up mechanisms that seek to compensate for the adverse effects of hypoxia, which are known as the accommodation process. The organic and functional changes observed during the stay of a few weeks are called acclimatization. Thus, there are players who get very tired faster within the 90 minutes of a Football game. There are teams that do not like to play in cities at high altitude and have even made the request not to play under these conditions, although this has not been accepted ${ }^{6,7,8}$. Then, some teams do a process of accommodation or acclimatization before the match. Moreover, the human body is made up largely of fluids, which exert an outward pressure ${ }^{2,3}$. Because the external atmospheric pressure decreases when the height of the city or place increases, the blood pressure of the organism (which depends of this external atmospheric pressure) can change with the atmospheric conditions and height of the city or place.

Therefore, in Football, it is important to measure the atmospheric pressure of the city and the blood pressure of the players when they plays a match in a high altitude city or place ${ }^{6,7,8}$. The formula that relates the pressure $\mathrm{P}$ and the deep $\mathrm{h}$ within of a fluid is: $\mathrm{P}=\mathrm{P}_{\mathrm{a}}+\rho g h$ where $\mathrm{P}_{\mathrm{a}}$ is the atmospheric pressure and $\rho$ is the density of the fluid. It is possible to observe at the formula that when the deep $\mathrm{h}$ decreases, then the pressure decreases. A device used to measure an unknown pressure $(\mathrm{P})$ is the manometer or pressure gauge $\mathrm{e}^{2,3}$. The device to measure the atmospheric pressure is the barometer which was invented by Torricelli ${ }^{2,3}$. The formula used to measure the atmospheric pressure at this device is: $\mathrm{P}_{\mathrm{a}}=\rho$ gh. Thus, if the measurement with this device is done in other place or city with a high altitude above sea level, then the height of the mercury tube $\mathrm{h}$ is lower than at sea level ${ }^{2,3}$. As result, the atmospheric pressure decreases when the altitude of the place or city increases: $\mathrm{P}_{\mathrm{a}}<1.013^{*} 10^{5} \mathrm{~N} / \mathrm{m}^{2}$ or $\mathrm{P}_{\mathrm{a}}<76 \mathrm{~cm}$ $\mathrm{Hg}$. For other hand, it is also explained at this article the measurement of the Blood pressure. Measuring a person's blood pressure involves measuring the pressure of the blood on the walls of the arteries, which is done with a device called a sphygmomanometer which measures the arterial pressure in mm Hg or Torr (Torricelli) $1 \mathrm{~atm}=760$ Torr. Blood pressure is reported by giving systolic and diastolic pressures as follows: 120/80. Normal systolic blood pressure varies between 100 and 140 and diastolic between 70 and $90^{2,3}$.

Even the weather conditions and match location can be used to make the result favorable in a Football match. For example, there are teams that play very well in cities with high altitude or for example with warm climates. Besides, there are teams that plays better if the level of the match is fast and then, the grass is watered to have a quick game ${ }^{6,7,8}$. Weather conditions are very important for the development of a good Football game. Many times matches are suspended due the extreme climatic conditions as heavy rain, wind, snow, hail or severe weather conditions high temperature or humidity. Thus, it is very difficult top play Football when where is too much rain or wind, high temperature or humidity, where the game can be suspended to avoid a sunstroke of the players or to 
wait a few hours until the weather condition changes. Nevertheless, it has been possible to apply the technology to build new stadiums that are suitable for these climates and to wear the respective clothing that facilitates the practice of Football ${ }^{6,7,8}$. For example, there are new stadiums with the possibility of moving roofs (Wembley Stadium) and so the game can be played in any weather condition (raining, snowing, winding or sunning) with or without a roof. Besides, when there is a lot of snow, there is the technology to heat the grass by means of heating devices under the grass ${ }^{6,7,8}$.

In Football, not only the strategies or tactical schemes are very important, but also using all the advantages, characteristics and resources of the team at the appropriate time. Actually, the technology helps a lot for the normal development of a Football game and for the efficient performance of players and to use all the best physical conditions on the Football field. For example, technologies have been incorporated to know characteristics of the players: control of distance run by the player on the field, velocity, power. In addition, Medical Technologies have been incorporated: control of their performance: sweating, calories, blood pressure ${ }^{6,7,8}$. Besides, the Football technology has also been incorporated in the trainings that are very helpful to the coach and physical trainer to obtain an efficiency of the player and of the strategies applied in the Football field. Therefore, it is possible to have a control of the performance and efficiency of the player's game on the Football field. In future, new technologies can also be incorporated to monitor player and match performance.

\section{Declarations}

\section{Source of Funding}

This research did not receive any specific grant from funding agencies in the public, commercial, or not-for-profit sectors.

\section{Competing Interests Statement}

The authors declare no competing financial, professional and personal interests.

\section{Consent to participate}

\section{Not Applicable}

\section{Consent for publication}

We declare that we consented for the publication of this research work.

\section{Availability of data and material}

Authors are willing to share data and material according to the relevant needs.

\section{References}

[1] Giovanni Alcocer, Basic Physics, 04/2020; Lambert Academic Publishing, ISBN: 978-620-2-52690-6.

[2] Serway, Física, Mc Graw Hill, México, 1993. 
[3] Wilson, Física, Pearson Education, México, 2003.

[4] Giovanni Alcocer, The Fundament of the Mass and Effects of the Gravitation on a Particle and Light in the Mass, Time, Distance, Velocity, Frequency, Wavelength: Variant Mass for a Particle which emits Gravitational Energy for a Particle Orbiting a large Planet or Sun and for a Binary Star and Variant Frequency for the Light Passing Close a Gravitational Field from a Massive Object (Sun), Mediterranean Journal of Basic and Applied Sciences (MJBAS), Volume 4, Issue 3, Pages 42-69, July-September 2020.

[5] Giovanni Alcocer, Variant Mass for an Accelerated Charged Particle, Asian Journal of Basic Science \& Research (AJBSR), Volume 2, Issue 3, Pages 43-59, July, September 2020.

[6] Giovanni Alcocer, Football: Rules, Strategies, Ticky Tacka \& Chocolate From: Pipo Zona, Science Scripts, International Book Market Service Ltd., OmniScriptum Publishing Group, 2020.

[7] https://www.youtube.com/watch?v=rtAR3D25pQI\&feature=youtu.be

[8] https://www.youtube.com/watch?v=ARpzjv9gtvw\&t=1s

[9] https://www.youtube.com/watch?v=Rir3xUbPxpY 